Programas e

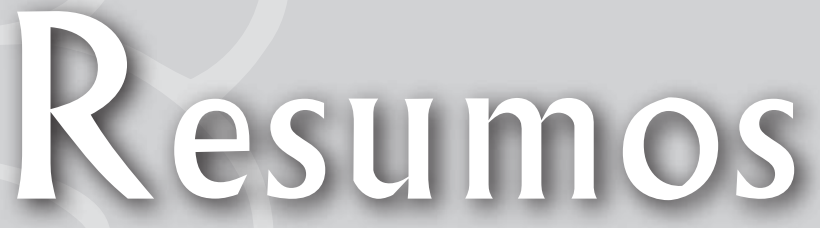

36 COMUABC - Congresso Médico Universitário do ABC

Santo André - SP • 15 a 20 de agosto de 2011

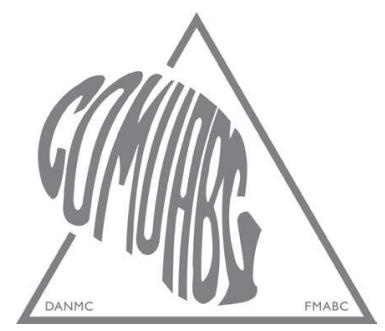

36 의 


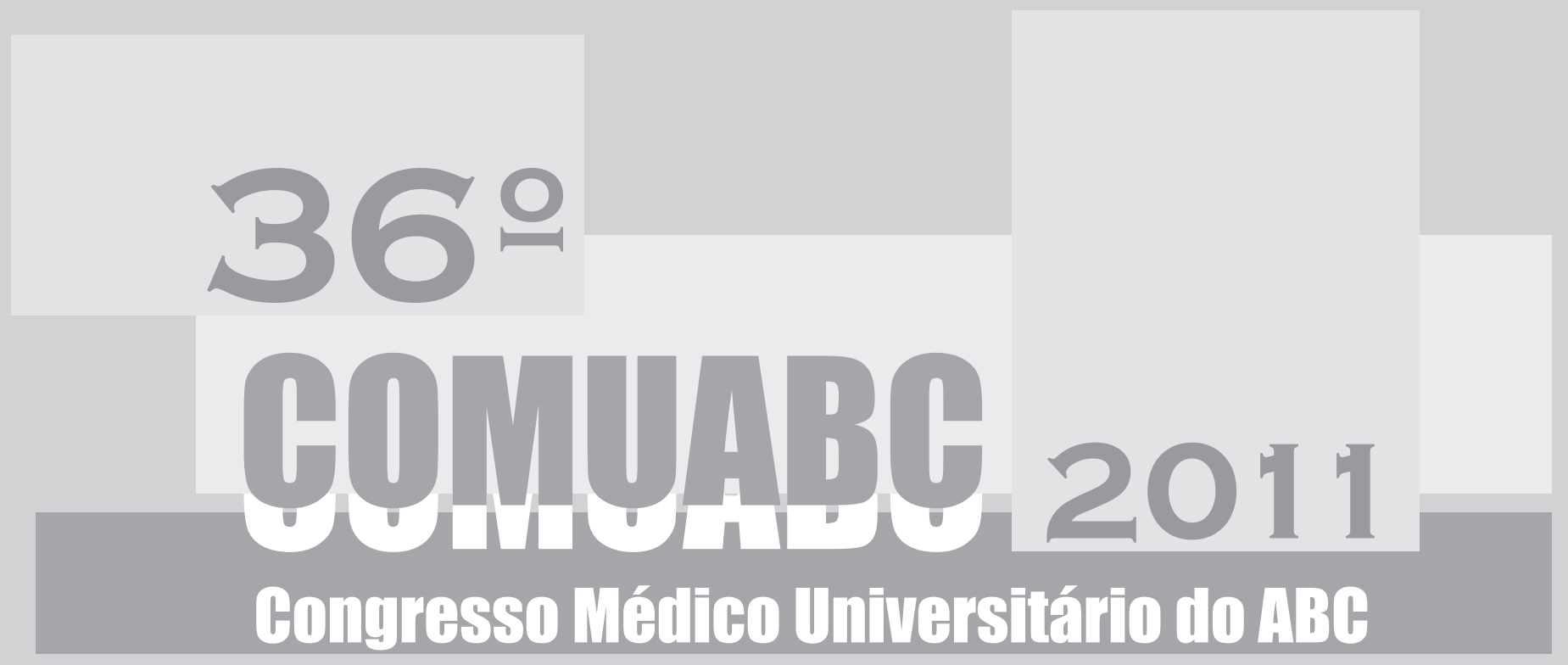

Santo André / SP / de 15 a 20 de agosto 


\section{Comissão Científica}

\author{
Presidência \\ Stephan Sperling \\ Verônica Carvalho de Figueiredo \\ Secretaria \\ Daniela de Souza Formigini \\ Gabriella Lima da Costa \\ Daniélle M. Cabral Amaro \\ Mariana P. Inácio Silvestri \\ Leticia Lumy Sato \\ Renata Pinheiro Modolo \\ Ana Carolina Pereira de Godoi \\ Renata de Almeida Bordim \\ Mayra Boldrini Silva \\ Tesouraria \\ Rodrigo Toledo Mota \\ Departamento científico e cultural \\ Michelle de Lima Farah \\ Renata Guise Soares de Almeida \\ Bruno Garcia Canizares \\ Taline Santos da Costa \\ Mariana Fernandes Barp \\ Erica Hoppacth \\ Bruna L. Chedid \\ Marcos Vinicios Credidio \\ Beatrice M. Zugaib Abdalla \\ Paula Nathana Fontanezzi \\ Renato Augusto loppe \\ Mariana Magalhães Soares \\ Alexandra A. Molnar Niero \\ Patricia Lopes
}

Departamento de trabalhos científicos

Renata Gimenez Costa

Verônica Eun Hue Kim

Andressa M. Paiva Rodrigues

Jordana Engel Racy

Micaela Frasson Montero

Giuliana Angelucci Miranda

\section{Departamento social}

Renata Colioni Mazar

Carolina Ogawa Matsubayashi

Henrique Barros Reis Soezina

Gabriela carolina Nazareth Pinto

Thais Menezes de Andrade

Giovanna Pizzanelli

Fernando Luvizotto Carvalho

Departamento de patrocínio e marketing Alana Asciutti Victorino

Karyse Helena C. R. Alves

\section{Departamento de divulgação}

Bruno Fonseca Bertoldo

Guilherme F. Bertolaccini de Aquino

Juliana Geangiardi Batista

Luiza Mutti e Matos

Natália I. Bernasovskaya Garção

Thais Yamada

Evellyn Dias Rodrigues
Adilson Casemiro Pires

Adilson West

Ana Fiorano

Ana Lúcia Ippolito Carbonell

Ana Luisa de Lara Uvun

André Luiz Pires de Freitas

Andre Paciello Romualdo

Angélica Castilho

Angélica Maria Bicudo Zeferino

Antônio Carlos Lima Pompeo

Auro Del Giglio

Bianca Azoubel Andrade

Caio Parente Barbosa

Carlos Roberto Douglas

Cintia Carniel Paraibuna

Claudio Lottenberg

Daniel Cubero

Danielle Souza Frois

Dante Piccioti

David Feder

Débora da Silva Fragoso de Campos

Edison Nobuko Fujiki

Eduardo Almeida e Dias de Souza

Enfermeira Divonélia Nogueira

Fábio Cotter

Fernanda Benetti

Fernando Luiz Affonso Fonseca

Flaviane Késia Rodrigues

Flavio Mendes de Oliveira

Francisco Carlos Marcondes

Francisco Valdez Santos

Gerson Vilhena Pereira Filho

Giselle Guedes Melo

Hélio Nishioka

Herniman Armdruster dos Santos

Hugo P. P. Gama

Jaques Waisberg

Jocielle Miranda

José Antonio Maluf

José Jorge Namura

Juvêncio José Duailibe Furtado

Leandro Luongo de Matos
Lelio Alves Silva

Ligia de F. N. Reato

Marcelo A. C. Nico

Marcelo Ferreira

Marcelo Wroclawski

Marcia Garcia R. Tamousauskas

Marco Prist

Marcos Mendes da Silva

Marcos Veiga

Maria Aparecida da S. Pinhal

Mário Paulo Faro Júnior

Marisa Gonzaga da Cunha

Michel Eid Farah

Mônica Akemi Sato

Mônica S. Lapa

Nédia M. Hallage

Nilton Gonçalves dos Santos Junior

Olinda do Carmo Luiz

Patricia Tempski

Pedro Munhoz Fernandez

Rafael Furst

Rafael Guerra Cintra

Rafael Ladeira

Regiane Micai Blasques

Ricardo Zugaib Abdalla

Rogerio P Caldana

Rosângela Filipini

Roseli Oselka Saccardo Sarni

Sandra Alves Moreira

Sérgio Paulo Rigonatti

Sérgio Tufik

Sheila Peres Severino de Moura

Sidnei José Galego

Silmara Colchão

Silvana Fideli Prado

Silvia Espiridião

Sônia Lodula

Vanessa Crispim

Vanessa Marques

Viviane Baptista Antunes

Viviane Lunardi

Wilson Roberto Catapani 


\section{6º COMUABC - CONGRESSO MÉDICO UNIVERSITÁRIO DO ABC}

Programação Científica

\section{PALESTRAS:}

Segunda-feira (15/08)

19h00: Cerimônia de Abertura e Coquetel.

Local: Auditório do Centro de Estudo, Pesquisa, Prevenção e Tratamento em Saúde (CEPES) - Campus da FMABC.

Terça-feira (16/08):

8h00: Os novos rumos da cirurgia geral - o papel da robótica Dr. Ricardo Zugaib Abdalla.

8h00: Doenças emergentes e reemergentes.

Enf. Flaviane Késia Rodrigues e Dr. Adilson West.

9h00: Marketing Pessoal.

Francisco Carlos Marcondes.

10h30: Lesões por esforço repetitivo.

Dr. Eduardo Almeida e Dias de Souza.

13h30: Dermatologia Funcional.

Ft. Fernanda Benetti

15h00: Crochetagem - Técnica de Aplicação

Ft. Angélica Castilho

16h30: Equoterapia

Ft. Ana Luiza de Lara Uvun e Instrutor Fábio de Cássio Teixeira Martins

18h00: Reabilitação pós reconstrução de LCA com PRP.

Ft. Fábio Cotter.

19h00: Apnéia do Sono - Diagnóstico e Intervenção Fisioterapêutica.

Ft. Regiane Micaia Blasques.

Palestra de destaque às $17 \mathrm{~h} 00$

Quarta-feira (17/08):

8h00: Crimes que abalaram São Paulo.

Dr. Sérgio Paulo Rigonatti.

8h00: Aspectos atuais em fisiologia do coração.

Prof. Carlos Roberto Douglas.

9h00: Doenças oftalmológicas da senilidade. Dr. Michel Eid Farah.

10h30: Atuação multidisciplinar em medicina do esporte. Enf. Vanessa Crispim e Dr. Marcelo Ferreira.

10h30: Desafios frente ao futuro na Medicina: como conciliar tecnologia, genética e sustentabilidade. Dr. Claudio Lottenberg.

13h30: Realidade oncológica na atuação do fisioterapeuta. Ft. Bianca Azoubel Andrade.

15h00: Atuação multidisciplinar em UTI neonatal Coordenadora: Ft. Cintia Carniel Paraibuna. Debatedores: Dra. Sandra Alves Moreira (pediatra), Enf. Viviane Lunardio (enfermeira); Ft. Sheila Peres Severino de Moura (fisioterapeuta).

17h00: Tecnologias para Marcha.

Ft. Débora da Silva Fragoso de Campos.

19h00: Remoção aérea.

Ft. Rafael Ladeira

Palestra de Destaque às $17 \mathrm{~h} 00$

Quinta-feira(18/08):

8h00: Ética e estética na adolescência.

Coordenadora: Dra. Ligia de Fátima Nóbrega Reato (hebiatra).

Debatedores: Dr. André Luiz Pires de Freitas (cirurgião plástico) e Dra. Marisa Gonzaga da Cunha (dermatologista). 9h00: Projeto Rondon: o papel do médico e dos estudantes de medicina.

Profa ${ }^{a}$ Silmara Conchão.

9h00: Hemodinâmica:

Enf. Danielle Souza Frois e Dr. Lelio Alves Silva.

10h30: Atuação multiprofissional na sala de emergência. Coordenador: Dr. Mário Faro (cirurgião geral e de urgência).

Debatedores: Dr. Jocielle Miranda (cirurgião geral), Dr. Marco Prist (neurocirurgião), Dr. Edison Nobuko Fujiki (ortopedista) Dr. Flavio Mendes de Oliveira (radiologista), Enf. Ana Fiorano (enfermeira).

18h30: Abordagem neurocirurgica no traumatismo cranioencefálico.

Dr. Dante Piccioti

Palestra de Destaque às $17 \mathrm{~h} 00$

Sexta-feira (19/08):

8h00: Rastreamento em medicina.

Dr. Auro Del Giglio e Dr. José Antonio Maluf.

9h30: A avaliação do aluno de medicina nas diferentes fases da formação acadêmica.

Coordenadora: Dra. Ligia de Fátima Nóbrega Reato. Debatedores: Dra. Angélica Maria Bicudo Zeferino, Dr. José Jorge Namura, Dra. Patricia Tempski, Dra. Marcia Garcia Rodrigues Tamousauskas.

10h00: ONG INATAA - terapia hospitalar com animais. Silvana Fideli Prado.

13h30: Eletroestimulação transcutânea Ganglionar - Perspectivas em Reabilitação Cardiovascular. Ft. Francisco Valdez Santos.

15:00 Síndromes Cardíacas Ft. Vanessa Marques.

17h00: Atualidades em ventilação não-invasiva Ft. Marcos Veiga.

19:00 Pilates.

Ft. Herniman Armdruster dos Santos

Palestra de Destaque às $17 \mathrm{~h} 00$.

\section{CURSOS PRÁTICOS:}

Terça-feira (16/08) e Quarta-feira (17/08)

8h00: Videolaparoscopia em Urologia. Coordenador: Dr. Marcelo Wroclawski. Local: Técnica Cirúrgica - 16 vagas - $\mathrm{R} \$ 30,00$.

10h30: Curso prático de debridamento -

Coordenadora: Enf. Divonélia Nogueira.

Local: Técnica Cirúrgica - 20 vagas - $\mathrm{R} \$ 20,00$.

Quinta-feira(18/08):

8h00: Reanimação neonatal.

Coordenadora: Dra. Silvia Espiridião.

Local: Laboratório de habilidades - 25 vagas - R\$15,00

Sexta Feira (19/08)

8h30: Curso prático de ECG.

Coordeandores: Dr. Carlos Roberto Douglas e Dra. Maria Odila.

Local: Laboratório de Fisiologia - 20 vagas - $R \$ 20,00$. 


\section{PAINÉIS:}

Terca-feira(16/08)

8h00: Reprodução Humana.

Coordenadores: Dr. Caio Parente, Dra. Angela Mara

Bentes de Souza e Dra. Denise Christofolini.

Local: Reprodução Humana - 15 vagas - R $\$ 5,00$

Atividade: Acompanhamento de uma fertilização assistida.

Quarta-feira(17/08)

8h00: Cirurgia Pediátrica.

Coordenador: Dr. Pedro Munhoz Fernandez.

Local: Anfiteatro do Hospital Estadual Mário Covas - 30 vagas $-\mathrm{R} \$ 5,00$.

Atividade: Transmissão ao vivo e discussão de cirurgia pediátrica.

Quinta-feira(18/08)

8h00: Cirurgia Cardíaca.

Coordenador: Dr. Adilson Casemiro Pires.

Local: Anfiteatro do Hospital Estadual Mário Covas - 30 vagas $-R \$ 5,00$.

Atividade: Transmissão ao vivo e discussão de cirurgia cardíaca.

\section{CURSOS DE IMERSÃO:}

\section{Diagnóstico por imagem}

Coordenador: Dr. Marcelo Astolfi Caetano Rico.

Terça-feira(16/08)

14h00-15h00: Avanços dos métodos diagnósticos.

Plexo braquial - relação anatômico clinica com 0

Diagnostico por imagem.

Dr. Marcelo A. C. Nico.

15h20-16h20: Diagnóstico por imagem do nódulo pulmonar solitário.

Dra. Viviane Baptista Antunes.

Quarta-feira (17/08):

14h00-15h00: Aspecto de imagem na avaliação do acidente vascular cerebral (AVC).

Dr. Hugo P. P. Gama.

15h20-16h20: Métodos de imagem na abordagem diagnóstica do abdome.

Dr. Rogerio P. Caldana

Quinta-feira (18/08):

14h00-15h00: Aterosclerose - o papel da ultrassonografia. Doppler na Síndrome do Desfiladeiro torácico. Dr. Andre Paciello Romualdo.

15h20-16h20: Métodos diagnósticos no rastreamento das lesões mamarias.

Dra. Giselle Guedes Melo.

\section{Discussão de casos clínicos}

Coordenador: Dr. José Jorge Namura.

Terça-feira (16/08):

14h00-15h00: Distúrbios neuropediátricos.

Dr. Rafael Guerra Cintra.

15h20-16h20: Coagulopatia a esclarecer.

Dr. José Jorge Namura.

Quarta-feira (17/08):

14h00-15h00: Desafio em pneumologia.

Dr. Nilton Gonçalves dos Santos Junior. 15h20-16h20: Discussão de caso clínico de reumatologia. Dra. Sônia Lodula.

Quinta-feira (18/08):

14h00-15h00: Discussão de caso clínico de infectologia.

Dr. Juvêncio José Duailibe Furtado.

15h20-16h20: Jovem com anemia em emergência. Dra. Ana Lúcia Ippolito Carbonell.

I Curso Hands on de Procedimentos Médicos de Urgência Coordenadores: Dr. Mario Faro e Dr. Rafael Fürst.

Terça-feira (16/08):

14h00-17h00: Módulo de sutura de pele.

DDr. Mario Faro.

DMódulo de principios de cirurgia laparoscópi-

ca.

DDr. Marcos Tobias Machado e Dr. Fernando Korkes.

Quarta-feira (17/08):

14h00-17h00: Módulo de procedimentos vasculares.

Dr. Rafael Fürst.

DMódulo de suturas vasculares.

DDr. Afonso César Polimanti.

Quinta-feira (18/08):

14h00-17h00: Módulo de suporte básico de vida e vias aéreas.

Dr. Mauro Orlando de Souza Potenza.

Módulo de procedimentos cirúrgicos de urgência.

Dr. Rafael Fürst.

\section{Bandagem Funcional}

Coordenador: Ft. Hélio

Quinta-feira (18/08)

14h00-17h00: Bandagem Funcional

Simulado para Concursos de Residência:

Coordenador: Dr. João Antonio Correa.

Terça-feira (16/08)

08h00: Simulado.

Local: Auditório do Centro de Estudo, Pesquisa, Prevenção e Tratamento em Saúde (CEPES) - Campus da FMABC.

Quarta-feira (17/08)

08h00 -12h00: Início da correção do simulado.

13h30-17h00: Término da correção do simulado

Departamento de Trabalhos Científicos.

Apresentação de produções científicas

Terça-feira (16/08)

08h00: Monografias

Pôster Cirúrgico

13h30: Epidemiológico

Quarta-feira (17/08)

08h00: Básico Experimental

Pôster Epidemiológico

13h30: Clínico

Quinta-feira (18/08)

08h00: Cirúrgico

13h30: Pôster Clínico

Sexta-feira (19/08)

08h00: Vídeo 
$\mathrm{A}$ pós três décadas oferecendo um espaço aos acadêmicos da Faculdade de Medicina do ABC e de outras instituições, para aperfeiçoamento em sua formação, seja por meio de conferências ou de painéis, de cursos de imersão ou de avaliação de produções científicas, o Congresso Médico Universitário do ABC alcança sua $36^{\mathrm{a}}$ edição, consagrando-se como o maior evento da categoria no país e um dos mais antigos.

Entretanto, nosso compromisso em produzir um evento de qualidade a toda Comunidade Acadêmica não se dá unicamente pela responsabilidade de que fomos incumbidos após assumirmos a gestão de um órgão com um histórico tão insigne, mas principalmente pela paixão de poder contribuir com o desenvolvimento profissional de tantos congressistas - que, ano após ano, nos prestigiam - e de valorizar o nome de nossa Instituição.

O Congresso, neste ano, prevê inúmeras alterações em seu funcionamento, buscando, por exemplo, conferir-lhe um caráter mais profissional e mesmo dinâmico, possibilitando maior interação entre os con- gressistas e as Comissões Científicas - que terão um papel pedagógico crucial nesta edição, e não meramente avaliativo - e os Conferencistas, por meio de um número maior de Mesas para Colóquios.

Outras alterações, que trarão inclusive maior conforto para aqueles que optarem por participar do evento, foram planejadas e estão sendo efetuadas, mas nenhuma delas ocorreria se não fosse o esmero e o engajamento de todos aqueles que compõem a Comissão Organizadora de nosso $36^{\circ} \mathrm{COMUABC}$, a quem agradecemos e registramos nossa imensa gratidão.

Fica aqui nosso convite para que todos acompanhem nossas atividades e desfrutem de nossas programações e nosso anseio de que o Congresso Médico Universitário do ABC possa impactá-los e marcálos ao longo desta nova edição.

Excelente congresso a todos,

Ac. Stephan Sperling e Ac. Verônica Figueiredo

\section{Palavra do Presidente de Honra}

into-me bastante orgulhoso e envaidecido pelo convite para ser o Presidente de Honra do XXXVI COMUABC. Gostaria de dividir esta homenagem com os alunos da FMABC, pioneiros, que há 36 anos decidiram realizar, praticamente sem ajuda, um Congresso Médico Universitário com o intuito de contribuir para o aprimoramento dos alunos de uma jovem e recente Faculdade. E começaram pensando alto, com convidados internacionais, professores renomados de outras instituições, cursos e com a apresentação de trabalhos científicos realizados por alunos. Foi o começo da iniciação científica na Faculdade que motivou vários alunos para a pesquisa e para o ensino, como no meu caso. Em geral, um pesquisador começa muito cedo, muitas vezes durante a iniciação científica. Gostaria de lembrar que muitos avanços na Medicina foram feitos por alunos. Paul Langherans identificou as ilhotas pancreáticas que hoje levam o seu nome. Jay McLean identificou a heparina em extratos do fígado. Charles Best ajudou decisivamente a isolar a insulina, tento sido, curiosamente, escolhido no cara ou coroa para fazer a iniciação científica no laboratório de Frederick Banting, sendo que só após mostrar a sua capacidade pôde permanecer por mais tempo na pesquisa.
Ao longo dos anos, as turmas que se seguiram na diretoria do COMUABC não se contentaram em manter o que já havia sido feito, mas aumentar e aprimorar cada edição do Congresso. E, assim, ininterruptamente, tenho assistido a cada ano novas inovações, como a inserção dos alunos dos novos cursos da FMABC, os trabalhos científicos em vídeos, as monografias, as atividades práticas como cirurgias laparoscópicas experimentais, etc. Em 2011, acompanhei também a introdução de novas modificações na inscrição e avaliação dos trabalhos científicos, com o objetivo de aproximar o COMUABC dos melhores congressos nacionais e internacionais. Espero que esta edição do COMUABC possa contribuir para o aprimoramento de alunos e professores, abrindo novos caminhos para os nossos alunos e que eles possam desenvolver o senso crítico, a criatividade e a curiosidade científica. Nós ainda tempos muitas perguntas não respondidas, muitas doenças incuráveis, e o tempo é o nosso inimigo. "Quem salva uma vida salva a Humanidade", diz o Talmud; então, estamos contribuindo para formar melhor aqueles que salvarão a Humanidade.

Prof. Dr. David Feder 


\section{A busca e 0 encontro da humanização}

$\mathrm{V}$

ocês não imaginam como me sinto profundamente emocionado em ser homenageado neste XXXVI Congresso Médico Universitário da Faculdade de Medicina do ABC.

Sinto-me feliz porque minha mensagem foi compreendida, tenho a esperança de que todos vocês serão os médicos humanizados de que a sociedade tanto precisa, usando o conhecimento com sensibilidade.

Em todas as épocas, sobretudo atualmente, é estranho pedir a nós, médicos, dispondo de tantos recursos, que sejamos humanizados ao atender o doente e sua família. Mas é a realidade. Parece que ainda não compreendemos que o aumento de nossos conhecimentos, pelo vertiginoso desenvolvimento da ciência e da tecnologia, é apenas um instrumento a mais para podermos cuidar melhor de quem nos procura. Mas com sensibilidade.

Como médico e professor, demorei para compreender, em profundidade, o quanto a humanização traz sentido à vida. Inicialmente, eu entendia minha profissão como conhecer bem a Medicina, procurando utilizar, com delicadeza, os conhecimentos adquiridos para melhor prevenir, diagnosticar e tratar os doentes e suas famílias. Com o tempo, aprendi que, na realidade, a Medicina é muito mais do que isso - de um modo natural ela faz parte praticamente de todos os momentos de nossa vida. Cuidando dos doentes e seus familiares, precisamos aprender a escutá-los, compreendê-los e saber como lidar com sua ansiedade e sofrimento.

A Faculdade de Medicina do ABC tem a missão de formar médicos com muito conhecimento e sensibilidade. E serem valorizados. Assim, eu entendo a homenagem que vocês me prestam neste Congresso. Eu a estendo a todos os meus colegas, sobretudo do Departamento de Pediatria, com quem convivi tantos anos, aos residentes e alunos, que considero meu filhos. Procuremos sempre buscar e lutar pelo encontro da humanização. Para que a vida tenha sentido. Este é o nosso compromisso. Se não, seríamos apenas técnicos, mas não médicos de verdade. Sou imensamente grato a vocês.

Prof. Dr. Drauzio Viegas 


\section{Temas Livres: Clínico}

Análise inicial do tratamento endovascular de hipertensão venosa de membros superiores em pacientes dialíticos
Almeida RC, Golfetti MG, Silva CMR, Barros HPC, Andrade TM, Fujii EY, Correa JA, Galego SJ

Introdução: A realização de fístulas arterio-venosas (FAV) promove altos fluxos sanguíneos e baixos índices de complicações imediatas, porém esses acessos não são tão factíveis de serem utilizados de modo imediato na maioria dos pacientes em regime de hemodiálise.Nesses casos utiliza-se cateteres venosos centrais que após uso prolongado podem evoluir com estenose dos vasos. Como consequiência o indivíduo pode apresentar hipertensão venosa do membro superior aonde foi confeccionada a FAV. Neste quadro, uma possibilidade de tratamento efetivo é a realização de angioplastia de veia subclávia. Objetivo: Analisa a angioplastia da veia subclávia como um tratamento efetivo para hipertensão venosa de membro superiores em pacientes dialíticos. Método: Foram realizadas 57 angioplastias de veia subclávia no período de 2003 a 2011, sendo $57,4 \%$ em veia subclávia direita e $45,6 \%$ ns esquerda. A maioria dos indivíduos eram homens $(68,9 \%)$, sendo as mulheres $31,1 \%$ dos casos analisados. Resultados: A taxa de sucesso inicial, a desobstrução dos vasos, reduzindo a hipertensão venosa foi de $82,45 \%$. Conclusão: A angioplastia de veia subclávia é uma nova possibilidade de tratamento da hipertensão venosa de membros superiores que tem se mostrado eficaz em sua análise inicial no serviço de Angioplastia e Cirurgia Vascular da Faculdade de Medicina do ABC.

Descritores: Fístula arteriovenosa, Angioplastia de via subclávia, Diálise, Hipertensão venosa.

\section{Aspectos radiológicos da síndrome de Kartagener: um relato de caso}

Morimoto TP, Maruyama MK, Higasiaraguti M, Martins RF, Kinjo CS, Campos ZMS, Castro CC

Introdução: A síndrome de Kartagener é um subgrupo da Síndrome da Imotilidade Ciliar, também chamada de discinesia ciliar primária, segue um padrão autossômico recessivo com prevalência na população, que varia na literatura de 1:20.000-1:60.000. Há alterações de proteínas que compõem a estrutura e o movimento ciliar do epitélio respiratório, causando infecções no trato respiratório desde a infância, além de pneumonia crônica, otite média crônica, pólipos nasais, tosse produtiva, hemoptises, e eventual falência respiratória e cardíaca. A tríade clássica de sinusopatia, bronquiectasia e situs inversus, pode vir acompanhada de infertilidade masculina, caracterizando a síndrome. Alguns exames com valor presuntivo podem ser realizados, como o teste da sacarina e a dosagem de óxido nítrico exalado. O diagnóstico definitivo deve ser realizado através do estudo da ultra-estrutura, da orientação e da função ciliar. Relato de caso: ISL, 43 anos, masculino, os principais achados radiológicas observadas foram o situs inversus totalis, caracterizado pela dextrocardia e inverção dos sítios de vísceras abdominais (baço e fígado); a sinusiopatia, caracterizada pelo espessamento da mucosa dos seios maxilares; e a bronquiectasia, caracterizada por dilatação brônquica e espessamento da parede brônquica. Discussão: Devido a raridade dessa síndrome, nosso objetivo neste trabalho é apresentar os aspectos radiológicos dessa síndrome por meio de um relato de caso.

Descritores: Síndrome de Kartagener, Situs Inversus, Sinusiopatia, Bronquiectasia.

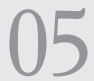

Avaliação dos níveis de homocisteina e de seus co-fatores em pacientes com câncer de mama em tratamento quimioterápico

\section{Teixeira BM, Yoshihara RN, Fonseca FLA}

Introdução: Dados do Instituto Nacional de Câncer de 2010 mostraram risco de câncer de mama entre brasileiras de 49 casos/100 mil. Estudos em mulheres com este câncer demonstram correlação com hiperhomocisteinemia, a qual poderia ser um fator de risco para câncer, além de estar associada à fenômenos tromboembólicos. A homocisteína é um aminoácido, cujo metabolismo envolve participação de co-fatores como vitamina B12 e folato. Objetivo: Avaliar concentraç̃os de homocisteína, ácido fólico e vitamina B12, contagem de plaquetas ao diagnóstico de câncer de mama, 3 e 6 meses após o início do tratamento e relacioná-las com dados clínicos. Método: 35 pacientes diagnosticadas com câncer de mama no Ambulatório Experimental Aplicado ao Câncer de Mama do serviço de oncologia da Faculdade de Medicina do ABC, das quais foram obtidas amostras por venopunção e analisadas por ensaio imunoenzimático pelo método de quimioluminescência para dosagem de homocisteína e co-fatores, enquanto que a contagem de plaquetas foi realizada por automação. Análise estatística pelo modelo eletrônico SSPS e correlação com dados clínicos. Resultados: Houve aumento de homocisteína $(\mathrm{p}=0,032)$ e vitamina $\mathrm{B} 12(\mathrm{p}<0,001)$ enquanto o ácido fólico e as plaquetas diminuíram $(\mathrm{p}<0,001)$ durante o tratamento quimioterápico. Entre os dados clínicos, o status menopausal teve correlação significativa $(\mathrm{p}=0,022)$ com a homocisteína. Conclusão: Avaliar a homocisteína durante o tratamento quimioterápico é extremamente importante, pois seus níveis aumentam quando este é instalado, parecendo sofrer influência deste. Dessa maneira, se sugere a discussão de introdução de drogas capazes de proteger o endotélio a fim de minimizar os efeitos dos agentes contidos na quimioterapia.

\section{Arterite de Takayasu: relato de caso}

Rocha LFL, Matar MR, Ricci R, Santos JPM, Maximiano FL

Introdução: A Arterite de Takayasu, doença inflamatória crônica não aterosclerótica de grandes e médio vasos, principalmente, e de etiologia desconhecida inicia-se na camada média e evolui para estreitamento arterial . É doença rara mais prevalente em mulheres. Na prática clínica, raramente se aventa esta hipótese e o diagnóstico pode levar anos. É, portanto, necessário que se conheça suas diversas formas de apresentação. Relato de caso: Paciente feminina, 18 anos, com queixas de astenia, dor em dorso, febre, sudorese noturna, perda ponderal de $5 \mathrm{Kg}$ em 1 mês, desconforto torácico, palpitação e tontura aos grandes esforços. Foi admitida em hospital universitário para investigação clínica após 3 dias de tratamento sintomático em outro serviço. Ao exame físico: ritmo cardíaco regular a 2 tempos com sopro sistólico em foco aórtico 4+/4, irradiação para subclávias e carótidas bilateralmente. O ecocardiograma transtorácico revelou ectasia de aorta, da raiz ao segmento descendente; o duplex scan de carótidas evidenciou obstrução hemodinamicamente significativa (70\%) em ambas carótidas comuns e a arteriografia estenose importante de carótida comum esquerda, ausência de estenose em carótida comum direita e artérias renais. Instituiu-se o tratamento com pulsoterapia de corticóide e após 3 dias a paciente apresentou melhora importante do quadro. Recebeu alta após 20 dias de internação, assintomática em uso de imunossupressão com corticóide. Discussão: A Arterite de Takayasu é doença grave e rara. É pouco suspeitada na prática clínica e sua investigação pode durar anos. Usualmente, o uso de corticóides em doses altas ou outros imunossupressores são reservados aos casos refratários. Nesse caso, devido ao risco de isquemia cerebral, a pulsoterapia com prednisona foi instituída precocemente.

Descritores: Relatos de casos, Estenose das Carótidas, Arterite, Arterite de Takayassu.

\section{Atuação da terapia ocupacional na paralisia cerebral infantil}

\section{Marcelino NCR, Ruis $C F$}

Introdução: Paralisia Cerebral (PC) é definida como um conjunto de ações que comprometem o Sistem Nervoso Central (SNC) em desenvolvimento, antes, durante o nascimento ou nos primeiros meses da infância ( 2 anos de idade) que apresenta distúrbio motor como uma de suas manifestações mais evidentes. Apesar de a principal característica da PC ser o distúrbio motor, é comum encontrar outros distúrbios associados, como: déficit cognitivo, convulsões, alteraç̃es oculares e visuais, distúrbios da deglutição, anormalidades da fala e linguagem, comprometimento auditivo, distúrbios do comportamento, entre outros. A paralisia cerebral se manifesta de diferentes formas, com isso recebe o nome de acordo com o tipo de comprometimento. E eles são: Espástico que representa 75\% dos casos, Extraperamidal que representa 15\% a 20\% dos casos, Misto repesenta aproximadamente $20 \%$ dos casos, Atáxico repesenta apenas $2 \%$ dos casos, Objetivo: Apresentar por dados levantados pela literatura específica sobre a atuação da terapia ocupacional na paralisia cerebral infantil. Justificativa: Tem como justificativa o papel da terapia ocupacional, uma vez que é um tema pouco explorado, surgindo assim um melhor entendimento para a TO. Método: pesquisa se trata de um levantamento bibliográfico de recorte social e qualitativa. Conclusão: A Terapia Ocupacional contribui com o desenvolvimento da criança com paralisia cerebral, entretanto é necessário ressaltar que o trabalho deve ser realizado por uma equipe multidisciplinar, todos com o objetivo de proporcionar o melhor desenvolvimento possível da criança em questão, além de dar suporte especializado à família.

Descritores: Paralisia cerebral, Terapia Ocupacional, Atuação, Desenvolvimento infantil.

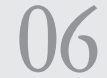

Avaliação ultrassonográfica do sistema venoso profundo após escleroterapia com espuma de polidocanol em pacientes com insuficiência venosa crônica

Almeida RC, Silva CMR, Barros HPC, Golfetti MG, Gracia MP, Correa JA, Galego SJ, Dias MCCPO

Introdução: A escleroterapia é um método antigo e consagrado para a erradicação de veias varicosas teleangectasias. $\mathrm{O}$ uso de detergentes esclerosantes misturados com ar forma uma espuma, que quando injetada em veias varicosas propicia uma maior superfície de contato com o endotélio e menor diluição do agente. O intuito é realizar a ablação química das doentes que causam insuficiência venosa crônica, visando melhorar a qualidade de vida dos indivíduos. Apresenta baixo custo e baixo índice de complicações, sendo a mais temida o tromboembolismo venoso. Objetivo: Avaliar a presença de trombose no sistema venoso profundo de pacientes tratados por escleroterapia com espuma de polidocanol a $3 \%$ através da ultrassonografia 7 dias após procedimento. Método: Foram tratados 101 membros com insuficiência venosa crônica todos apresentavam sistema venoso profundo normal na avaliação ultrassonográfica prévia. Os membros tratados dividiam-se de acordo com a classificação CEAP. Realizada escleroterapia com espuma guiada por ultrassom em regime ambulatorial. Controle com Doppler ultrassom após 7 dia da aplicação para avaliar sistema venoso profundo. Resultados: Houve 12,8\% casos de oclusão do sistem venoso profundo, sendo $9 \%$ de oclusões distais, $1,8 \%$ de trombo flutuante na junção safeno femoral e $0,9 \%$ oclusão de veia poplítea. Nenhum dos pacientes apresentou sintomatologia ou quadro clínico de embolia pulmonar ou trombose venosa profunda. Conclusão: Apesar da incidência de trombose venosa profunda após a esclerose, não houve morbi mortalidade relacionada. Com isso, respeitando indicações criteriosas, a escleroterapia com espuma é uma ferramenta para o tratamento da insuficiência venosa crônica, principalmente em pacientes que não se adéquam ao tratamento cirúrgico.

Descritores: Escleroterapia, Insuficiência venosa crônica, Varizes, Polidocanol. 
Bupropiona para fogachos após câncer de mama: estudo piloto de fase II

\section{Zanellato RM, Lera AT, Lerner TG, Tateyama LTC, Nuñę GR, Cubero D, Cruz FM, Giglio AD}

Introdução: Aproximadamente $65 \%$ das mulheres após câncer de mama sofrem de fogachos. A bupropiona é uma medicação antidepressiva usada para tratamento do abandono do cigarro, estudada previamente para disfunção sexual. Objetivo: Avaliar a bupropiona para controle de fogachos em mulheres sobreviventes de câncer de mama e analisar disfunção sexual, depressão e melhora da qualidade de vida nessas mulheres. Método: Estudo prospectivo randomizado, duplo-cego, placebo controlado, com cruzamento de braços, que incluiu 55 pacientes tratadas de câncer de mama que apresentavam mais de 7 fogachos por semana. Um dos grupos (27 pacientes) recebeu bupropiona por 4 semanas e após uma semana de washout (descanso) recebeu 4 semanas de placebo. Outro grupo (28 pacientes) recebeu placebo por 4 semanas e após uma semana de descanso recebeu bupropiona por 4 semanas. A média da atividade diária dos fogachos quanto à frequiência e ao escore de fogachos (número de episódios x severidade) foi avaliada. Disfunção sexual, depressão e qualidade de vida foram avaliados por meio das escalas AESX, Beck e EORTC-Q30, respectivamente. Concluíram todas as fases do estudo 48 pacientes (uma paciente foi excluída por não preencher os diários e houve 3 desistências em cada grupo). Resultados: A bupropiona reduziu 1,26 fogachos/dia e 6,31\% no escore de severidade de fogachos enquanto o placebo reduziu 2,25 fogachos/dia $(p>0,05)$ e $30,47 \%$ no escore de severidade $(\mathrm{p}>0,05)$. Não foi verificada diferença estatística entre os grupos nas escalas ASEX, Beck e EORTC-Q30. Ao final do estudo, $47 \%$ das pacientes preferiram a bupropiona, enquanto $53 \%$ preferiram placebo. Conclusão: Quando comparada a placebo, bupropiona não mostrou atividade mínima esperada no controle dos fogachos em sobreviventes de câncer de mama.

Descritores: Câncer, Fogachos, Câncer de mama, Estudos clínicos.

\section{Encefalite e celulite pós-varicela em paciente de 2 anos de idade}

Briones BS, E₹⿱乛龰urra TCSP, Laranjeira M, Santos VP

Introdução: Varicela é doença exantemática maculopapulovesicular causada pelo vírus varicela zoster. Sua complicação mais comum é a infecção das lesões cutâneas por S. aureus. Nos casos graves, pode ocorre celulite e infecções sistêmicas, inclusive em SNC, que são mais severas e podem gerar seqüelas (15\%) e morte (37\%). Relato de caso: RRDC, 2 anos, masculino. História de vesículas em cavidade oral com disseminação cefalocaudal e evolução para crostas. Diagnosticada varicela. Evoluiu com movimento tonicoclônicos em MSD e MID acompanhados de desvio do olhar para a direita, sialorréia, dificuldade para sentar sem apoio e deambular, além de facilidade de queda para a direita. Ao exame: REG, afebril, consciente, hipoativo. Lesões crostosas em tronco, dorso e membros e lesões vesiculares em mãos e pés. Exame neurológico: ataxia apendicular e axial; marcha ebriosa. TC de crânio e LCR normais. Admitid na enfermaria com diagnóstico de encefalite pós-varicela. Tratado com aciclovir. Evoluiu com celulite em pé direito. Tratado com cefalotina. Voltou a sentar sem apoio, apresentando melhora da orientação, da ataxia e da marcha além de diminuição da sonolência. Recebeu alta no $16^{\circ}$ DIH com resolução da celulite, deambulando com apoio e mantendo leve ataxia. Discussão: Paciente apresentou celulite, uma das complicações da varicela, e acometimento do SNC na forma de encefalite, que geralmente apresenta TC de crânio e LCR normais. 1 mês e meio após a alta, mantinha alteração da marcha como seqüela, o que é esperado em $15 \%$ dos casos. É escasso encontrar na literatura estudos e relatos de caso acerca das complicações da varicela, sendo necessário aprofundamento das pesquisas referentes às suas causas e fatores predisponentes, no intuito de diminuir sua morbimortalidade.

Descritores: Varicela, Encefalite, Celulite, Encefalite pós-varicela.

\section{Hemangioma papebral tratado com propanolol: um relato de caso}

Mota RT, Pachon S, Toloi GC, Salomão GHA

Introdução: Os hemangiomas são os tumores benignos mais frequentes na infância, com incidência estimada entre 4 a $10 \%$ em crianças abaixo de 1 ano de idade. São neoplasias vasculares benignas, decorrentes de uma rápida proliferação das células endoteliais. Aproximadamente $20 \%$ dos hemangiomas evoluem com complicações que podem afetar os mais variados locais, comprimindo ou obstruindo estruturas importantes, como olhos, nariz, boca, vias aéreas superiores, entre outros. O tratamento de escolha dos hemangiomas infantis são os glicocorticóides. Nos últimos anos, alguns estudos apontaram o beneficio do uso de propranolol, um beta bloqueador não seletivo, no tratamento desta doença. Relato de caso: Apresentamos um caso de uma lactente de 2 meses de idade e quadro de hemangioma facial de rápida evolução, com comprometimento de fronte e pálpebra superior a direita, que devido ao crescimento tumoral, em poucas semanas evolui com ptose (queda palpebral) mecânica e obstrução do eixo visual. Pela ameaça ao desenvolvimento visual, optamos pelo tratamento farmacológico com propanolol $2 \mathrm{mg} / \mathrm{kg} / \mathrm{dia}$, que se mostrou eficaz em poucas semanas reduzindo a massa tumoral e possibilitando a reabertura da fenda palpebral, impedindo o comprometimento visual da criança. Conclusã̃o: Propranolol via oral foi eficaz na redução do hemangioma, com efeito rápido e consistente além de boa tolerância clínica.

Descritores: Hemangioma/terapia, Criança, Propanolol, Lactente.

\section{Diagnóstico diferencial de rinossinusite persistente}

Yamamoto AYP, Burlamaqui JCF, Silveira BS, Formigoni DS, Yamauti LS, Baptista MAFB, Prescinotto $R$

Introdução: $O$ linfoma de Burkitt, um raro diagnóstico diferencial da rinossinusite, é um tipo de linfoma não-Hodgkin que normalmente se manifesta como uma grande lesão osteolítica no maxilar ou uma massa abdominal. Embora muito raro, outro sítio de acometimento é a nasofaringe. Relato de caso: Paciente de quatro anos de idade com quadro de rinossinusite foi tratado sem sucesso com antibioticoterapia durante um mês. Durante investigação aprofundada, foi detectada massa em nasofaringe (Linfoma de Burkitt) que, após tratamento quimioterápico, regrediu totalmente. Discussão: Frente a uma rinossinusite com falha terapêutica, deve-se continuar a investigação com propedêutica armada para que outras patologias mai graves possam ser diagnosticadas precocemente. Em estágios iniciais, o linfoma de Burkitt responde bem ao tratamento quimioterápico.

Descritores: Neoplasia de nasofaringe, Nasofaringe, Linfoma de Burkitt, Sinusite.

\section{Experiência do grupo de DST/AIDS do município de São Bernardo do Campo no tratamento de condilomas genitais em homens comparando o uso de eletrocoagulação com e sem podofilotoxina tópica em lesões extensas e/ou numerosas}

Picosse VD, Pedrenho Neto R, Barros RASA, Schalch MS, Okamoto ECG, Ferreira AACM, Watanabe MS

Introdução: O HPV é uma das principais causas de DST \'s do mundo com mais de 100 tipos. Há tipos mais oncogênicos, como o $16 \mathrm{eo} 18$, e outros menos agressivos como os $6 \mathrm{e} 11$, que causam verrugas genitais, conhecidas como condiloma acuminado. Existem diversas modalidades de tratamento das lesões, sendo algumas dolorosas como eletrocauterização e ácido tricloroacético e a auto-aplicada que é a podofilotoxina tópica $0,15 \%$, a principal substância ativa da podofilina. Objetivo: Relatar a experiência no tratamento de lesões condilomatosas penianas para analisar suas complicações, taxas de recidivas e cura, com emprego da técnica de eletrocoagulação isolada, como também com uso prévio de podofilotoxina. Método: De um total de 250 pacientes do sexo masculino, foram selecionados 167 homens entre janeiro de 2010 a janeiro de 2011, por apresentarem lesões genitais compatíveis com verrugas condilomatosas. Resultados: Dos 140 pacientes submetidos à eletrocoagulação exclusiva, 98 não tiveram recidivas com o tratamento em única sessão. Dos outros 42, 9 necessitaram duas aplicações; 12 necessitaram de três e 21 necessitaram de mais de três aplicações. Enquanto que nos 27 pacientes submetidos ao uso prévio de podofilotoxina, 18 necessitaram de uma sessão de cauterização; 6 de duas e 3 de três sessões. Conclusão: A maioria dos condilomas $(70 \%)$ não recidiva com eletrocoagulação exclusiva nem com associação à podofilotoxina. Porém, no primeiro a recidiva é maior (23,5\% com 3 ou mais aplicações) quando comparado ao segundo (11\% com 3 aplicações com eletrocautério), podendo assim ser considerado um método mais eficiente na prevenção da recidiva de condiloma genital, afirmando a conduta do uso aditivo da podofilotoxina na terapêutica de base.

Descritores: Eletrocoagulação, Recidiva, Condiloma acuminado, Podofilotoxina.

\section{Hipertensão arterial pulmonar associada a comunicação interatrial: a importância da confirmação diagnóstica}

Introdução: Comunicação Interatrial (CIA) é uma cardiopatia associada a complexa formação embriológica do septo atrial. Representa um terço das cardiopatias congênitas dos adultos e predomina em mulheres. É a cardiopatia com evolução mais benigna e com diagnóstico frequente na idade adulta, tendo como complicação a Hipertensão Arterial Pulmonar (HAP), podendo impedir o tratamento cirúrgico. Relato de caso: Mulher, 62 anos, ex-tabagista há 4 meses, fumou por 30 anos, queixa de dispnéia aos esforços. Exame físico: murmúrio vesícular presente, hiperfonese e sopro sistólico em foco pulmonar, sopro diastólico em foco tricúspide. ECO: câmaras cardíacas direitas com dilatação, PSVD: $43 \mathrm{mmHg}$, CIA-ostium secundum, $15 \mathrm{~mm}$, shunt esquerda-direita. Em Tomografia Computadorizada (CT): dilatação do tronco da artéria pulmonar (40mm) e ramo descendente APD (28) e APE (23). BNP: 54,9. Função pulmonar VEF1: 64\% e, pós broncodilatador, VEF1: 73\%. Cateterismo: TP:20x30x23; AD: 8; PAOP: 10; RVP: 151; DC:6,9; qp:13; qs:8,2; e shunt: 1,96. Discussão: CIA do tipo ostium-secundum é localizada dentro da fossa oval e representa $75 \%$ das CIAs. O shunt provoca um estado de hiperfluxo sanguíneo pulmonar, promovendo a dilatação das artérias pulmonares e a HAP. A dispnéia, a presença de sopros cardíacos, a dilatação do tronco pulmonar e a PSVD aumentada levaram a supeita de HAP, afastada pelo cateterismo de câmaras direitas. Paciente encaminhada ao tratamento cirúrgico de CIA. Assim, o diagnóstico precoce da cardiopatia e o uso do cateterismo para a confirmação de HAP são fundamentais para avaliar o prognóstico da doença e para o seu tratamento adequado.

Descritores: Comunicação interatrial, Hipertensão pulmonar, Comunicação interatrial/diagnóstico, Cateterismo. 


\section{HIV relacionado à bronquiectasia e hipertensão arterial pulmonar}

\section{Agena J, Hirai CCG, Ferreira AACM, Moraes GBB, Lapa MS}

Introdução: Uma das manifestações relacionadas ao vírus HIV é a hipertensão arterial pulmonar (HAP), com prevalência de $0,5 \%$ na população HIV positiva. Relato de caso: GE, 50 anos, masculino. Portador de bronquiectasia, hepatite $\mathrm{C}$ e HIV. Possui cargas virais não detectáveis e contagem de CD4 e CD8 de 1000 células $/ \mathrm{mm}^{3}$. Refere dispnéia e chiado desde a infância com piora da dispnéia há um ano aos médios esforços (classe funcional III). Há um mês houve piora da dispnéia, edema de membros inferiores e queda da saturação de oxigênio. Exame físico: emagrecido, dispnéico, cianótico com baqueteamento digital. Saturação de $\mathrm{O} 2$ de $60 \%$, freqüência cardíaca $=131 \mathrm{bpm}$, estertores finos difusos. Raio-X de tórax:opacidades heterogêneas difusas em ambos hemitoraces com distorção arquitetural e presença de cistos e cardiomegalia. Ecocardiograma (ECO): diâmetro de ventrículo direito $(\mathrm{VD})=38 \mathrm{~mm}$, fração de ejeção (FE): $60 \%$ e Pressão sistólica do VD(PSVD) $=89 \mathrm{mmHg}$. Tomografia de tórax bronquectasias císticas difusas, sinais de HAP sem falhas de enchimento. Foi tratado com furosemida, espironolactona, antibioticoterapia e oxigenoterapia. Após dois meses houve melhora da dispnéia, em CF II. Novo ECO: $\mathrm{VD}=20 \mathrm{~mm}, \mathrm{FE}=69 \%$, PSVD=54mmHg. Espirometria: Capacidade vital funcional 1,74L $(47 \%)$,Volume expiratório forçado em 1 minuto (VEFl): 1,21L(41\%) e VEFl/CVF 0,7 sem resposta ao uso de broncodilatador. Discussão: HAP-HIV ocorre em fases precoces e tardias da infecção e não parece estar relacionada ao grau de deficiência imunológica. $O$ diagnóstico é difícil e tardio devido aos poucos sintomas do paciente. Doenças pulmonares avançadas também podem evoluir com HAP. Após tratamento houve compensação clínica e diminuição da sobrecarga cardíaca. Neste caso, a HAP é provavelmente associad às duas doenças.

Descritores: Hipertensão pulmonar/etiologia, HIV, Bronquiectasia, Hipertensão pulmonar/terapia.

\section{Marcadores hepáticos, prevalência de anormalidades da síndrome metabólica e o efeito do bypass gástrico em Y de Roux em indivíduos com obesidade mórbida}

Margeotto FB, Pessoa GB, Moreno R, Serpa Neto A

Introdução: A doença hepática gordurosa não - alcoólica (DHGNA) está crescendo como um componente da síndrome metabólica, embora não se saiba ao certo se os marcadores da DHGNA, o que inclue concentrações elevadas de aspartato aminotransferase (AST), alanina aminotransferase (ALT) e gamaglutamiltransferase (GGT), predizem o desenvolvimento da síndrome metabólica. Objetivo: Avaliar as relações entre os marcadores hepáticos (GGT, AST e ALT) e a síndrome metabólica (e seus componentes) em indivíduos com obesidade mórbida e determinar a resposta desses fatores metabólicos e das enzimas hepáticas após perda de peso induzida pelo bypass gástrico em Y de Roux (BPGYR). Método: Foram avaliados 140 indivíduos com obesidade mórbida, com idade entre 18 e 60 anos, submetidos ao BPGYR e que foram acompanhados por um período médio de oito meses. Pacientes com histórico de etilismo, diabetes tipo I e/ou doenças hepáticas foram excluídos. Resultados: Marcadores hepáticos, especialmente GGT, foram fortemente associados com anormalidades metabólicas, principalmente hiperuricemia. A prevalência da diabetes tipo II aumentou significativamente com o aumento dos níveis de GGT (quartil superior vs inferior de GGT: razão de risco de 3,89). Marcadores hepáticos diminuíram significativamente oito meses após bypass gástrico em Y de Roux e a redução dos níveis de GGT foi associada com a redução dos níveis de glicose (Pearson $\mathrm{r}=0.286 ; \mathrm{p}=0.001$ ). Conclusão: Níveis elevados de marcadores hepáticos, principalmente GGT, em indivíduos com obesidade mórbida foram associados com anormalidade metabólicas. Além dos conhecidos benefícios da cirurgia bariátrica, o BPGYR reduziu os níveis de marcadores hepáticos aos valores de normalidade.

Descritores: Síndrome metabólica, Obesidade mórbida, Marcadores hepáticos, Bypass gástrico.

\section{Pneumoencéfalo pós punção inadvertida de dura máter}

\section{Okamoto ECG, Moura F, Yoshii HK, Assi HEB, Carelli Neto I, Salhago AK, Barsella AR}

Introdução: Injeção de corticóide no espaço epidural é um procedimento usual para tratamento de dores lombares refratárias ao uso de antiinflamatórios não hormonais. Em nosso serviço, é comum o uso da técnica de Dogliotti com o paciente sentado. Relato de caso: Paciente MJFM, 62 anos, branco, $80 \mathrm{Kg}$, sexo masculino, com queixa de dor lombar de forte intensidade, refratária ao uso de analgésicos. Foi encaminhado pelo grupo da Ortopedia para tratamento da lombalgia com a realização de peridural com corticóide. No centro cirúrgico, foi posicionado na posição sentado para realização de peridural no espaço L4/L5 usando a técnica da perda da resistência com seringa de vidro contendo $5 \mathrm{~mL}$ de ar. Houve perfuração acidental da dura-máter, evidenciada pelo refluxo de líquor na agulha. Nova punção foi feita em espaço L3/L4 com sucesso. No $1^{\circ}$ pós-operatório (PO), paciente evoluiu com cefaléia, em posição ortostática e decúbito. $\mathrm{O}$ tratamento foi hidratação associada a analgésicos e antiinflamatórios. Houve piora do quadro com náuseas e vômitos. A tomografia computadorizada (TC) solicitada evidenciou pneumoencéfalo intraventricular. A conduta foi expectante, utilizando-se analgésicos. Houve regressão da cefaléia no $7^{\circ} \mathrm{PO}$ e alta no $9^{\circ}$ dia sem sequelas. Discussão: $\mathrm{O}$ pneumoencéfalo é uma complicação atribuída ao uso de ar para identificação do espaço epidural. Apenas $2 \mathrm{~mL}$ de ar são suficientes para causar cefaléia intensa, sendo que, mesmo em repouso, não há remissão do quadro álgico. Devido às características da dor e evidências na literatura, a peridural terapêutica não apresenta eficácia. A TC é o exame de escolha para diagnóstico do pneumoencéfalo. $\mathrm{O}$ tratamento é expectante e a regressão dos sintomas ocorre em 5-7 dias. A persistência dos sintomas pode indicar uma abordagem cirúrgica.

Descritores: Pneumoencéfalo, Peridural, Cefaléia, Corticóide.

\section{Importância da biópsia renal no prognóstico e tratamento das glomerulonefrites}

\section{Amaro DMC, Nogueira MB, Campos MAM, Poblete NCO, Feo LB, Moreira LA, Bergamo RR}

Introdução: A Glomerulonefrite é uma doença renal, caracterizada por inflamação de glomérulos. Apresenta diversos padrões patológicos,agrupados em não-proliferativos ou proliferativos,com tratamento e prognóstico diferentes. Costumam apresentar o mesmo conjunto de manifestações clínicas, assim a definição da etiologia depende de biópsia. A glomerulonefrite rapidamente progressiva apresent o pior prognóstico,rápida evolução para insuficiência renal, é positiva para Anticorpos Anticitoplasma de Neutrófilos e inicia-se com sintomas inespecíficos confundindo-a com tipos menos preocupantes. Nestes variados contextos, há uma ampla gama de diagnósticos diferenciais onde a biópsia é indispensável para diagnóstico apurado, fornecer informacões críticas sobre evolução e prognóstico ou desenvolve abordagem racional do tratamento. Relato de caso: E.S.D., sexo masculino, 60 anos, diagnosticado de HAS há 29 anos, apresentou Glomerulonefrite Rapidamente Progressiva em fevereiro de 2011. Internado com suspeita de Glomerulonefrite ANCA-mediada ou Pós-infecciosa. Foi realizada pulsoterapia com solumedrol por 3 dias sem melhora da função renal.Foi feita biópsia renal que indicou glomerulonefrite proliferativa difusa,padrão endocapilar, com exsudato inflamatório e crescentes celulares $(9 / 14)$, atrofia fibrose discretas em interstício. Imunofluorescência C3+. Diurese normal e edema generalizado. Em 1/03 iniciou pulso de coflofosfamida, apresentou melhora na função renal. Discussão: Como o paciente não respondeu ao solimedrol a hipótese de Glomerulonefrite Pós-infecciosa foi descartada. Caso o paciente realizasse apenas pesquisa de ANCA sem biópsia ele seria encaminhado para hemodiálise. Porém a biópsia mostrou que o quadro em questão era melhor do que o esperado descartando a necessidade de diálise

Descritores: Glomerulonefrite, Vasculite mediada por anticorpos, Anticitoplasma de neutrófilos, Biópsia renal por agulha, Hemodiálise.

\section{0 cam-icu é o melhor método para diagnosticar delirium em pacientes críticos: resultados de uma análise cumulativa de 1.051 pacientes}

\section{Michaelis LF, Burlamaqui JCF, Daniel MB, Baccaro BM, Chiota FL, Arrym TP, Serpa Neto A}

Introdução: O delirium afeta uma proporção substancial de pacientes hospitalizados e aumenta probabilidade de desfechos desfavoráveis. Nosso foco foi de revisar sistematicamente a acurácia diagnóstica de instrumentos de beira de leito para diagnosticar delirium em pacientes críticos. Método: Essa é uma revisão sistemática e análise cumulativa de estudos publicados entre 1966 e 2011. Os bancos de dados do Medline e Embase foram usados para procurar estudos publicados sobre delirium em pacientes críticos. Os dados avaliados foram: sensibilidade, especificidade, razão de probabilidade e curvas ROC resumidas contra o padrão-ouro (questionário DSM-IV). Resultados: Onze artigos cobrindo 1.051 participantes foram incluídos na revisão sistemática. A sensibilidade e especificidade agrupada para 0 CAM-ICU para deteç̧ão de delirium em pacientes críticos foi de $81,0 \%$ e $96,1 \%$ e para o ICDSC foi de $74,4 \%$ e $75,2 \%$. O CAM-ICU em pacientes em ventilação mecânica mostrou uma maior sensibilidade com uma especificidade similar $(94,6 \%$ e 96,7\%) sem nenhum sinal de heterogeneicidade quando comparado ao ICDSC. Conclusão: O CAM-ICU é a melhor ferramenta de beira de leito para avaliação de delirium em pacientes críticos a ser utilizada por médicos não-especialistas. O desempenho do CAM-ICU é ainda melhor em pacientes em ventilação mecânica.

Descritores: Delirium, CAM-ICU, Terapia intensiva, Análise cumulativa

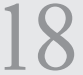

Prevalência da hiperuricemia e relação do ácido úrico sérico com componentes da síndrome metabólica antes e depois do bypass gástrico em Y de Roux em indivíduos com obesidade mórbida

Pessoa GB, Margeotto FB, Moreno R, Serpa Neto A

Introdução: A síndrome metabólica compreende várias anormalidades que ocorrem juntas com um frequêencia maior do que o esperado. Objetivo: $\mathrm{O}$ objetivo do estudo foi investigar a prevalência da hiperuricemia em indivíduos com obesidade mórbida antes e depois do bypass gástrico em Y de Roux (BPGYR) e a sua relação com as anormalidades relacionadas à síndrome metabólica. Método: Foram avaliados 420 pacientes com obesidade mórbida. Foram colhidas amostras de sangue nos períodos pré e pós operatórios (8 meses após o BPGYR). Os pacientes obesos foram submetidos ao bypass gástrico em Y de Roux laparoscópico e 8 meses depois os testes foram repetidos. Resultados: A prevalência total de hiperuricemia foi de $34,28 \%$. A hiperuricemia teve maior prevalência em homens do que em mulheres ( 51,72 vs. $29,72 \% ; p=0,0002)$. Homens com hiperuricemia mostraram maior predisposição para desenvolverem diabetes $(\mathrm{P}=0,034)$ e níveis de glicemia de jejum mais elevados $(\mathrm{P}=0,027)$. Mulheres com hiperuricemia mostraram maior predisposição para desenvolverem hipertensão $(p=0,003)$, síndrome metabólica $(p=$ $0,001)$, triglicérides elevado $(p=0,001)$, GGT elevado $(p=0,009)$ e HDL diminuído $(p=0,011)$. Após a cirurgia, os níveis de ácido úrico caíram de 5,60 $\pm 1,28$ para $4.23 \pm 1.20(\mathrm{p}<0,001)$. A prevalência de hiperuricemia caiu de 33,6 para $6,4 \%$ ( $p<0,0001$ ), em homens de $48,3 \%$ para $17,2 \%(p<0,0001)$ e em mulheres de 29,7\% para 3.6\% ( $\mathrm{p}<0,0001)$. Conclusão: Concentrações de ácido úrico foram associadas a prevalência de anormalidades metabólicas nessa amostra de obesos mórbidos. Além disso, a perda de peso após BPGYR pode levar à redução dos níveis de ácido úrico e da prevalência de hiperuricemia.

Descritores: Síndrome metabólica, Hiperuricemia, Bypass gástrico, Obesidade mórbida. 
Miranda RR, Agena J, Hirai CCG, Freitas PHB, Moraes GBB, Ferreira AACM, Lapa MS

Introdução: Hipertensão arterial pulmonar (HAP) define-se por aumento da pressão arterial pulmonar média acima de $25 \mathrm{mmHg}$ e pressão de oclusão de artéria pulmonar normal. Denominada HAPI após exclusão de doenças associadas. Relato de caso: EP, 36 anos, feminino. Há um ano, dispnéia à grandes esforços(classe funcional II). Nega tabagismo, refere chiado. Usou anorexígenos há 15 anos por 4 meses. Exame físico: hiperfonese de $2^{\mathrm{a}}$ bulha (P2). Raio-X: cardiomegalia,abaulamento de tronco da artéria pulmonar. Ecocardiograma (ECO)O): átrio esquerdo (AE) de $27 \mathrm{~mm}$, fração de ejeção (FE) de 66\%, átrio $7 \mathrm{~mm}$, fração de ejeção (FE) de $66 \%$, átrio direito (AD) e ventrículo direito (VD) aumentados,pressão sistólica da artéria pulmonar de $88 \mathrm{mmHg}$ e pressão média da artéria pulmonar de $30 \mathrm{mmHg}$. Tomografia: sinais de HAP sem falha de enchimento e AD aumentado. Katokatz negativo, Hepatite $\mathrm{C}$ reagente, Fato reumatóide (FR)5,4, HIV e fator antinúcleo (FAN) negativos. Prova de função pulmonar com distúrbio inespecífico leve. Cateterismo cardíaco direito: pressão sistólica da artéria pulmonar (PAP): 70, média 47, diastólica: 29mmHg. Pressão de oclusão da artéria pulmonar (POAP): 10mmHg. Resistência vascular pulmonar: 13,2Woods. Débito cardíaco: 3,42 L/min. Teste de vasorreatividade pulmonar irresponsivo. Discussão: A HAPI é uma doença rara e grave que leva a insuficiência cardíaca direita e óbito em 3 ano se não tratada. Sem causa definida, pode iniciar por uso de anorexígenos. Em $8 \%$ dos casos há teste de vasorreatividade pulmonar positivo e sobrevida maior. Diagnóstico é de exclusão, e no caso, avaliados sintomas (dispneia), exame físico (hiperfonese de P2), raio-X e ECO. O FR, FAN, sorologia para HIV, hepatite, Katokatz devem ser pedidos para excluir causas associadas. Diagnóstico sugestivo de HAPI apesar da sorologia pra hepatite $\mathrm{C}$ positiva, dada função hepática normal.

Descritores: Hipertensão pulmonar/etiologia, Hipertensão pulmonar/diagnóstico, Hipertensão pulmonar/classificação, Depressores do apetite/efeitos adversos.

\section{Riscos cardiometabólicos estão associados ao câncer de próstata: resultados de um estudo transversal no Brasil}

Peixoto GA, Almeida RC, Soares GA, Toneto BR, Sertori Neto A, Manchini CV, Serpa Neto A, Machado MT

Introdução: $\mathrm{O}$ câncer de próstata (CaP) é o segundo câncer mais comum entre os homens, superado apenas pelo câncer de pele não-melanoma. Embora o uso da terapia de privação de andrógeno (ADT) tenha um resultado de melhora na sobrevida de homens com câncer de próstata avançado, o hipogonadismo resultante está associado a profundos efeitos adversos. Objetivo: Avaliar a síndrome metabólica distúrbios metabólicos em pacientes com câncer de próstata. Método: Este é um estudo transversal que envolve setenta e nove pacientes do sexo masculino. Para definir a síndrome metabólica, utilizaram-se os critérios da Federação Internacional de Diabetes (IDF). Alterações metabólicas e marcadores metabólicos foram associados e correlacionados com o uso, ou não, da terapia de privação de andrógeno. Os pacientes foram comparados com um grupo de obesos mórbidos. Resultados: Pacientes sob a terapia de privação de andrógeno apresentaram ocorrência significativamente maior de diabetes, obesidade abdominal e níveis elevados de colesterol e LDL. O risco de desenvolver doença coronariana em um tempo médio de 10 anos foi significativamente maior em pacientes submetidos à terapia de privação de andrógenos $(39,97 \pm 12,53 \%$ vs $26,09 \pm 14,80 \%, p=0,021)$. Nos indivíduos obesos mórbidos o risco de desenvolver doença coronariana em um tempo médio de 10 anos foi comparável à encontrada nos pacientes em terapia de privação de andrógeno $(\mathrm{p}=0,054)$. Conclusão: Nosso estudo sugere que pacientes submetidos à terapia de privação de andrógeno apresentam maior prevalência de distúrbios metabólicos e maior risco cardiovascular, semelhante àqueles encontrados em obesos mórbidos.

Descritores: Câncer de próstata, Risco cardiovascular, Síndrome metabólica, Antagonistas de receptores de andrógenos.

\section{Tratamento clínico da hipertensão arterial pulmonar associada a comunicação interatrial}

\section{Ferreira AACM, Moraes GBB, Agena J, Hirai CCG, Miranda RR, Freitas PHB, Lapa MS}

Introdução: Comunicação Interatrial (CIA) é a cardiopatia com evolução mais benigna porém, seu diagnóstico precoce é importante uma vez que quando não tratada pode desenvolver Hipertensão Arterial Pulmonar (HAP). Embora seja rara esta complicação, a presença de HAP é uma das principais causas de morte e contra-indica o tratamento cirúrgico da CIA. A sobrevida de pacientes com HAP associada CIA aumenta com o uso de drogas específicas para HAP, como antagonistas do receptor da endotelinal. Relato de Caso: Mulher, 71, queixa-se de dispneia há 3 anos CFIII. Exame físico:PA, saturação de O2 e FC normais, RCR2T, sopro diastólico em foco pulmonar .ECO: FE: 65\%; AE:50; PSVD: 68mmHg(nl=35), CIA ostiumsecundum-30mm com repercussão. Tomografia Computadorizada: Tronco AP:5; APD:5, APE: $3,5 \mathrm{~cm}$, sem falhas de enchimento. Função Pulmonar: CVF: 69\%; VEF1: 95\%; TIF: 0,68, sem resposta prova do broncodilatador. Cateterismo Cardíaco: TP: 67x26x40mmHg; AE: 13mmHg; RVP: 3,42 WOODS e Indice Cardíaco: $3,0 \mathrm{~L} / \mathrm{min} / \mathrm{m} 2$, sem resposta ao teste de vasorreatividade. BNP: $800 \mathrm{pg} / \mathrm{mL}$. Iniciou o uso de Bosentan $125 \mathrm{mg}$ duas vezes ao dia e, após três meses, evoluiu com melhora da classe funcional para II e redução de BNP (253pg/mL). Discussão: HAP é uma consequência do shunt que determina sobrecarga volumétrica no circuito pulmonar. A dispneia, o sopro e a dilatação tronco arterial pulmonar sugerem o diagnóstico de HAP, confirmado pelo cateterismo. O caso mostra a eficácia do uso de medicamentos para HAP em pacientes com cardiopatia congênita. $\mathrm{O}$ uso de antagonista de receptor da endotelina é indicado para CFIII e prova de vasorreatividade negativa, pois diminui a vasoconstrição e a resistência vascular pulmonar, ocasionando a melhora do índice cardíaco e, consequentemente, melhora dos sintomas

Descritores: Comunicação interatrial/complicações, Hipertensão pulmonar/diagnóstico, Hipertensão Pulmonar/terapia, dispnéia.
Relato de caso: trombólise de enxerto axilo-bifemoral recanalizado após uso de tenecteplase

Silva CMR, Golfetti MG, Almeida RC, Barros HPC, Toneto BR, Correa JA, Fujii EY, Galego SJ

Introdução: A realização de trombólise com a utilização de agentes trombolíticos diretamente na prótese com trombo, com o intuito de destruí-lo ou dissolvê-lo, apresenta melhores resultados e menores riscos de complicações, como a hemorragia,em relação as técnicas cirúrgicas convencionais. Relato de caso: paciente masculino de 78 anos em pós operatório tardio (32 anos) de aneurismectomia de aorta abdominal com enxerto aorto-biilíaco evoluiu com claudicação e isquemia dos membros inferiores sendo submetido à confecção de enxerto axilo-bifemoral cruzado com melhora importante da claudicação e cicatrização das lesões tróficas. Evoluiu com dor em membros inferiores após a realização do exame de cineangiocoronariografia onde puncionaram a prótese com compressão local provocando a trombose do enxerto. Paciente foi avaliado e submetido ao exame de arteriografia que evidenciou oclusão completa do enxerto, optando-se pela realização de fibrinólise com tenecteplase. Realizado punção pela artéria braquial direita e passagem de fio guia e cateter para infusão do agente fibrinolítico diretamente no trombo. A infusão foi realizada segundo protocolos encontrados na literatura com injeção intra-prótese e intraarterial em bolus $(0,5 \mathrm{mg} / \mathrm{Kg})$ de tenecteplase com mobilização cranial progressiva do cateter.Realizado monitorização em unidade de terapia intensiva com controle arteriográfico após 12 horas e 24 horas com infusão contínua de heparina para potencializar o procedimento. Após 24 horas da fibrinólise foi observada a recanalização completa do enxerto não sendo necessária nova abordagem cirúrgica. Discussão: A trombólise farmacológica local é uma técnica factível para tratamento da oclusão aguda de enxertos protéticos, com baixa incidência de complicaç̃es hemorrágicas maiores.

Descritores: Trombose de enxerto, Tenecteplase, Trombo, Aneurisma.

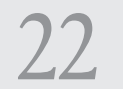

Taxa metabólica basal: correlação entre a calorimetria indireta e as equações de Harris-Benedict, Mifflin e Schofield

\section{Person NC, Cordeiro RA, Moreno R, Sertori Neto A, Catapani WR}

Introdução: As medidas mais precisas da Taxa Metabólica Basal (TMB) são obtidas através da calorimetria que pode ser direta ou indireta. Ambos são métodos onerosos e, por este motivo, pesquisadores têm procurado desenvolver equações que possam predizer a TMB usando parâmetros facilmente mensurávei tais como: peso, estatura, sexo e idade. Objetivo: Avaliar o grau de correlação entre o valor da TMB calculado por 3 destas equações (Harris-Benedict, Mifflin e Schofield) com os valores fornecidos pela calorimetria indireta. Método: A amostra foi composta por pessoas saudáveis, sendo 17 mulheres e 12 homens. Os participantes foram classificados quanto ao estado nutricional e quanto ao nível de atividade física. Para cada um deles a TMB foi calculada pelo calorímetro e pelas equações preditivas. A correlação entre os dados foi realizada pela técnica do $r$ de Pearson. Resultados: A correlação entre a TMB fornecida pelo calorímetro e calculada através das equações para as mulheres é ruim e não significante. Para os homens, as correlações são razoáveis (Harris $r=0,60, p=0,03$; Mifflin $r=0,61, p=0,03$ e Schofield $r=0,57$, $\mathrm{p}=0,05)$. Entretanto, se todos os participantes forem colocados em um único grupo, a correlação entre a calorimetria e as equações melhora (Harris $\mathrm{r}=0,80, \mathrm{p}<0,001$; Mifflin $\mathrm{r}=0,78, \mathrm{p}<0,001$ e Schofield $\mathrm{r}=0,80$ $\mathrm{p}<0,001)$. A piora dos índices de correlação quando se consideram separadamente homens e mulheres pode dever-se ao pequeno número de indivíduos em cada grupo resultante desta divisão. Conclusão: Estudos com casuísticas maiores são necessários para estabelecer com mais fidelidade esta correlação. Entretanto, as 3 equações, usadas indistintamente e sem classificação por sexo, parecem ser capazes de prever a TMB com razoável acurácia.

Descritores: Taxa metabólica basal, Calorimetria indireta, Equações preditivas, Harris-Benedict.

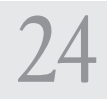

Tratamento da osteomielite no pé diabético com terapia fotodinâmica

\section{Barros HPC, Almeida RC, Silva CMR, Golfetti MG, Amaral JP, Abdalla TE, Correa JA, Tardivo JP}

Introdução: Com uma população global crescente de mais de $4 \%$ de adultos, o Diabetes Mellitos (DM), é um dos grandes problemas da saúde pública mundial. No Brasil, estima-se que $11 \%$ da população adulta seja portadora. Dentre as complicações, está o pé diabético, condição que afeta cerca de $20 \%$ dos pacientes em alguma época de suas vidas. Estima-se que em 50\% dos casos de pé diabético são notadas úlceras de pele, que além de diminuir a qualidade de vida, elevam o risco de desenvolvimento de osteomielite e outras infecções, precedendo amputações. Seu tratamento é pouco eficaz, de alto custo, necessitando de grande quantidade de antibióticos e longos períodos de internação. Na tentativa de mudar esse quadro, foi desenvolvida a técnica de terapia fotodinâmica, que visa diminuir o uso de antibióticos e mesmo assim combatendo as infecções, evitando amputações e consequentemente diminuindo os custos e a ocupação de leitos. Relato de caso: Paciente masculino, 57 anos, diabético, $3^{\circ}$ e $5^{\circ}$ dedo do pé esquerdo amputado, com mal perfurante plantar no pé esquerdo e processo inflamatório, internado, foi constatado osteomielite de falange proximal e epífise de $1^{\circ}$ metatarso tendo indicação de amputação de $1^{\circ}$ dedo do pé esquerdo. Encaminhado para terapia fotodinâmica, recebeu alta hospitalar, sendo tratado ambulatorialmente duas vezes por semana com tratamento fotodinâmico, injeção de fenotiazínicos intra lesional seguida de irradiação por 10 minutos, com luz de fibras ópticas e/ou de fonte RL 50. Após 59 dias, recebeu alta, com mal perfurante plantar totalmente cicatrizado. Discussão: Foi utilizada uma técnica eficiente e de baixo custo, que deve ser considerada, visto que a amputação foi evitada e o combate à infecção teve sucesso com uso reduzido de antibióticos e de tempo de internação.

Descritores: Terapia fotodinâmica, Osteomielites, Pé diabético, Úlcera diabética. 


\section{Um caso raro de trissomia 15PTER-013 derivado de uma translocação entre os cromossomos 15 e 16 familiar}

\section{Evo CPR, Paiva CP, Cavalheiro CM, Lerner TG, Christofolini DM, Bianco B, Mafra FA, Barbosa CP}

Introdução: As translocações cromossômicas podem estar envolvidas em perdas gestacionais recorrente e em malformações na prole, pela geração de gametas contendo alterações cromossômicas que podem dar origem a trissomias e monossomias parciais. Relato de caso: Paciente de 6 anos de idade com alterações fenotípicas sugestivas de alteração cromossômica. Foi realizada avaliação clínica e cariótipo com bandamento G e C, NOR e FISH da paciente e cariótipo da família. A paciente apresentou cariótipo 47,XX,+mar. A avaliação familiar demonstrou cariótipo na mãe e na tia 46,XX,t(15;16)(q13;p13.2) e cariótipo 46,XY,t(15;16)(q13;p13.2) no avô materno da paciente. A paciente apresentou à analise clínica, em face, implantação alta de cabelos anteriormente; sinófris discreta, hipertelorismo ocular, fenda palpebral oblíqua para cima; ponte nasal baixa com base nasal alargada, hipoplasia de asas nasais, proeminência da columela nasal e filtro nasal proeminente; lábio superior fino e mento discretamente proeminente; dentes com aspecto cônico. Nas mãos, a região palmar com poucas pregas e sem alterações das mesmas, clinodactilia dos 10 dedos, persistência das almofadas digitais; dedos com extremidades afiladas e pregas interdigitais proeminentes. A paciente apresentou microssomia, retardo no desenvolvimento neuropsicomotor e problemas na audição, fala, sucção e deglutição. Discussão: O marcador cromossômico foi derivado de uma translocação materna associado a um fenótipo alterado devido à trissomia parcial de 15q. Esse estudo corrobora a prerrogativa de que a presença de translocaç̃os cromossômicas promove importantes efeitos na prole e propõe que na presença de perdas reprodutivas consecutivas seja realizada a investigação cromossômica associada ao aconselhamento reprodutivo familiar.

Descritores: Translocação cromossômica, Cromossomos humanos par 15, Trissomia, Duplicação cromossômica.

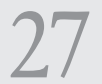

Velocidade de hemossedimentação e proteína c-reativa na doença inflamatória intestinal: vale a pena dosá-los?

\section{Moreno R, Souza MG, Pessoa GB, Margeotto FB, Abdalla TE, Cordeiro RA, Catapani WR}

Introdução: A Doença de Crohn (DC) e a Retocolite Ulcerativa (RU) compreendem as Doenças Inflamatórias Intestinais (DII) e são afecções crônicas que cursam de maneira imprevisível. Marcadores de atividade inflamatória VHS (Velocidade de Hemossedimentação) e PCR (Proteínca C-Reativa) podem ser úteis na avaliação do estado geral do paciente e atividade da DII. Não há, porém, consenso quanto à relação direta entre esses marcadores e à atividade da doença. Objetivo: Estabelecer o grau de correlação direta entre os marcadores inflamatórios, VHS e PCR, e a sintomatologia das DII. Métodos: Estudo retrospectivo de revisão de 70 prontuários de pacientes do Ambulatório de Gastroenterologia da Faculdade de Medicina do ABC diagnosticados com DII. Definiu-se Momento Clínico (MC) do paciente o período que envolve a data de coleta de exames com a data da consulta mais próxima. Resultados: Dos 197 MC que tinham registro de VHS,em 86 (43.65\%) o paciente se encontrava assintomático, dos quais $67(77.91 \%)$ o VHS encontrava-se acima do valor de referência. Para o sintoma diarréia: $68 \mathrm{MC}$ tinham registro de VHS, 58 (85.29\%) com valores acima da normalidade; $62 \mathrm{MC}$ possuiam registro de PCR, 31 (50\%) deles com valores acima da normalidade. Para dor abdominal: 68 tinham registro de VHS,58 (85.29\%) com valores acima da normalidade; 57 MC possuiam registro de PCR, 30 (52.63\%) deles possuíam valores acima da normalidade. Para hemorragia digestiva baixa: 54 MC registraram VHS, 42 (77.78\%) com valores acima da normalidade; $47 \mathrm{MC}$ possuiam registro de PCR, 17 (36.17\%) deles com valores acima da normalidade. Conclusão: Para MC de pacientes assintomáticos, valores elevados de VHS e PCR foram encontrados, o que mostra que a própria DII pode aumenta seus níveis séricos, independentemente de sua atividade. O VHS tem se mostrado melhor marcador para esses sintomas.

Descritores: Velocidade de hemossedimentação, Proteínca C-reativa, Doença de Crhon, Retocolite ulcerativa.

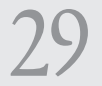

Avaliação da frequência dos polimorfismos C677T e A1298C do gene mthfr em mulheres inférteis com endometriose e sua correlação com a síntese de estradiol folicular: estudo piloto

Santos AA, Teles JS, Kayaki EA, Bianco B, Christofolini DM, Barbosa CP

Introdução: o gene MTHFR é essencial no metabolismo do folato participando das reações de metilação. Os polimorfismos mais comuns encontrados para o gene são C677T e A1298C que quando presentes estão relacionados à hipometilação do DNA e a diminuição nas concentrações de estogeno serico e no liquido folicular. Podendo alterar a qualidade e o desenvolvimento do oocito. Objetivo: correlacionar os nívei de estradiol no sangue e líquido folicular de mulheres inférteis com endometriose com a presença do polimorfismo no gene MTHFR, e associar a indicadores de qualidade do embrião. Método: Foram triadas 19 mulheres que apresentavam endometriose como causa de infertilidade, estas foram submetidas ao tratamento de reprodução assistida no serviço de Reprodução Humana da FMABC. Foi realizada dosagem de estradiol do sangue periférico e liquido folicular e avaliação genético-molecular dos polimorfismos C677T e A1298C do gene MTHFR a partir de sangue periférico. Resultados: foram delimitados grupos através da analise genético molecular e a dosagem de estradiol sérico e folicular foi relacionada aos achados. A distribuição de estradiol sérico e folicular não revelou diferença estatisticamente significante para o polimorfismo C677T. A presença do alelo polimorfico para A1298C indicou diferença estatística apenas para o estradiol sérico $\mathrm{p}=0,033$. A qualidade e desenvolvimento embrionário não revelaram diferença estatisticas, porem na presença do polimorfismo a qualidade e taxa de gravidez podem ser reduzidas. Conclusão: Os dados encontrados neste estudo piloto sugerem que apesar dos polimorfismos do gene MTHFR não estarem relacionados aos níveis de estradiol folicular estes podem resultar em impacto sobre os parametros embrionários e resultados de gravidez.

Descritores: Estradiol, Gene MTHFR, Polimorfismos, Reprodução humana.
Vasopressina e terlipressina no choque vasodilatatório: resultados de uma revisão sistemática e meta-análise de 11 ensaios clínicos randomizados

Michaelis LF, Burlamaqui JCF, Daniel MB, Campos MC, Kataguiri A, Abdalla TE, Serpa Neto A

Introdução: A taxa de mortalidade entre os pacientes com choque séptico e insuficiência circulatória permanece elevada. Atualmente, as catecolaminas são os agentes vasopressores de escolha usados clinicamente no choque com vasodilatação, mas o desenvolvimento de hipossensibilidade adrenérgica com a perda dos efeitos pressóricos das catecolaminas em casos avançados torna necessária a busca de outras opções. Objetivo: Nosso objetivo foi resumir os efeitos da vasopressina (AVP) e seu análogo terlipressina (TP) nos estados de choque com vasodilatação. Método: Uma revisão sistemática da literatura foi feita com base em ensaios clínicos randomizados publicados avaliando o uso de vasopressina e/ou terlipressina em pacientes com choque com vasodilatação. Os desfechos avaliados foram: sobrevivência global, as alterações nas variáveis hemodinâmicas e bioquímicas, a diminuição das necessidades de catecolaminas, e toxicidade. Resultados: Onze artigos (1.111 participantes) foram incluídos na revisão sistemática. Encontrou-se uma redução mais significativa na necessidade de norepinefrina (NE) em pacientes sob TP ou infusão de AVP em comparação com norepinefrina isoladamente $(\mathrm{p}<0,0001$ para ambos os medicamentos) e um tempo menor para a redução no grupo AVP comparado com NE isoladamente $(\mathrm{P}=0,03)$. A associação de AVP ou TP com noradrenalina não resultou em melhora da sobrevid e não resultou mais efeitos colaterais. Conclusão: A combinação de AVP com o NE em estado de choque com vasodilatação é segura e, apesar de não aumentar a sobrevida dos pacientes, facilita o desmame de catecolaminas, evitando o seu potencial de eventos adversos. A associação não resultou em diminuição do índice cardíaco ou DO2i. Todas estas mudanças são mais significativas em pacientes adultos com choque séptico.

Descritores: Vasopressina, Terlipressina, Choque vasodilatatório, Revisão sistemática.

\section{Temas Livres: Básico experimental}

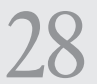

A ausência de reprodutibilidade da nanotecnologia na dosagem de DNA plasmático livre em amostras de pacientes com câncer de próstata

Moreno R, Fonseca FLA

Introdução: O Câncer de Próstata (CP) afeta milhares de pessoas no mundo. Frente a tantas incertezas a respeito de seus marcadores biológicos, diversos estudos buscam aquele que seria o ideal. Pacientes com afecções em que há aumento de morte celular possuem aumento da quantidade de DNA plasmático(DNAp),dando a ele um certo valor de critério diagnóstico, resposta terapêutica e evolução do tumor. Objetivo: Validar a determinação de valores de DNAp por meio de nanotecnologia (NanovueTM-NV) em amostras de pacientes com CP. Método: Foram analisadas amostras de 80 pacientes do Ambulatório de Urologia da Faculdade de Medicina do ABC con diagnóstico de CP. Compararam-se as dosagens através da espectrofotometria tradicional (GeneQuant(B-GQ) e do NV. Resultados: Das 80 amostras, realizou-se medição em 51(63,75\%) e optou-se por interromper os testes pela total discordância de resultados e ausência de reprodutibilidade. As dosagens de DNA plasmático pelo NV foram feitas em duplicata. Houve quantidade variável de diferença de valores entre a primeira e a segunda dosagem pelo NV. Apenas 2 amostras $(0,04 \%)$ tiveram diferença ZERO entre as duas medidas,a diferença média foi de $10,29 \mu \mathrm{g}$ / $\mathrm{mL}$ e $21(41,2 \%)$ ficaram acima disso. Não houve correspondência direta entre valores crescentes de DNAp pelas duas técnicas. Apesar de haver alguns valores aceitáveis, num panorama geral isso não ocorre. Frente a isso, criouse um relatório de testes, desta vez com medições em triplicata. Através de diversos testes e análises, considerou-se que os resultados não foram reprodutíveis. Após análise da fabricante, outros testes foram realizados, também sem reprodutibilidade. No gráfico de dispersão, o r2 na análise de correlação foi 0,0044 . Conclusão: A nanotecnologia não se mostrou reprodutivel na dosagem de DNAp em amostras de pacientes com CP.

Descritores: Câncer de próstata, DNA plasmático, Nanotecnologia.

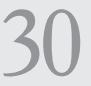

Avaliação da incidência do polimorfismo G1502A do GENE LH $\beta$; em mulheres com falência ovariana prematura

Kayaki EA, Paiva CP, Santos AA, Evo CPR, Christofolini DM, Bianco B, Cordts EB, Barbosa CP

Introdução: Falência ovariana prematura (POF) é caracterizada pela cessação da função ovariana ante dos 40 anos. Ela afeta aproximadamente 1:1000 mulheres antes dos 30, 1:250 aos 35 e 1:100 aos 40 ano de idade. Sua etiologia pode envolver distúrbios autoimunes, deficiências enzimáticas, deficiências na sinalização hormonal e anormalidades cromossômicas. Estudos associam POF com mutações de vários genes, como FMR1, LHR, FSHR e INHA. A literatura mostra que mutações do LH $\beta$; estão relacionadas à infertilidade e o polimorfismo G1502A foi associado à infertilidade em mulheres com endometriose da população. Objetivo: Sabendo que a POF é responsável por 2-3\% das causas de infertilidade feminina, o presente estudo teve como objetivo estabelecer a frequência deste polimorfismo em pacientes com a doença. Método: 169 mulheres foram selecionadas para este estudo. Genótipos de LH $\beta$; foram avaliados por análise de RFLP. Os resultados foram analisados estatisticamente e $\mathrm{p}<0,05$ foram considerados significativos. Resultados: Este estudo incluiu 84 pacientes e 85 controles. Entre os pacientes, $51,19 \%$ tinham genótipo GG, $44,05 \%$ GA e $4,76 \%$ AA. No grupo controle, $61,18 \%$ tinham genótipo GG, 36,47\% GA e 2,35\% a AA $(\mathrm{p}=0,360)$. Das pacientes $73,21 \%$ tinham o alelo $\mathrm{G}$ e $26,79 \%$ o alelo $\mathrm{A}$. Em controles $79,41 \%$ tinham o alelo $\mathrm{G}$ e $20,59 \%$ o alelo A $(p=0,225)$. Conclusão: Não foi observada uma correlação entre o polimorfismo LH $\beta$; com a FOP. Esse resultado mostra que a infertilidade envolve diferentes mecanismos genéticos. É essencial continuar este estudo a fim de aumentar a população e ampliar a análise de genes para identificar a etiologia da doença, permitindo a deteç̧ão e intervenção precoces. Isso possibilitaria melhor direcionamento para potenciais alvos como tratamento futuro.

Descritores: Falência ovariana precoce, Polimorfismo, Gene LH $\beta$, Infertilidade. 
Células envolvidas no remodelamento da matriz extracelular após infarto agudo do miocárdio

Garcia LF, Pinhal MAS

Introdução: Neste estudo, ratos foram submetidos á transferência gênica com VEGF e foram divididos de acordo com o tamanho do infarto em grande (LMI), pequeno (SMI), com ou sem tratamento com a transferência gênica. $O$ grupo controle também foi analisado. Objetivo: Investigar quais as células envolvidas no remodelamento da matriz extracelular após o IAM. Para isso, serão analisados anticorpo de células indiferenciadas (fibronectina, vimentina e CD-44), diferenciadas (E-caderina) e marcadore de proliferação celular (PCNA). Método: Imunohistoquímica. Os anticorpos anti-fibronectina, antivimentina, anti-E-caderina e anti-PCNA, foram diluídos, respectivamente, na proporção 1:300, 1:700, 1:700 e 1:1000. O anticorpo anti-CD44 não precisa ser diluído. Quantificação Digital da IH. Os parâmetros obtidos do programa digital serão: porcentagem de células (IP), intensidade de coloração digital (ItE) indicador de expressão digital (IE). Análise estatística. Os resultados serão expressos como média e erro padrão. Resultados: O grupo controle e grupo que sofreu infarto grande sem tratamento apresentaram maior quantidade de células indiferenciadas do que diferenciadas. Os demais grupos apresentaram uma maior quantidade de células diferenciadas em relação às células indiferenciadas. Conclusão: Os marcadore avaliados até o momento permitem concluir que possivelmente células diferenciadas (como os miócitos) participam do remodelamento da matriz extracelular, tanto nos grupos tratados quanto não tratados, apó IAM.

Descritores: Terapia gênica, Infarto agudo do miocárdio, Anticorpos, VEGF.

\section{Estudo experimental da migração melanocítica em halos \\ pigmentares}

\section{Bittencourt F, Machado Filho CDS}

Introdução: Estudo experimental em cobaias com o objetivo de desenvolver modelo de migração celular com halos pigmentares em animal. Sabe-se que as cobaias malhadaspossuem a propriedade de formar halos pigmentares por difusão de melanócitos quanto se enxerta pele pigmentada em pele não pigmentada. Esse fenômeno é utilizado em humanos para tratamento cirúrgico do vitiligo, porém faltan estudos na literatura sobre os fenômenos envolvidos na migração de melanócitos. Objetivo: Desenvolve um modelo experimental da migração celular de halos pigmentares em cobaias; determinar a migração temporal dos melanócitos no halo pigmentar e a relação entre migração temporal e expressão visual dos halos pigmentares. Método: Cinco cobaias da espécie Cavia porcellus, bicolores (preta e branca). $\mathrm{Na}$ área pigmentada (doadora) será coletado um fragmento de pele de $3 \mathrm{~mm}$. Na área despigmentada (receptora) será removido um fragmento de $2 \mathrm{~mm}$ de diâmetro,o fragmento pigmentado da área doadora será colocado na área branca receptora e fixado com cola de metacrilato. A partir do fragmento central implantado será traçado um círculo com $0,5 \mathrm{~cm}$ de raio em cuja superfície serão coletadas biópsias de $5 \mathrm{~mm}$ em pontos distintos em: D0, D7, D15, D30, D60. Em D60 será também coletada uma amostra com $1 \mathrm{~cm}$ de raio totalizando 7 amostras. Todos os fragmentos serão coletados em frascos com formol e serão corados con azul de metileno. Resultados: Ocorre a formação do halo pigmentar. Conclusão: Foi comprovado que as cobaias malhadas possuem a propriedade de formar halos pigmentares por difusão de melanócitos quanto se enxerta pele pigmentada em pele não pigmentada.

Descritores: Halos pigmentares, Migração celular, Difusão melanocítica, Vitiligo.

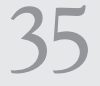

Impacto da composição corporal na fertilidade de pacientes do sexo masculino do serviço de reprodução assistida

Christofolini J, Santos AA, Cavalheiro CM, Teles JS, Bianco B, Christofolini DM, Barbosa CP, Gava MM

Introdução: Estudos monstram que 51\% dos brasileiros têm sobrepeso, 14\% são obesos e 3\% são obeso mórbidos. O excesso de peso está ligado ao aumento do risco de doenças crônicas e a um aumento do risco de problemas reprodutivos. Pesquisas sobre o impacto do IMC relacionados a saúde reprodutiva masculina tem sido limitadas em comparação às pesquisas realizadas para investigar a infertilidade feminina. Objetivo: Investigar a influência do IMC nos parâmetros seminais de homens atendidos no serviço de reprodução assistida. Método: Análise retrospectiva de 80 homens com oligospermia e azoospermia não obstrutiva e 80 homens normospérmicos no grupo controle. Os dados foram obtidos do banco de dados de serviço de Reprodução Humana da Faculdade de Medicina do ABC. Resultados: Segundo a classificação da OMS (Organização Mundial de Saúde) foram encontrados entre os pacientes inférteis 26 eutróficos, 34 com sobrepeso, 20 obesos e 21, 39, 20 nos controles respectivamente. A distribuição de IMC nos dois grupos não foi diferente $(p=0.6453)$. Nos parâmetros seminais e volume ejaculado não foram observadas diferenças ente obesos e eutróficos $(\mathrm{p}=0.2790, \mathrm{p}=0.5059)$, entre obesos e sobrepeso $(\mathrm{p}=0.690, \mathrm{p}=0.8071)$ e sobrepeso e eutróficos $(\mathrm{p}=0.575, \mathrm{p}=0.7370)$. Conclusão: $\mathrm{De}$ acordo com este estudo piloto o IMC não parece estar relacionado a alterações seminais. $\mathrm{O}$ uso isolado do IMC talvez não seja o mais indicado, pois, não diferencia hipertrofia muscular de obesidade, sendo indicada a associação com outros métodos, como circunferências e porcentagem de gordura corporal, tornado o diagnóstico mais apropriado. Um estudo mais abrangente com um número maior de pacientes, parâmetros hormonais e a utilização de outros parâmetros de avaliação antropométricas podem trazer diferentes resultados.

Descritores: Composição corporal, Infertilidade masculina, Reprodução assistida, Parâmetros seminais. beta em homens brasileiros com infertilidade idiopática

Introdução: Os estrogênios desempenham um importante papel no sistema reprodutivo humano. Sua ação é mediada por dois receptores: ER $\alpha$; e ER $\beta$;. Variantes polimórficas nestes genes foram previamente associadas a distúrbios reprodutivos. Um estudo realizado com pacientes Iranianos com oligoastenoteratozoospermia idiopática encontrou associação dos genótipos do $\operatorname{ER} \alpha$; e $\operatorname{ER} \beta$ com o alto risco de infertilidade. Entretanto, um estudo Grego encontrou associação positiva apenas entre os polimorfismos do ER $\alpha$; com a motilidade e a concentração espermática em homens oligozoospérmicos. Objetivo: Determinar a distribuição dos polimorfismos de ER $\alpha$; e ER $\beta$; em pacientes inférteis e controles férteis brasileiros. Método: Foram avaliados 78 homens com azoospermia não-obstrutiva (NOA), 119 com oligozoospermia grave(SO) e 216 homens férteis. Os polimorfismos do ER $\alpha$;(PvuII e XbaI) e ER $\beta$;(AluI e RsaI) foram detectados através de TaqMan. Os resultados foram analisados estatisticamente e o valor de $\mathrm{p}<0.05$ foi considerado significante. Resultados: A análise individual de cada polimorfismo revelou que nem PvuII nem XbaI estavam associados com o grupo $\mathrm{NOA}(\mathrm{p}=0.662 \mathrm{e} \mathrm{p}=0.527)$ ou com o grupo $\mathrm{SO}(\mathrm{p}=0.777$ e $\mathrm{p}=1.0)$. Nenhuma diferença estatística foi observada entre os polimorfismos AluI e Rsal o grupo $\mathrm{NOA}(\mathrm{p}=1.0$ e $\mathrm{p}=0.740)$ ou com o grupo $\mathrm{SO}(\mathrm{p}=0.423$ e $\mathrm{p}=0.920)$ e controles. Os genótipos combinados do $E R \alpha$; e ER $\beta$; não demonstraram associação de haplótipos com a infertilidade masculina. Conclusão: O presente estudo mostrou que os polimorfismos PvuII, XbaI, AluI e RsaI não estão associados com a infertilidade idiopática em homens brasileiros.

Descritores: Infertilidade masculina, Polimorfismos, Receptor de estrógeno, ER alfa e beta.

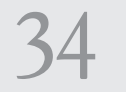

Expressão de CK-19, Galectina-3 E HBME-1 na diferenciação das lesões tireoideanas: revisão sistemática e meta-análise diagnóstica

Giglio ABD, Farah ML, Matsubayashi CO, Giglio AD, Pinhal MAS, Matos LL

Introdução: A distinção entre lesões malignas e benignas da tireóide muitas vezes necessita de prova histológica pela limitação do método de punção aspirativa por agulha fina aplicado pré-operatoriamente. Marcadores tem sido estudados, destacando-se a citoqueratina-19(CK-19), a galectina-3(Gal-3) e o antígeno mesenquimal Hector Battifora-1(HBME-1) pelas técnicas de imunocito e imuno-histoquímica, entretanto os resultados atuais são controversos. Objetivo: Estabeler a acurácia diagnóstica dos marcadores CK-19, Gal-3 e HBME-1, e suas associações para diferenciação entre lesões benignas e malignas da tireóide. Método: Realizou-se revisão sistemática de artigos no Medline e após estabelecidos critérios de inclusão e exclusão, 65 artigos foram selecionados. Empregou-se a técnica de meta-análise de acurácia diagnóstica, sendo determinados os valores globais de sensibilidade, especificidade, área sob a curva ROC (ASC) e odds ratio diagnóstico (dOR). Resultados: A positividade de CK-19 para diagnóstico de lesões malignas demonstrou sensibilidade de 81\% (IC95\%: 79-83\%), especificidade de 73\% (IC95\%: 70-75\%), ASC de 88\% e dOR de 15,8 (IC95\%: 8,9-27,8); para Gal-3, sensibilidade de 83\% (IC95\%: 81-84\%), especificidade de $81 \%$ (IC95\%: 80-83\%), ASC de $91 \%$ e dOR de 27,5 (IC95\%: 18,1-41,7) e para HBME-1, sensibilidade de $78 \%$ (IC95\%: 76-80\%), especificidade de 83\% (IC95\%: 81-84\%), ASC de 92,4\% e dOR de 39,5 (IC95\%: 22,669,0). A associação dos marcadores determinou sensibilidade de $85 \%$ (IC95\%: 78-90\%), especificidade de 97\% (IC95\%: 90-99\%), ASC de 93,3\% e dOR de 95,1 (IC95\%: 25,2-359,1). Conclusão: Deve-se continuar a busca por novos marcadores visando aprimorar a acurácia diagnóstica das lesões da tireóide, pois os resultados encontrados ainda demonstram testes falso-negativos e falso-positivos.

Descritores: Marcador tumoral, Biológico, Tireóide, Revisão.

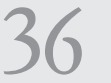

Interação gênica entre FCRL3 E FOXP3 em mulheres inférteis com endometriose

Lerner TG, Teles JS, Brandes A, Cavalheiro CM, Mafra FA, Christofolini DM, Bianco B, Barbosa CP

Introdução: Um mecanismo imunológico anormal está envolvido na patogênese da endometriose Presença de anticorpos anti-endométrio e ativação policlonal de células B autoimunes foi encontrad em casos de endometriose. Vários estudos demonstraram que as células B interagem com células $\mathrm{T}$ em cultura, resultando na proliferação dos linfócitos $\mathrm{T}$, ou na sua conversão em Tregs,as quais podem suprimir células do sistema imunológico. Assim, supomos uma possível relação entre a infertilidade relacionada à endometriose os genótipos dos genes FCRL3 e FOXP3. Objetivo: Devido à interação descrita entre linfócitos B, que expressam a proteína FCRL3, e as células T, que podem expressar a proteína FOXP3, o estudo teve como objetivo avaliar a associação entre os polimorfismos FCRL3 rs7528684 e FOXP3 rs3761549 em um grupo de mulheres inférteis com endometriose e controles. Método: Estudo casocontrole incluindo 174 mulheres inférteis com endometriose e 169 mulheres em idade fértil como controles. Deteç̧ão de (C-2383T/rs3761549) FOXP3 e FCRL3 (C-169T/rs7528684) polimorfismos foi identificado por TaqMan PCR em tempo real. Os genótipos foram comparados usando tabelas de contingência e os valores de $\mathrm{x}^{2}$. Os resultados foram analisados estatisticamente e um valor de $\mathrm{p}<0,05$ foi considerado significativo. Resultados: a análise individualizada dos SNPs revelou que FOXP3 rs3761549 e FCRL3 rs 7528684 foram significativamente associados com a infertilidade relacionada à endometriose $(p=0,003$ ep $=0,001$, respectivamente), enquanto a análise associada não mostrou significância. Conclusão: Os resultados sugerem que, na população brasileira, a análise individualizada dos polimorfismos estudados está significativamente associada à endometriose relacionada à infertilidade em mulheres brasileiras.

Descritores: Auto-imunidade, Endometriose, Gene FCRL3, Gene FOXP3. 
Teles JS, Lerner TG, Brandes A, Cavalheiro CM, Mafra FA, Bianco B, Christofolini DM, Barbosa CP

Introdução: Um mecanismo imunológico anormal parece estar envolvido no desenvolvimento da endometriose. FOXP3, um membro da família de fatores de transcrição forkhead, desempenha um papel fundamental na função de células $\mathrm{T}$ reguladoras, podendo suprimir várias células do sistema imunológico, tais como CD4, CD8, células B e células NK. O FOXP3 pode ser ativado proteína supressora de tumor p53, fator de transcrição que induz a expressão de genes reguladores de diversas respostas celulares, tais como parada do ciclo celular, apoptose e senescência. Objetivo: Devida à interação entre o FOXP3 e o p53, avaliamos a associação entre o polimorfismo C-2383T (rs3761549) do gene FOXP3 e a troca Arg/ C:Pro/G do códon 72 (rs1042522) do gene p53 em um grupo de mulheres inférteis com endometriose e controles. Método: Estudo caso-controle composto por 174 mulheres inférteis com endometriose e 169 mulheres férteis como grupo controle. A detecção dos polimorfismos foi realizada por meio de ensaio TaqMan PCR em tempo real. Os resultados foram analisados estatisticamente através do teste de quiquadrado e um valor de $\mathrm{p}<0,05$ foi considerado significativo. Resultados: Embora o polimorfismo rs3761549 do gene FOXP3 tenha sido significativamente associado com infertilidade e endometriose ( $p=$ $0,003)$, não houve associação entre a doença e o polimorfismo rs 1042522 do gene $\mathrm{p} 53(\mathrm{p}=0,5)$. Quando estratificado de acordo com os genótipos do p53, não houve efeito do genótipo de susceptibilidade do FOXP3 nas pacientes com endometriose. Conclusão: Embora o polimorfismo C-2383T do gene FOXP3 esteja relacionado com a endometriose na população brasileira, não foi encontrada interação genética entre os polimorfismos estudados nestes pacientes.

Descritores: Auto-imunidade, Endometriose, Gene p53, Gene FOXP3.

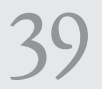

Projeto de estímulo ao aprendizado de forma lúdica, realizado na Escola Estadual Maria Cristina Schimidt, através do Núcleo Integrador de Práticas (NIP), disciplina do segundo ano de Medicina da Faculdade de Medicina do $A B C$

Pedroso C, Barletta HM, Mattos LM, Bereta BD, Bezerra DF

Introdução: Promover o protagonismo da escola como espaço de produção de saúde exige discussão a respeito do determinantes sociais da saúde/doença nessa população, mobilizaç̃o em torno do direito à saúde e o fortalecimento da participação da comunidade escolar nos espaços de controle social. Com base nisto, abordando o tema "dificuldade de aprendizagem”, realizou-se uma feira teve por objetivo promover um projeto de integração e intervenção na escola, visando estimular o gosto das crianças pelo aprendizado de uma forma mais lúdica. Método: Dividiram-se os alunos de medicina envolvidos para administrar atividades lúdicas e educativas em cinco salas da escola com a ajuda de uma comissão de adolescentes formada por alunos previamente selecionados pela coordenação da escol por terem mau desempenho escolar. Cada sala teve uma atividade diferente, sendo todas voltadas à verificação de habilidades básicas, tais como a utilização correta da gramática ("Soletrando"), a capacidade de abstração e correlação de imagem e palavras ("Taboo"), o nivel de conhecimentos gerais ("Tabuleiro Gigante”), interpretação e apreensão de textos (Sala do Sistema Solar) e noção espacial e habilidade de efetuar operações matemáticas (Sala de Matemática). Resultados: Com um pouco de insistência, os alunos da comissão não só foram criativos e participativos na montagem da feira, mas também esforçados durante a participação e entendimento das brincadeiras, mesmo das que abordavam temas não muito queridos por eles, tais como gramática e matemática. Conclusão: O sucesso dos alunos considerados pela escola "crianças-problema" na realização das atividades nos faz refletir a respeito da utilização de métodos menos tradicionais como forma de complementação do aprendizado.

Descritores: Aprendizado lúdico, Dificuldade escolar, Crianças, Complementação do aprendizado

\section{Variantes genéticas em genes do sistema fibrinolítico relacionados em mulheres inférteis com e sem endometriose}

Brandes A, Teles JS, Lerner TG, Cavalheiro CM, Vilarino FL, Christofolini DM, Bianco B, Barbosa CP

Introdução: Há evidências de que uma alteração da atividade fibrinolítica no endométrio eutópico de mulheres com endometriose, pode resultar em fragmentos do endométrio, com um elevado potencial de adesão para o revestimento peritoneal, degradação dos componentes da matriz extracelular, crescimento invasivo por proteólise pericelular e migração celular para o tecido circundante. Objetivo: Nosso objetivo foi avaliar uPA e genótipos TAFI em um grupo de mulheres inférteis com e/ou sem endometriose e controles. Método: Estudo caso-controle de 180 mulheres inférteis com endometriose e 68 mulheres com infertilidade idiopática e 152 mulheres em idade fértil como controles. A deteç̧ão de UPA (C422T) rs2227564) e TAFI (G438A/rs2146881) polimorfismos foi identificado por PCR TaqMan. Os resultados foram analisados estatisticamente e um valor de $\mathrm{p}<0,05$ foi considerado significativo. Resultados: Não houve associação entre os polimorfismos tanto uPA ou TAFI endometriose e a infertilidade relacionada ( $=0,920 \mathrm{ep}=0,356$, respectivamente $)(\mathrm{p}=0,502 \mathrm{e} \mathrm{p}=0,392$, respectivamente $)$ e infertilidade idiopática em relação aos controles, mesmo considerando endometriose mínima/leve e moderada/grave separadamente. Todos os grupos estudados estavam em equilíbrio de Hardy-Weinberg para ambos os polimorfismos uPA e TAFI. A análise combinatória de ambos os polimorfismos uPA e TAFI à infertilidade endometriose relacionados, infertilidade idiopática e grupo controle não mostrou diferença estatística para qualquer combinação. Conclusão: Os dados sugerem que, na população brasileira, as variações genéticas em ambos, UPA e TAFI, não foram relevantes para a endometriose e /ou infertilidade.

\section{Fidelis MA, Almeida CM}

Introdução: No Brasil, a profissão foi criada em 1959 e regulamentada em 1969. Na área da saúd mental sua prática foi voltada à assistência hospitalocêntrica, com a tarefa de ocupar os pacientes, num processo de manutenção e organização dos hospitais e de reabilitação, tendo em vista que, com o advento das terapêuticas biológicas e farmacológicas, os pacientes melhoravam rapidamente dos sintomas. A experiência da antipsiquiatria italiana, na década de 1970, trouxe inovações para a terapia ocupacional no campo da Reabilitação Psicossocial, ao assumir como objeto da ação terapêutica a pessoa e suas necessidade no âmbito de suas ações no cotidiano e não a doença e os sintomas. Objetivo: Identificar a atuação da Terapia Ocupacional frente á pacientes com transtornos mentais. Método Levantamento bibliográfico de artigos científicos de Terapia Ocupacional, com intervenções terapêuticas ocupacionais na área de saúde mental. Resultados: A terapia ocupacional atua na organização do cotidiano, significação de ações, e no desempenho das tarefas do dia a dia. Um processo de terapia ocupacional deve ser marcado por uma relação terapêutica que proporcione ao pacientes condiç̃es efetivas de facilitação do fazer. Um fazer resultante de uma relação dinâmica entre sujeito e ambiente que se concretiza no processo de construção das atividades Assim, na Saúde Mental, a Terapia Ocupacional vem oferecendo sua contribuição principalmente em ações que concretiza, organiza, constrói e transforma conteúdos da relação, no processo permeado pela busca, identificação e atribuição de significados para as atividades.

Descritores: Terapia ocupacional, Saúde mental, Reabilitação psicossocial, Atividade, Abstract.

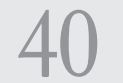

Variante $-817 C>$ T na região promotora do gene estimulador de linfócitos B - BLYS, e suscetibilidade à endometriose e infertilidade na população brasileira

Cavalheiro CM, Teles JS, Lerner TG, Brandes A, Christofolini DM, Bianco B, Barbosa CP

Introdução: Muitas teorias foram propostas para explicar o desenvolvimento da endometriose e, recentemente, a etiologia autoimune foi sugerida. Sabe-se que a endometriose em estágios avançados pode comprometer fertilidade. O estimulador de linfócitos B (BLyS) é uma citocina produzida por macrófagos necessária para o desenvolvimento normal das células $\mathrm{B}$ e um dos polimorfismos mais estudados é o -817C/T na região promotora do gene. Objetivo: Avaliar a frequência do polimorfismo BLyS $-817 \mathrm{C} / \mathrm{T}$ em mulheres inférteis com e sem endometriose e controles. Método: Estudo caso-controle composto por 165 mulheres inférteis com endometriose, 87 com infertilidade idiopática e 145 férteis como controles. A detecção do polimorfismo foi realizada por PCR em tempo real e os resultados foram analisados estatisticamente. Resultados: Os resultados revelaram semelhança na frequência dos alelos e dos genótipos entre os grupos endometriose-associada à infertilidade e o grupo controle $(\mathrm{p}=0.225, \mathrm{OR}=1.25,95 \% \mathrm{CI}=0.89-1.76)$, independente do estádio da doença $(\mathrm{p}=0.213, \mathrm{OR}=1.33$, $95 \% \mathrm{CI}=0.88-2.03$ e $\mathrm{P}=0.462, \mathrm{OR}=1.19,95 \% \mathrm{CI}=0.80-1.77$, respectivamente para endometriose mínima/leve e moderada/grave). No entanto, diferença significativa foi observada entre o grupo de infertilidade idiopática e o controle ( $\mathrm{p}=0.048, \mathrm{OR}=1.53,95 \% \mathrm{CI}=1.02-2.28$ ). Considerando os modelos de herança autossômica dominante e recessiva, não houve diferença significativa em ambos os grupos de endometriose $(\mathrm{p}=0.806$ e $\mathrm{p}=0.172)$ infertilidade idiopática $(\mathrm{p}=0.082$ e $\mathrm{p}=0.214)$. As frequêencias genotípicas estavam em equilibrio de HardyWeinberg em todos os grupos estudados. Conclusão: Os resultados apontam para uma possível associação entre o polimorfismo BLyS -817C/T e infertilidade idiopática na população brasileira.

Descritores: Endometriose, Infertilidade, Gene BLyS, Polimorfismo.

\section{Temas Livres: Cirúrgico}

\section{Adenocarcinoma primário de duodeno: relato de caso}

\section{Pelaggi ER, Bragatto FB, Batistela VCS, Furquim ECG, Corsi CER}

Introdução: Neoplasias do intestino delgado são raras e correspondem a cerca de $1 \%$ das malignidade gastrointestinais, sendo o adenocarcinoma o tipo histológico mais comum. O quadro clínico é bastante vago e inespecífico, retardando o diagnóstico e diminuindo o prognóstico da doença. O tratamento de escolha é a ressecção cirúrgica, curativa em $40-60 \%$ dos pacientes. Relato de caso: R.N., 70 anos, masculino, branco, natural de São Mateus do Sul (PR), procedente de Santo André há 6 meses, casado, marceneiro, $1^{\circ}$ grau incompleto, católico,apresentava queixa de dispepsia contínua há 3 meses, sendo tratado em outro serviço para Doença Ulcerosa Péptica. Há 2 meses iniciou quadro de vômitos biliosos em grande quantidade, alteração do hábito intestinal, empachamento, saciedade precoce e emagrecimento de $15 \mathrm{~kg}$ neste período. Antecedentes familiares: Mãe falecida de neoplasia de intestino e pai de neoplasia de esôfago. Exames de imagem rotineiros foram inconclusivos. Optou-se pela enteroscopia onde foi encontrada, logo abaixo do ângulo de Treitz, uma lesão vegetante, infiltrativa e ulcerada de cerca de $4 \mathrm{~cm}$. Realizou-se ressecção cirúrgica com linfadenectomia. O laudo anátomo-patológico da peça cirúrgica caracterizou a lesão como adenocarcinoma viloso bem diferenciado invasivo. Discussão: Adenocarcinomas primários de duodeno são neoplasias extremamente raras, sendo escassos os seus relatos. Embora a prevalência desta entidade tenha aumentado em grande parte devido ao avanço nos exames capazes de fazer o diagnóstico, a sintomatologia inespecífica e a demora na suspeita clínica são dois fatores que contribuem para o atraso no seu diagnóstico. As neoplasias do intestino delgado, mesmo raras devem ser inclusas no diagnóstico diferencial das síndromes dispépticas e obstrutivas intestinais.

Descritores: Adenocarcinoma, Intestino delgado, Duodeno, Enteroscopia. 


\section{Aneurisma de veia porta extrahepática: 10 anos de evolução clínica e radiológica}

Yonamine RY, Waisberg $J$

Introdução: $\mathrm{O}$ aneurisma de veia porta extrahepática é afecção vascular rara. Desde o

primeiro relato por Bazilai e Kleckner, em 1956, somente 68 casos foram publicados na literatura em língua inglesa e até o presente não identificamos casos na literatura nacional. Sua etiologia ainda não está completamente esclarecida, porém sua origem pode ser congênita ou relacionada à hipertensão portal, pancreatite ou trauma. O diagnóstico do aneurisma de veia porta extrahepática geralmente é incidental, sendo realizado por exames de imagem (ultrassom, tomografia computadorizada e ressonância magnética) de rotina em doentes com dor abdominal inespecífica, icterícia ou sangramento gastrintestinal. Suas complicações mais frequentes são trombose, rutura do aneurisma e compressão de estruturas adjacentes. Os métodos terapêuticos mais frequentemente utilizados no tratamento do aneurisma da veia porta são a observação clinica, ressecção do aneurisma e sua substituição por prótese vascular, trombectomia e/ ou descompressão venosa portal. Relato de caso: Este estudo relata o caso de uma mulher, 68 anos, com 10 anos de acompanhamento radiológico e evolução clínica sem complicações do aneurisma de veia porta extrahepática com $9,3 \mathrm{~cm}$ no seu maior diâmetro. Discussão: Neste estudo relatamos um caso de aneurisma de veia porta extrahepática e sua evolução clínica por 10 anos, possibilitando um melhor manejamento do tratamento clínico e cirúrgico.

Descritores: Aneurisma, Veia porta, Cirurgia, Venoso

\section{"BOOP" pós transplante de fígado}

Yamada FB, Carvalho JPV, Ferreira FAY, Oliveira LO, Towata F, Shiroma ETM, Miranda MP, Genzini T Introdução: A bronquiolite obliterante com pneumonia organizada (BOOP) caracteriza-se pela proliferação de tecido fibroblástico, de maneira continua do lúmen dos bronquilos terminais e respiratório até os ductos alveolares e alvéolos. Casos de BOOP após pacientes serem submetidos a transplantes hepático são raros, havendo relatados apenas 5 casos até o presente. Relato de caso: Trata-se de uma paciente, 31 anos, submetida a transplante de fígado por cirrose hepática auto-imune. Evoluiu com piora dos parametros respiratórios 4 dias após o transplante. Raio-x de tórax com infiltrado bilateral para-hila e broncoscopia revelou sangramento alveolar importante. Foi iniciada antibioticoterapia, havendo piora do quadro radiológico não acompanhada por sinais clínicos e laboratoriais de sepse.Notou-se migração da condensação pulmonar de uma área pulmonar para outra com rapidez atípica.Biópsia transbronquica mostrou lesão pulmonar sub-aguda com padrão de pneumonia organizante.Suspeitou-se de lesão induzida por imunosupressores, sendo suspenso o tacrolimo após o que houve rápida melhora clínica e radiológica. Discussão: Casos de BOOP podem ser idiopáticos ou determinados por radiação, agentes infecciosos, fármacos e pela imunossupressão em pacientes transplantados.Alguns autores consideram o tacrolimo fator de risco para a BOOP.Pacientes previamente relatados apresentam idade entre 48 e 67 anos e tempo de inicío dos sintomas variando de 10 a 15 meses após o transplante.Nossa paciente era mais jovem e teve início do quadro mais precoce.Conclusão:Apesar da BOOP ser condição rara após transplantes hepáticos, ela deve ser considerada diagnóstico diferencial em casos de pacientes que apresentam quadros respiratórios graves e atípicos, uma vez que o tacrolimo pode ser fator desencadeante.

Descritores: Pneumonia por Bronquiolite Obliterante em Organização, Transplante de Fígado, Pneumopatia induzido quimicamente, Tacrolimo.

\section{Cirurgia de aorta: experiência do Serviço de Cirurgia Cardiovascular da Faculdade de Medicina do ABC no Hospital de Ensino da Fundação do ABC}

Moreno R, Silva AMA, Ulrych BK, Moraes FA, Shiroma ETM, Freitas ACO, Pires AC

Introdução: A maioria das doenças da aorta tratadas cirurgicamente são representadas por aneurismas e dissecções, manifestações locais da hipertensão arterial sistêmica e da aterosclerose. Objetivo: Relatar experiência da FMABC no tratamento cirúrgico destas doenças. Método: Estudo retrospectivo que inclui 47 cirurgias de aorta torácica, realizadas no Hospital de Ensino da FUABC. Resultados: Do total, 23 $(48,93 \%)$ foram em caráter de urgência e 24 (51,07\%) eletivas. Para a correção de aneurismas verdadeiros e dissecções agudas ou crônicas da aorta foram realizadas a Cirurgia de Bentall de Bono em 24 (51,07\%) pacientes, troca da aorta ascendente em $21(44,68 \%)$, Cirurgia de Cabrol em $1(2,12 \%)$ e implante de stent em $1(2,12 \%)$. A média de idade foi de 57,73 anos, sendo 35 pacientes $(74,47 \%)$ do sexo masculino e 12 $(25,53 \%)$ do feminino. Todas as cirurgias foram realizadas sob circulação extracorpórea e para o retorno arterial foram utilizadas a artéria femoral em $19(40,42 \%)$ casos, a artéria axilar direita em $16(34,04 \%)$ e a aorta ascendente em $09(23,07 \%)$. Em $32(68,08 \%)$ pacientes foi empregada parada circulatória total e hipotermia profunda. Houve perfusão com fluxo adequado em todos os casos e o tempo médio foi de 160,08 minutos. A principal complicação foi a instabilidade hemodinâmica no período pós-operatório, especialmente nas cirurgias de urgência. Dois pacientes $(4,25 \%)$ apresentaram acidente vascular cerebral isquêmico no pós-operatório e a mortalidade global foi de $17,02 \%$ (8 pacientes). Conclusão: A experiência da FMABC no tratamento cirúrgico do aneurisma e dissecção da aorta encontra-se compatível com os resultados expostos na literatura.

Descritores: Cirurgia de aorta, Aneurisma, Dissecção, Cirurgia cardiovascular.

\section{Autotransplante renal no tratamento de aneurisma de artéria renal}

Towata F, Ferreira FAY, Yamada FB, Shiroma ETM, Oliveira LO, Miranda MP, Genzini T

Introdução: $\mathrm{O}$ aneurisma de artéria renal (AAR) é incomum, com incidência variando de 0,09-1,5\%. Em geral, é assintomático, porém podem ocorrer complicações como expansão, rotura ou embolia de trombos do aneurisma, com conseqüente infarto renal. A maioria dos achados clínicos é encontrada acidentalmente por exames de imagem na investigação de outras doenças. $\mathrm{O}$ autotransplante renal (ATR) constitui-se uma alternativa de tratamento de AAR, havendo poucas publicações internacionais e nenhuma em nosso meio. Relato de caso: Paciente masculino, 48 anos, com histórico de hipertensão arterial sistêmica, plaquetopenia e esquistossomose hepatoesplênica. Procurou nosso serviço por dor lombar direita, sendo constatado AAR direita com $2,5 \mathrm{~cm}$ de diâmetro na tomografia computadorizada e arteriografia. $\mathrm{O}$ tratamento consistiu em nefrectomia direita com preservação renal com solução, aneurismectomia e reconstrução arterial, seguido de reimplante do rim na fossa ilíaca direita com anastomoses dos vasos ilíacos e do ureter. A cirurgia teve duração de 385 minutos, e o tempo de isquemia do rim foi de 140 minutos. O paciente permaneceu na unidade de terapia intensiva por 6 dias devido descompensação da hepatopatia. Recebeu alta hospitalar no 20 o $\mathrm{PO}$, com creatinina de $1,4 \mathrm{mg} / \mathrm{dL}$, uréia de $41 \mathrm{mg} / \mathrm{dL}$, volume urinário de $1400 \mathrm{~mL} / 24 \mathrm{~h}$ e ascite tratad com diuréticos. Discussão: ATR está indicado basicamente em 3 casos: reconstrução extracorpórea de aneurismas complexos do pedículo renal, lesão ureteral extensa e cirurgia conservadora de câncer renal em pacientes com único rim ou com tumores irressecáveis acompanhado de insuficiência renal. Em pacientes que apresentam risco clínico de descompensação renal após nefrectomia, o ATR deve ser considerado para tratamento de AAR não tratável radiologicamente.

Descritores: Autotransplante renal, Aneurisma de artéria renal, Tratamento de aneurisma de artéria renal, Complicações de aneurisma de artéria renal.

\section{Canulação da artéria axilar na circulação extracorpórea: um relato de caso}

Moraes FA, Silva AMA, Ulrych BK, Shiroma ETM, Moreno R, Freitas ACO, Pires AC

Introdução: A artéria axilar é considerada uma via de acesso alternativa na circulação extracorpórea. Apesar de possuir uma técnica mais complexa, promove-se fluxo anterógrado por um vaso usualmente livre de doença aterosclerótica. É indicada principalmente em pacientes com doença aterosclerótica grave, aneurismas ou dissecção da aorta. Objetivo: demonstrar através de relato de caso, a utilização da artéri axilar como via de canulação arterial para circulação extracorpórea em cirurgias de aorta ascendente. Método: Descrição de caso de paciente R.P.L, 40 anos, masculino, com diagnóstico de dissecção aorta ascendente, operado no Hospital de Ensino da Fundação do ABC em maio de 2011 (cirurgia de troca de aorta ascendente e troca de valva aórtica) com utilização da técnica de canulação da artéria axilar direita. Resultados: Alguns estudos mostram como complicação da cirurgia: IRA(15\% dos casos; IR em 13\% dos casos; mortalidade hospitalar em $17 \%$ dos casos. Atik et. al). Dentre as complicações mais frequentes do uso da técnica, apresentam-se a linfocele, isquemia do membro e lesão do plexo braquial. O paciente permaneceu na UTI até o $2^{\circ}$ dia de pós-operatório, evoluindo com alta no $7^{\circ}$ dia de pós-operatório. Conclusão: Cirurgia sem intercorrências e paciente com boa evolução no pós-operatório, com alta hospitalar no $7^{\circ}$ dia de pósoperatório e em acompanhamento no ambulatório de cirurgia cardiovascular.

Descritores: Dissecção de aorta, Canulação da artéria axilar, Circulação extracorpórea, Cirurgia cardiovascular.

\section{Clampeamento da aorta em transplante de pâncreas. Há algum dano ao enxerto renal transplantado?}

Shiroma ETM, Ferreira FAY, Towata F, Oliveira LO, Yamada FB, Victorino AA, Miranda MP, Genzini $T$ Introdução: Situações específicas requerem clampeamento da aorta durante transplante de pâncreas (TP) tanto no TP após rim (TPAR) quanto no TP e rim simultâneo (TPRS). Seu principal problema é a lesão gerada pelo processo de isquemia-reperfusão do rim previamente transplantado e suas consequências não estão completamente estabelecidas. Objetivo: Demonstrar experiência com clampeamento de aorta em TP sem medidas de proteção ao enxerto renal e seu impacto na função renal. Método: 6 pacientes submetidos a TP (5 TPAR e 1 TPRS) com clampeamento da aorta por calcificação severa da artéria ilíaca, uso de coto arterial prévio (retransplante) e enxerto em Y que não atingiu a artéria ilíaca comum. Em todos os casos, o pâncreas, posicionado no espaço retrocólico direito, teve drenagem portal-entérica. Creatinina sérica foi avaliada no pré e pós TP. Resultados: O tempo médio de isquemia foi de 19 minutos. A média de creatinina sérica no pré-TP, nos dias 1 e 7 do pós-TP e na alta hospitalar foi de 1.1, 1.15, 0.95 e 1.0, respectivamente. Como complicações tivemos 1 caso de trombose venosa que levou a perda do enxerto pancreático, 1 caso de pielonefrite tratad com antibiótico e 1 paciente (TPRS) com necessidade de diálise por uma semana recuperando a função renal. As sobrevidas dos pacientes, enxerto renal e pancreático foram de $100 \%, 100 \%$ e $83 \%$, respectivamente. O clampeamento de aorta é muito utilizado no reparo de aneurismas de aorta abdominal. Nesses casos, quando isquemia prolongada (>30 minutos) já é esperada, preconiza-se hipotermia e perfusão do órgão para preveni lesão renal. Conclusão: O clampeamento da aorta em casos selecionados de TP não parece afetar o rim transplantado, mesmo sem medidas de proteção e desde que o tempo de isquemia seja breve.

Descritores: Clampeamento de aorta, Transplante de pâncreas solitário, Lesão de isquemia reperfusão, Função renal. 


\section{Divertículo de Meckel provocando obstrução intestinal aguda}

\section{Bęerra EA, Ferreira FAY, Oliveira NM, Sales SMA, Amarante RDM, Souza AJF, Faro Junior MP}

Introdução: Divertículo de Meckel (DM) é a anomalia congênita mais prevalente do trato gastro-intestinal e resulta da obliteração incompleta do ducto onfalomesentérico. A maioria dos indivíduos sintomáticos são crianças. As principais complicações são sangramento, diverticulite, neoplasias e obstrução intestinal. Esta acomete principalmente adultos e decorre de estrangulamento, volvo, intussuscepção ou neoplasia. Há poucos relatos de DM complicado em adultos. Neste trabalho, descrevemos adulto com abdome agudo obstrutivo por DM. Relato de caso: DSS, 21 anos, masculino, procurou PS referindo dor em epigástrio e mesogástrio, incaracterística, forte intensidade e contínua, associada à saciedade precoce, vômitos e parada de eliminação de gases e fezes. Nega comorbidades e antecedentes familiares significativos. Mesmo con suporte clínico, paciente evoluiu com piora da dor e distensão abdominal, sem sinais de peritonite. O toque retal não evidenciou alteraç̃oes. Exames de imagem mostraram distensão de delgado, indicando-se laparotomia exploradora, que identificou DM aderido à cicatriz umbilical, promovendo acotovelamento de alça de delgado subjacente e dilatação a montante. Realizou-se enterectomia segmentar com enteroenteroanastomose término-terminal. Anatomopatológico revelou processo inflamatório sem evidências de malignidade. O paciente recebeu alta sem queixas. Discussão: Diagnóstico de DM geralmente é intraoperatório, pois exames de imagem costumam ser inconclusivos e o quadro clínico é comum a vária desordens. Seu tratamento é cirúrgico, sendo indicada ressecção se houver sintomatologia ou suspeita de mucosa gástrica ectópica. O DM deve ser considerado no diagnóstico diferencial de abdome agudo obstrutivo, mesmo se tratando de condição rara em adultos.

Descritores: Divertículo de Meckel, Abdome agudo, Obstrução intestinal aguda, Dor abdominal aguda.

\section{Emprego da ecoendoscopia para monitorização do enxerto após transplante de pâncreas}

\section{Oliveira LO, Ferreira FAY, Towata F, Shiroma ETM, Yamada FB, Genzini T, Costa AF}

Introdução: $O$ transplante de pâncreas (TP) apresenta diversas alternativas técnicas para drenagen exócrina e endócrina. Os métodos de drenagem entérica (DE) até hoje empregados, no trânsito intestinal ou em Y de Roux, tornavam o sitio de anastomose praticamente inacessível. Recentemente, foi introduzido com bons resultados a duodenoduodeno anastomose (DDA), método mais fisiológico de $\mathrm{DE}$ e que permite investigação por diversos métodos endoscópicos. Neste relato apresentamos caso inédito de ecoendoscopia de pâncreas transplantado. Relato de caso: RAC, feminino, DM1 desde os 15 anos de idade, submetido a transplante renal por nefropatia diabética. Permanecendo com DM tipo 1 de difícil controle e complicações secundárias, indicou-se TP, que foi realizado com DDA, não apresentando intercorrências. No segundo mês pós-operatório, a paciente evoluiu flutuação dos níveis de amilase, sendo realizada endoscopia digestiva alta (EDA) e ecoendoscopia. Os exames foram realizados sem intercorrências, possibilitaram investigação endoscópica do duodeno do enxerto e ecoendoscópica do pâncreas transplantado, assim como do duodeno nativo e das regiões periampulares de ambos. Discussão: A DDA após TP possibilita um fáci acesso endoscópico ao enxerto pancreático, viabilizando procedimentos diagnósticos anteriormente não possíveis e terapêuticos, como passagem de próteses, biópsias sob visão direta ou por punção ecoguiad de forma rápida e segura.

Descritores: Diabetes mellitus tipo 1, Transplante de pâncreas, Duodenoduodenoanastomose, Ecoendoscopia.
5 Divertículo epifrênico

Tarragó MG, Segre JM, Silva PA, Henriques AC

Introdução: Divertículos esofágicos epifrênicos são raros e associados a distúrbios de motilidade do esôfago. Os autores deste trabalho relatam um caso de paciente com espasmo difuso do esôfago submetido à ressecção cirúrgica de um divertículo epifrênico. Relato de caso: Um paciente masculino de 60 anos apresentava disfagia a sólidos há dois anos. Relatou ainda regurgitação, que nos últimos dois meses passou a ser diária e após cada alimento ingerido, além da perda de $10 \mathrm{~kg}$ neste período. Na endoscopia digestiva alta verificou-se imagem de uma formação diverticular e esôfago com mucosa íntegra. Além do divertículo na porção distal do esôfago, o esofagograma baritado revelou ondas terciárias sugestivas de espasmo difuso do esôfago. Na manometria esofágica, os achados de hipertonia do esfíncter inferior do esôfago e de aperistalse intermitente do corpo esofágico confirmaram o diagnóstico de espasmo difuso de esôfago. $O$ paciente foi submetido a uma abordagem abdominal aberta com diverticulectomia, esofagocardiomiotomi ampla e fundoplicatura parcial. O paciente recebeu alta hospitalar apresentou boa evolução pós-operatória. Discussão: Existem poucas séries publicadas com pacientes cirúrgicos por divertículos epifrênicos. O diagnóstico pode ser difícil, sendo necessária a utilização de alguns métodos, como esofagograma baritado, endoscopia digestiva alta e principalmente a manometria esofágica $\mathrm{O}$ tratamento ainda é controverso, tanto quanto aos critérios de indicação do tratamento cirúrgico quanto à escolha da técnica cirúrgica. Apesar de muitos pacientes com divertículo epifrênico serem assintomáticos, complicações como aspiração já foram documentados em outras séries de estudos, mostrando a importância do tratamento dessa doença para se evitar essa e outras complicações.

Descritores: Divertículo, Esôfago, Transtornos da motilidade esofágica, Cirurgia.

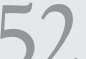

Emprego de enteroscopia no tratamento de estenose de colédoco após transplante de fígado

Introdução: Reestabelecimento do trato biliar durante transplante hepático (TxF) é freqüentemente realizado por meio de hepaticojejunostomia com alça jejunal exclusa (Y-de-Roux). Tratamento endoscópico das complicações da colédoco-colédocoanastomose até recentemente não era possível devido à extensão da alça jejunal exclusa. Assim, enteroscópio de balão único ou duplo representa avanço nos métodos diagnósticos e terapêuticos que permite o acesso a regiões antes inabordáveis no intestino delgado. Objetivo: Relatar o uso de enteroscopia de balão único (EBU) para tratamento de estenose da anastomose biliodigestiva em paciente com lesão da árvore biliar após TxF, no qual foi realizada hepaticojejunostomia com alça jejunal exclusa em Y-de-Roux. Relato de caso: DMS, 42 anos, masculino, submetido à TxF por cirrose biliar secundária à estenose da anastomose biliodigestiva realizada para restauração da via biliar, que fora lesionada durante colecistectomia. A reconstrução biliar foi feita com derivação em Y-deRoux, havendo boa evolução pós-operatória. No PO tardio, observou-se aumento da GGT e retardo no esvaziamento biliar à cintilografia com DISIDA, diagnosticando-se estenose da anastomose biliodigestiva. Realizou-se dilatação e colocação de duas próteses biliares $7 \mathrm{Fr}$ por meio de EBU, com sucesso. Discussão: A estenose de trato biliar é complicação comum após TxF, com uma incidência de 2-14\%. A dilatação do trato biliar por balão com colocação de próteses teve sua eficácia demonstrada em alguns estudos, variando entre 50- 91\%. Enteroscopia permitiu visualizar áreas antes inacessíveis aos endoscópios convencionais, tornando-se uma alternativa interessante e segura para diagnóstico e tratamento de pacientes que requerem abordagem de reconstruções biliares em Y-de-Roux.

Descritores: Enteroscopia de balão único, Tratamento endoscópico, Transplante de fígado, Obstrução de vias biliares.

\section{3}

Emprego de enteroscopia no tratamento de estenose de colédoco após lesão iatrogênica em colecistectomia laparoscópica

\section{Ferreira FAY, Towata F, Shiroma ETM, Yamada FB, Trevižl AP, Yamashita ET, Genzini T, Costa AF}

Introdução: A incidência de lesões das vias biliares cresceu com aumento do número de colecistectomia laparoscópicas devido à alta prevalência de colecistopatias. A reconstrução da via biliar é feita por anastomose biliodigetiva (hepaticojejunostomia em alça jejunal exclusa). No caso de estenose, tratamento endoscópico, menos invasivo que procedimentos cirúrgicos ou radiológicos, é opção interessante, tendo resultados satisfatórios. Entretanto, endoscópio convencional não atinge o sítio da anastomose devido à extensão da alça exclusa. Assim, enteroscópio de balão único ou duplo é uma possibilidade. Relatamos o uso de enteroscopia de balão único (EBU) para tratamento de estenose da anastomose biliodigestiva em paciente com lesão $d$ árvore biliar após colecistectomia laparoscópica. Relato de caso: MGT, 49 anos, masculino, submetido à colecistectomia laparoscópica por colecistopatia crônica calculosa. Durante o procedimento, houve lesão do colédoco, sendo realizada anastomose ducto-ducto no mesmo ato cirúrgico. No pós-operatório tardio, evoluiu com quadros sucessivos de colangite, necessitando ser feita derivação biliodigestiva em Y-de-Roux, que evoluiu com estenose. O paciente foi submetido à EBU para dilatação do colédoco, com sucesso. Discussão: Estenose da anastomose biliodigestiva em Y-de-Roux gera dificuldades, pois o diagnóstico torna-se restrito à colangiografia por ressonância magnética e colangiografia percutânea transhepática. A eficácia da dilatação biliar por balão e colocação de próteses varia de 50-91\%. Assim, a enteroscopia, capaz de visualizar áreas antes inacessiveis aos endoscópios convencionais, é alternativa interessante e segura para diagnóstico e tratamento de pacientes que requerem abordagem de reconstruções biliares em Y-de-Roux.

Descritores: Enteroscopia de balão único, Tratamento endoscópico, Colecistectomia - complicações, Obstrução de vias biliares.
Epistaxe grave provocada por hemangioma capilar lobular de concha nasal inferior em criança de 7 anos

\section{Barros LLF, Bonadio CMA, Ferreira FAY, Baptista MAFB, Silva RFN}

Introdução: Hemangioma representa $7 \%$ dos tumores benignos da infância. $O$ hemangioma capilar lobula (HCL) pode ocorrer em todas as faixas etárias, sendo mais frequente em homens com menos de 18 ano e mulheres na $3^{a}$ e $4^{a}$ décadas de vida. Apesar da cabeça e pescoço não serem uma região incomum de HCL, a cavidade nasal é um sítio raro de ocorrência desta entidade em crianças. Apresentamos um caso de uma criança com HCL de corneto inferior apresentando-se com epistaxe grave. Relato de caso: BWC, masculino, 7 anos, procurou serviço de Otorrinolaringologia 7 dias após episódio de epistaxe maciça. No seguimento da investigação diagnóstica, exames de imagem detectaram lesão expansiva em topografia de corneto inferior direito. Procedeu-se arteriografia com embolização da lesão para evitar sangramentos durante a cirurgia. Realizou-se turbinectomia inferior radical. O anatomopatológico mostrou um HCL "granuloma piogênico like". O paciente apresentou boa evolução pós-operatória, apenas com episódios de epistaxe de pequeno volume. Discussão: $\mathrm{O}$ vestíbulo e as conchas nasais são localizações incomuns do HCL. A literatura mostra maior prevalência do HCL de corneto inferior em adultos. Em crianças, o HCL de corneto inferior é ainda mais raro. Além disso, o quadro clínico mais freqüente é epistaxe intermitente leve e não grave como ocorreu neste relato. Os estudos de imagem ajudam a diferenciar HCL de processos neoplásicos mais agressivos. A lesão é efetivamente tratada através da excisão endoscópica, que inclui ressecção ampla do tumor com margem de segurança. Em tumores grandes, pode-se associar à ressecção completa a embolização pré-operatória da lesão. Considerando-se os diagnósticos diferenciais possíveis, o HCL, embora raro, deve sempre ser pesquisado.

Descritores: Hemangioma capilar lobular, Epistaxe, Cavidade nasal, Concha nasal. 
Estudo prospectivo, randomizado e comparativo entre ressecção do carpo da fileira proximal do carpo e artrodese dos quatro cantos para pacientes com diagnóstico de SNAC

Longuino LFF, Vanzin AM, Mota RT, Ikeuti DH, Moraes GBB, Fugiki EN, Fukushima WY, Aita MA

Introdução: A fratura do escafóide não diagnosticada evolui com pseudartrose, e se não tratada, gera diversas complicações como sobrecarga no lado radial do carpo, degenerando a articulação rádio-escafódea e levando a um impacto local. Além disso, leva a migração proximal do capitato e gera o desarranjo do carpo, descrito como SNAC (Scaphoid Non Union Advanced Colapse). A carpectomia e a artrodese dos quatro cantos são os métodos de tratamento mais estudados para esta fratura. Objetivo: Comparar resultados clínico-funcionais de pacientes com diagnóstico de SNAC estágio II submetidos à ressecção da fileira proximal do carpo ou a artrodese dos quatro cantos. Método: Foram incluídos 27 pacientes entre 18 a 59 anos, sendo 13 submetidos à ressecção da fileira proximal (grupo A), e 14 à artrodese dos quatro cantos (grupo B). O acompanhamento ambulatorial variou de 21 e 49 meses. Avaliou-se os arcos de movimento, dor, força de preensão palmar, DASH e o retorno ao trabalho. Resultados: No grupo A, pacientes apresentaram $65,5 \%$ do arco de movimento do lado não afetado e no grupo B, $55,01 \%$. Na avaliação subjetiva da dor obtivemos 2,4 no grupo A e 3, I no grupo B. A força de preensão palmar em relação ao lado não acometido foi de $75,67 \%$ no grupo A e 74,42\% no grupo B. O DASH no grupo A foi 11 e no grupo B foi 13 . Retornaram ao trabalho $69,23 \%$ no grupo A e 57,14\% no grupo B. As complicações foram a osteoartrose do punho sintomática no grupo A e soltura de um parafuso no grupo B. Conclusão: Pacientes com SNAC estágio II apresentaram melhora clínico-funcional, ganho de força de preensão palmar, diminuição da dor e aumento da qualidade de vida. Os submetidos à ressecção da fileira proximal apresentaram melhora no ganho de força de preensão palmar.

Descritores: Fratura do escafóide, Ressecção da fileira proximal do carpo, Artrodese dos quatro cantos, Colápso da não união avançada do escafóide (SNAC).

\section{Experiência com utilização de filtros de veia cava inferior realizados na Faculdade de Medicina do ABC}

Barros HPCB, Golfetti MG, Almeida RC, Silva CMR, Milazzotto PHM, Correa JA, Fujii EY, Yamazaki YR

Introdução: O tromboembolismo pulmonar (TEP) é uma doença de alta morbidade e mortalidade com incidência de 500.000 casos por ano e a utilização de filtros de veia cava inferior tem o objetivo de preveni a embolia pulmonar. Objetivo: Apresentar a experiência endovascular com a utilização dos filtros de veia cava inferior na Faculdade de Medicina do ABC. Método: Este trabalho foi realizado no período de janeiro de 2003 a março de 2011 no serviço de Angiologia e Cirurgia Vascular da Faculdade de Medicina do ABC. Oitenta e cinco pacientes foram tratados sendo quarenta e sete do sexo masculino $(55,3 \%)$ trinta e oito do sexo feminino (44,7\%). A média de idade foi de 57,7 anos. As indicações para colocar o filtro foram: risco de sangramento $(53 \%)$, alto risco para TEP (33\%), cirurgia de grande porte $(9,4 \%)$, trombose venosa profunda proximal $(4,6 \%)$. Resultados: A taxa de sucesso técnico inicial foi de $96,47 \%$ (82 casos), satisfatório de 2,35\% (2 casos) e sem sucesso 1,18\% (1 caso). Os pacientes foram acompanhados inicialmente por trinta dias e não apresentaram complicações no pós-operatório. Conclusão: A implantação destes dispositivos se mostrou eficaz na prevenção da tromboembolia pulmonar. No entanto é preciso um acompanhamento em longo prazo para avaliar melhor a sobrevida dos pacientes no serviço.

Descritores: Filtro de veia cava, Tromboembolismo, Veia cava, Trombose venosa profunda.

\section{9 대}

Cavinato MFR, Alquéres RA, Brunelli JB, Silveira BS, Marçon TA, Friaģa AMV, Faro Junior MP

Introdução: Íleo biliar é uma obstrução intestinal mecânica devido à impactação de um ou mais cálculos em algum ponto de estreitamento do trato gastrointestinal. É uma complicação pouco freqüente da colelitíase que acomete mais pacientes idosos. Relato de caso: Paciente de 80 anos, sexo feminino, com quadro de 6 dias de vômitos incoercíveis associados à distensão abdominal e dor difusa, e parada de eliminação de gases e fezes nos últimos 3 dias. Não apresentou febre, icterícia, colúria ou outros sinais e sintomas relevantes no período. Ao exame físico, mostrou-se anictérica e pouco desidratada. Abdome distendido, flácido ligeiramente doloroso à palpação, timpânico à percussão, ruídos hidroaéreos aumentados à ausculta, ausência de visceromegalias ou massas palpáveis, manobra de descompressão brusca negativa. Sob a hipótese diagnóstica de abdome agudo obstrutivo, realizou tomografia computadorizada e radiografia contrastada de abdome, nas quais uma pneumobilia, uma distensão importante de alça de delgado e a presença de cálculo em região de íleo foram evidenciados. Paciente foi submetida à laparotomia exploradora, na qual constatou-se presença de cálculo biliar impactado em íleo proximal, com distensão a montante e diminuição do peristaltismo a jusante. Após ileotomia para retirada do cálculo sem realização de colecistectomia, paciente evoluiu sem complicações. Discussão: Em casos de abdome agudo obstrutivo, particularmente em idosos com história de doença calculosa crônica, deve-se considerar o íleo biliar como diagnóstico diferencial. Comorbidades importantes, presença de intenso processo inflamatório e bloqueios de epíplon, indicam uma colecistectomia em segunda abordagem, para diminuir a morbimortalidade dos pacientes em questão.

Descritores: Íleo biliar, Abdome agudo obstrutivo, Colelitíase, Abdome agudo em idosos.

Experiência com drenagem portal por acesso retrocólico e duodeno-duodenoanastomose nos transplantes de pâncreas solitários

Ferreira FAY, Towata F, Oliveira LO, Shiroma ETM, Yamada FB, Victorino AA, Miranda MP, Genzini T Introdução: A elevada morbidade associada ao transplante pancreático (TP) permitiu o desenvolvimento de novas técnicas, a fim de melhorar seus resultados e torná-lo mais fisiológico. O TP com drenagem portal por acesso retrocólico acomoda o enxerto muito próximo ao duodeno nativo, tornando a duodenoduodenoanastomose (DDA) uma alternativa interessante. Objetivo: Demonstrar nossa experiência atual com TP solitário realizado com drenagem portal por acesso retrocólico e DDA. Método: 14 pacientes submetidos à TP solitários (10 TP após rim, sendo 3 retransplantes, e 4 TP isolados) por acesso retrocólico, drenagem venosa na veia mesentérica superior e drenagem exócrina através de DDA. O esquema de imunossupressão incluiu timoglobulina, tacrolimus, micofenolato de sódio e esteróides. Resultados: Pacientes com média de 35 anos de idade, 24 anos de diabetes e IMC de $23 \mathrm{Kg} / \mathrm{m} 2$. O tempo médio de isquemia foi de aproximadamente $13 \mathrm{~h}$ e o tempo médio cirúrgico de $3 \mathrm{~h}$, sem necessidade de hemoderivados. Houve um caso de trombose venosa, que requereu transplantectomia e rafia do duodeno nativo. As sobrevidas de paciente e enxerto foram de $100 \%$ e $93 \%$, respectivamente. Discussão: Existem poucas séries de TP empregando DDA, com bons resultados relatados até o momento. A DDA permite menor tempo cirúrgico e fácil acesso endoscópico para monitoramento do enxerto, sendo considerado o modelo mais fisiológico de TP. Conclusão: Essa experiência inicial foi favorável, atingindo excelentes resultados e tornando-a nossa técnica de escolha. Não utilizamos a DDA apenas quando o enxerto duodenal não apresenta bom aspecto após a reperfusão, pois o reparo do duodeno nativo pode ser problemático.

Descritores: Diabetes mellitus tipo 1, Transplante de pâncreas, Drenagem portal-entérica, Duodenoduodenoanastomose.

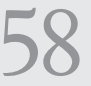

Experiência inicial da Faculdade de Medicina do ABC em angioplastia de carótida comparada com a endarterectomia de carótida

Golfetti MG, Barros HPC, Silva CMR, Almeida RC, Ulrych BK, Correa JA, Fujii EY, Galego SJ

Introdução: A endarterectomia é um procedimento cirúrgico que consiste na remoção da placa de aterosclerose que está bloqueando a artéria, restaurando assim o fluxo sanguíneo. A angioplastia é um procedimento terapêutico minimamente invasivo. Um pequeno balão, integrado a um cateter, é guiado até a artéria comprometida e inflado e desinflado para comprimir a placa de aterosclerose contra a parede arterial, desobstruindo o vaso. Em alguns casos, um pequeno tubo feito de uma malha de metal (stent) é posicionado na artéria para mantê-la aberta e, assim, garantir um fluxo desobstruído.Essa técnica é uma alternativa à cirurgia aberta convencional (endarterectomia de carótida), tendo grande importância para pacientes de alto risco frente ao procedimento cirúrgico tradicional. Objetivo: Este trabalho tem por objetivo apresentar a experiência inicial do tratamento endovascular das estenoses carotídeas. Método: Foram analisados os primeiros 25 casos de angioplastia de carótida comparativamente com os 107 casos de endarterectomias no período de 2004 a 2011. As angioplastias foram indicadas na maioria por aterosclerose de artéria carótida interna e quatro casos foram indicados por reestenose após tratamento convencional. As endarterectomias foram indicadas por estenose carotídea maior que $60 \%$ nos pacientes sintomáticos e maior que $70 \%$ nos assintomáticos. O dispositivo mais utilizado foi o sistema de proteção Angiogard e o stent utilizado foi o Precise. Resultados: A taxa de sucesso inicial das angioplastias foi de $84 \%$ e nas endarterectomias foi de 88,78\%. Conclusão: A angioplastia de carótida é uma nova forma de tratamento da estenose de carótida com resultados satisfatórios na amostra estudada.

Descritores: Angioplastia, Endarterectomia, Estenose de carótida, Aterosclerose.

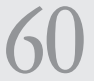

Influência da biópsia de rim nativo na decisão entre transplante de pâncreas solitário e transplante simultâneo de pâncreas e rim

Towata F, Yamada FB, Shiroma ETM, Oliveira LO, Trevižol AP, Yamashita ET, Miranda MP, Genzini T

Introdução: $\mathrm{O}$ clearence de creatinina $(\mathrm{ClC})$ e a proteinúria podem apresentar-se erráticos e imprecisos, particularmente na Diabetes Mellitus tipo 1 com disfunção renal intermediária (DRI). Objetivo: Estabelecer o papel da biópsia de rim nativo (BRN) para pacientes que serão submetidos a transplante de pâncreas (TP) e apresentam DRI. Método: Analisamos 13 pacientes diabéticos $(8$ mulheres, com idade média de 36 anos, variando entre 26 e 60 anos) inscritos para TP em que a BRN foi realizada. A indicação da BRN foi o $\mathrm{ClC}$ entre 35 e $80 \mathrm{ml} / \mathrm{min}$ e/ou proteinuria $>\lg / 24$ horas em vários exames. A BRN foi guiada por ultrassonografia e fibrose glomerular e intersticial. Taxa de fibrose inferior a $20 \%$ foi considerada moderada, e acima de $20 \%$, grave. Os achados histológicos foram correlacionados com a decisão clínica final em cada caso e os pacientes foram distribuídos em 3 grupos: $\mathrm{A}=\mathrm{TP}$ solitário (TPS) realizado; $\mathrm{B}=\mathrm{TP}$ e rim simultâneo (TPRS) ou TP após rim (TPAR) realizado; C= paciente em lista de espera. Resultados: A média de $\mathrm{ClC}$ foi de $52,7 \mathrm{ml} / \mathrm{min}(37-76 \mathrm{ml} / \mathrm{min})$ e proteinúria de 2,58g/24h $(0,15-6,6 \mathrm{~g} / 24 \mathrm{~h})$. Oito BRN foram consideradas graves e 5 moderadas. Dois pacientes compuseram o grupo A, 3 o B, e 8 o C. Em 11 pacientes (85\%), a BRN influenciou fortemente na decisão clínica final, e em 2, apesar de resultado moderado, a decisão clínica era contra o TP solitário devido a deterioração clínica e funcional durante seguimento. Em 8 pacientes com lesão renal grave, a BRN contraindicou o TPS e foram submetidos a TPRS, TPAR ou encontram-se em espera por TPRS. Conclusão: A BRN foi preditiva de evolução renal e influenciou fortemente na decisão clínica final em $85 \%$ dos pacientes inscritos para TP com função renal intermediária.

Descritores: Transplante de pâncreas, Biópsia renal, Função renal, Diabetes mellitus tipo 1. 

potencialmente prejudiciais à reperfusão venosa portal durante o transplante hepático (TH). A ligadura da veia renal esquerda (LVRE) seria opção para o restabelecimento do fluxo portal, necessário à boa perfusão do enxerto. Relato de caso: $\mathrm{CCR}$, feminino, 61 anos, nefrectomizada há 13 anos, portadora de cirrose por vírus da hepatite B e hipertensão arterial com ascite volumosa, icterícia, encefalopatia, com um MELD de 21. À ultrassonografia com Doppler, evidenciou-se veia porta (VP) e esplênica (VE) pérvias, porém parte do fluxo da VE estava desviado em direção ao hilo renal por veia colateral esplenorrenal. Foi submetida à TH, onde se notou VP da receptora pérvia, mas com baixa pressão. Após dissecção da veia renal esquerda (VRE), observou-se aumento importante do fluxo portal após seu clampeamento, optando-se por realizar a LVRE. No período pós-operatório, a creatinina variou de 1,4 à 2,4 mg/dl. Em um seguimento de quatro meses, não houve prejuízo da função renal atribuída a esta manobra. Discussão: $\mathrm{O}$ tratamento cirúrgico de SER, durante o TH, quando necessário, é realizado pela ligadura das veias colaterais esplenorrenais, com ou sem esplenectomia. No entanto, complicações podem ocorrer. A LVRE foi proposta como tratamento mais eficaz dos SERS por possibilitar perfusão portal hepática (PPH) adequada no momento do TH, sem manipulação direta dos shunts, evitando assim os riscos relacionados. Neste caso, mesmo com rim único, a LVRE garantiu PPH adequada, sem alteração da função renal.

Descritores: Transplante de fígado, Circulação colateral-tratamento, Ligadura de veia renal, Cirrose hepática.

\section{Mensuração da qualidade de vida dos pacientes submetidos a artroplastia da articulação trapézio- metacárpica no tratamento da rizartrose}

Longuino LFF, Vanzin AM, Mota RT, Ikeuti DH, Moraes GBB, Gasparotti E, Alves RS, Aita MA

Introdução: As artroplastias de ressecção e interposição no tratamento da rizartrose estão bem estabelecido e apresentam bons resultados em $85 \%$ dos pacientes. Atualmente, inúmeros implantes são desenvolvidos, mas os resultados ainda não estão bem documentados. Objetivo: O estudo tem como objetivo apresentar os resultados clínico-funcionais dos pacientes submetidos a artroplastia de ressecção da articulação trapéziometacárpica com a interposição, não cimentada, de uma prótese de piocarbono (Ascension R). Materiais e Método: $\mathrm{O}$ estudo possui um segmento de treze meses e analisou dezenove pacientes com o diagnóstico de rizoartrose idiopática submetidos à artroplastia de ressecção e interposição de prótese de piocarbono. No grupo analisado, quinze são mulheres e quatro são homens e a idade média é de 59,95 anos (48 - 71). Foram operados doze mãos dominantes, oito não dominantes e em uma paciente bilateralmente, totalizando vinte articulações trapézio-metacárpicas. Resultados: Na avaliação subjetiva da dor (VAS), ocorreu uma redução de 8,75 para 1 na escala utilizada. Com relação a força de prensão, aumentou-se de 2,28 Kof para 3,41 Kof após o sexto mês pós-cirúrgico. Neste mesmo período, o arco de movimento (abdução e adução palmar) aumentou de 64,45 para 78,75. Aplicou-se o questionário DASH e obteve-se, em média, 59,05 no período pré-operatório e 8,68 no pós-operatório. Como complicações, observou-se três luxações, sendo 2 reoperadas, e nenhum caso apresentou soltura ou fratura do implante. Conclusão: Após a análise de todos os dados obtidos após o sexto mês pós-operatório, pode-se concluir que este método é eficaz e seguro, além de apresentar uma significativa melhora clínica e funcional, proporcionando uma melhora na qualidade de vida de todos os pacientes.

Descritores: Mensuração da Qualidade de Vida, Artroplastia da Articulação Trapézio-Metacárpica, Rizartrose, Piocarbono.

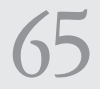

Relato de caso de osteossíntese percutânea minimamente invasiva (MIPO) no tratamento das fraturas instáveis da extremidade distal do rádio

Longuino LFF, Vanzin AM, Mota RT, Ikeuti DH, Moraes GBB, Credidio MV, Gasparotti E, Aita MA

Introdução: A fratura da extremidade distal do rádio na população economicamente ativa brasileir aumentou sua incidência e prevalência nos últimos anos. O tratamento cirúrgico é necessário na maiori dos casos e necessita-se de retorno às atividades profissionais precocemente. Assim é necessário formulação e aprimoramento de técnicas menos traumáticas e seguras para seu tratamento. Objetivo: Relatar um caso clínico-cirúrgico com o diagnóstico de fratura da extremidade distal do rádio esquerdo, submetido ao procedimento cirúrgico de MIPO. Método: C.O.S., feminina, branca, 37 anos, atendente, vítima de queda de escadas, evoluindo com fratura redutível, instável e extra-articular da extremidade distal do rádio esquerdo. No Centro Hospitalar Municipal de Santo André, realizou-se no terceiro dia de internação o tratamento cirúrgico,com bloqueio do plexo braquial. Transcorreu-se com a redução incruenta e estabilização parcial com 2 fios de Kirschner através de fluoroscopia. Obteve-se uma via de acesso de $1 \mathrm{~cm}$ na região dorsal ao estilóide radial para a confecção do orifício ósseo e colocação da haste micronail R -Wright R. Realizou-se a fixação proximal desta com três parafusos bloqueados,propiciando a estabilidade angular e a fixação distal com dois parafusos convencionais. Finalizou-se com a limpeza, sutura da pele e a confecção de curativo oclusivo. Resultados: Na avaliação radiográfica, visualizou-se a consolidação óssea e manutenção da redução inicial. O edema reduziu no terceiro dia, o ganho completo de arco de movimento na terceira semana e o retorno ao trabalho após o $45^{\circ}$ dia. Conclusão: Este método é rápido, eficaz e seguro. Apresenta excelente resultado funcional pós-operatório. Assim, é uma alternativa no tratamento das fraturas extra-articulares instáveis da extremidade distal do radio.

Descritores: Osteossíntese Percutânea Minimamente Invasiva (MIPO), Fratura da extremidade distal do rádio, Micronail R, Resultado funcional.

\section{Ligadura tática de veia renal esquerda por shunt esplenorrenal durante transplante hepático}

Oliveira LO, Ferreira FAY, Towata F, Yamada FB, Trevižol AP, Yamashita ET, Miranda MP, Genzini T

Introdução: A presença de shunts esplenorrenais (SERS) pode prejudicar a hipertensão e a reperfusão venosa portal durante o transplante hepático $(\mathrm{TH})$. A ligadura da veia renal esquerda (LVRE) seria opção para o restabelecimento do fluxo portal, necessário à boa perfusão do enxerto hepático $(\mathrm{EH})$. Objetivo: Avaliar os resultados da LVRE durante TH para garantia de perfusão portal adequada em pacientes com circulação colateral venosa. Material e Método: Analisamos seis pacientes ( 4 homens e 2 mulheres), no quais se realizou LVRE durante TH. No momento do TH, os pacientes tinham MELD com média de 29 (21-40). O SER e a circulação portal foram avaliados antes do TH por ultrassonografia com Doppler (USD) ou angiotomografia. Resultados: Todos os pacientes apresentaram melhora do fluxo portal hepático ao teste de clampeamento da veia renal esquerda durante o TH, optando-se pela LVRE. A ausência de fluxo venoso com sentido esplenorrenal foi demonstrada por meio de USD no pós-operatório. Todos pacientes apresentaram evolução satisfatória do EH e não houve disfunção renal permanente. Conclusão: $\mathrm{O}$ tratamento cirúrgico de SER, durante o TH, é realizado frequentemente por meio de ligadura das veias colaterais esplenorrenais, com ou sem esplenectomia. Porém, podem ocorrer diversas complicações. A LVRE garantiu a perfusão portal hepática adequada, possibilitando boa evolução no pós TH, sem alteração da função renal. Portanto, a LVRE para prevenir o desvio do fluxo sanguíneo para vasos colaterais parece ser um procedimento seguro e efetivo, evitando-se prejuízos à perfusão do EH quando ocorre SER.

Descritores: Transplante de fígado, Circulação colateral-tratamento, Ligadura de veia renal, Cirrose hepática.

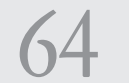

Relação entre tabagismo e pós-operatório em cirurgia de coluna

Ferreira GF, Bisson G, Silva BDKM, Schaffhausser HL, Michaelis LF, Yamamoto AYP, Pohl PHI, Rodrigue $L M R$

Introdução: O tabagismo é conhecidamente relacionado a diversos processos patológicos, entre eles a degeneração discal e do ânulo fibroso, causando lombalgia e lombociatalgia tendo impacto elevado na qualidade de vida da população. No entanto, existem poucos estudos que evidenciem o efeito prejudicial do tabaco em pacientes no seguimento pós-operatório em patologias da coluna vertebral. Objetivo: Verificar e avaliar a associação entre o tabagismo e a dor no pós-operatório em cirurgia de coluna para tratamento de hérnia discal lombar, estenose de canal lombar e espondilolistese. Método: os autores avaliaram prospectivamente 96 pacientes que foram submetidos a três tipos de procedimentos em cirurgia de coluna, para correção de hérnia discal lombar, estenose do canal medular lombar, e espondilolistese vertebral. Aplicou-se a Escala Visual Analógica (EVA) no pré-operatório, três meses, seis meses, nove meses, e doze meses, assim como um questionário de banco de dados com informaç̃es específicas sobre hábito e comorbidades. Calculou-se a diferença algébrica entre a EVA no pré-operatório e nos doze meses comparando pacientes tabagistas e não tabagistas. Resultados: A frequiência de tabagistas na população estudada foi de $16,67 \%(n=16)$. A diferença entre a média do grupo de tabagistas e não tabagistas fo comprovada estatísticamente $(p<0,001)$. Conclusão: Há relação entre o tabagismo e evolução pósoperatória em cirurgia de coluna, no que se refere à diminuição da dor, quando comparado com não tabagistas.

Descritores: Tabagismo, Dor, Cirurgia, Dor lombar.

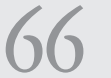

Resultados do tratamento cirúrgico das fraturas do rádio distal com acometimento da coluna medial com placa angular invertida

Longuino LFF, Vanzin AM, Mota RT, Ikeuti DH, Moraes GBB, Credidio MV, Gasparotti E, Aita MA

Introdução: Sendo as fraturas distais do rádio bastante freqüentes e consideradas complexas, o tratamento cirúrgico tem sido cada vez mais indicado, com grande evolução dos implantes desenvolvidos para extremidade distal do rádio. Objetivo: Apresentar os resultados clínico-funcionais dos pacientes com diagnóstico de fratura intraarticular da extremidade distal do rádio, submetidos ao tratamento cirúrgico com placa de estabilidade angular variável invertida. Método: No período de 18 meses, foram avaliados 42 pacientes com fraturas instáveis tipos $23 \mathrm{C}$ (Classificação $\mathrm{AO}$ ), foram submetidos à abordagem vola estendida do punho e tiveram suas fraturas fixadas com placa de estabilidade angular variável, com o lado invertido. Todos os dados foram enviados para análise estatística. Utilizou-se o programa SPSS (Statistical Package for Social Sciences), em sua versão 13.0, para a obtenção dos resultados. Resultados: Os pacientes apresentam arco de movimento de $84,5 \%$ em comparação ao lado normal e a força de preensão palmar foi de $91,6 \%$ do lado não acometido. O DASH Score foi de seis e a avaliação subjetiva da dor foi de 1,3 . O índice de complicações foi de 4,76\%. Conclusão: Os pacientes com diagnóstico de fratura intraarticula da extremidade distal do rádio, submetidos ao tratamento cirúrgico com placa de estabilidade angular variável invertida apresentaram melhora clínico-funcional e da qualidade de vida, com baixo índice de complicações, permitindo considerar o método seguro e eficaz.

Descritores: Fratura intrarticular do rádio, Coluna medial, Placa de estabilidade angular variáve invertida, Abordagem volar estendida do punho. 


\section{Transplante hepático realizado para tratamento de equinococose policística causada por Echinococcus vogeli}

Ferreira FAY, Towata F, Oliveira LO, Shiroma ETM, Trevizol AP, Yamashita ET, Miranda MP, Geninin T

Introdução: O Brasil é responsável por $58 \%$ dos casos mundiais de hidatidose policística (HP), que se manifesta por múltiplos cistos coalescentes no fígado. A ressecção cirúrgica é opção quando não há comprometimento avançado das vias biliares e do sistema porta ou doença hepática difusa. Na impossibilidade de ressecção, o transplante de fígado $(\mathrm{TxF})$ tem oferecido bons resultados. Relatamos o primeiro caso de $\mathrm{TxF}$ utilizado par tratamento de HP, causada por Echinococcus vogeli. Relato de caso: AOS, 48 anos, masculino, natural procedente do Acre, com história epidemiológica positiva para criação de cães e prática de caça. Observou-se hepatomegalia importante, com superfície irregular e consistência endurecida. Tomografia computadorizada de abdome revelou cistos difusos no fígado com calcificações periféricas. O Western blot apontou sorologia positiva para Echinococcus spp, confirmando a suspeita de HP. Após 2 anos de tratamento clínico com albendazol, apresentou múltiplos episódios de colangite e evoluiu com insuficiência hepática por compressão do sistema porta pelos cistos e comprometimento das vias biliares, indicando-se o TxF. Discussã̃: TxF para tratamento da hidatidose alveolar é indicado na presença de lesões perihilares inoperáveis, insuficiência hepática severa ou acometimento difuso do sistema biliar, sendo a sobrevida em 5 anos de $71 \%$ e sobrevid livre de doença de 58 \%. Apesar do alto risco de proliferação dos parasitas não-detectados no intra-operatório ou nos métodos de imagem e das complicações pós-operatórias, o TxF oferece os melhores resultados, sobretudo em casos avançados. Este relato demonstra factibilidade técnica com bons resultados, tornando TxF uma alternativa interessante ao tratamento da HP avançada em nosso país.

Descritores: Hidatidose hepática, Equinococose hepática, Transplante de fígado, Echinococcus.

\section{Tromboangeíte obliterante: relato de caso}

Barros HPC, Golfetti MG, Silva CMR, Almeida RC, Silva AMA, Correa JA, Costa AJV, Fujii EY

Introdução: A Tromboangeíte obliterante (TAO), ocorre em sua grande maioria em pacientes jovens, faix etária inferior a 45 anos, principalmente na raça branca, sem fatores de risco para doença aterosclerótica A sua etiologia ainda não é conhecida, porém existe uma forte associação com o uso do tabaco, sendo um critério de diagnóstico a história atual ou recente de tabagismo. $O$ tratamento requer a imediata suspenção do hábito de fumar e a terapêutica depende dos sintomas apresentados. Relato de caso: Paciente sexo feminino, 32 anos deu entrada no pronto atendimento com quadro de dores em artelhos há 3 meses acompanhada por necrose em 1o, 2o, 3o pododáctilo direito. No mesmo período apresentou cianose em quirodáctilos esquerdos. Tabagista de 40 anos/maço com antecedentes familiares de tromboangeíte obliterante avô materno com necrose em dedos da mão e pé esquerdos. Ao exame apresentava diminuição dos pulsos poplíteos bilaterais e ausência de pulsos distais. Necrose de falange distal de hálux, da falange média de 20 pododáctilo e falange distal de 30 pododáctilo esquerdo. Paciente submetida à arteriografia, mostrou padrão de vasculite pela retificação das artérias e estenose de artérias ilíacas comum. Optado pela realização de angioplastia de artérias ilíacas pela técnica de kissing baloon e melhora imediata da perfusão distal.Paciente evoluiu com melhora da dor e delimitação da necrose de artelhos após a suspensão do tabagismo e tratamento endovascular das estenoses arteriais. Discussão: Nos casos de tromboangeíte obliterante a suspensão do tabagismo melhora os sintomas, mas no caso descrito a paciente apresentava estenoses hemodinamicamente significativas com necessidade de correção cirúrgica endovascular que é uma técnica com menor comorbidade e com bons resultados.

Descritores: Tromboangeíte obliterante, Angioplastia, Tabagismo, Doença aterosclerótica.

\section{Avaliação do conhecimento entre adolescentes sobre sexualidade e desenvolvimento puberal}

Melo LRC, Pedroso C, Blumetti AMC, Cintra RMB, Reato LFN

Introdução: A adolescência é uma fase de mudanças físicas,psicológicas e sociais. Nela ocorre ainda o desenvolvimento da sexualidade que se inicia com o auto-conhecimento até a capacidade de estabelece relações afetivas com o outro. Conhecer o próprio corpo e suas modificações permite ao jovem fazer escolhas de forma mais consciente diminuindo assim sua exposição a riscos como doenças sexualmente transmissíveis e gravidez precoce. Objetivo: Avaliar o conhecimento sobre as mudanças decorrentes da puberdade. Método: Foi realizado um estudo quantitativo com aplicação de um questionário que avaliou: percepção de mudanças no próprio corpo,a idade em que os jovens acreditam começar a adolescência,auto avaliação de tanner,presença de menarca,conhecimento sobre o que é ficar,a presença de dúvidas sobre sexualidade e a possibilidade de conversar com alouém sobre elas. Resultados: Foram avaliados 48 adolescentes,sendo $77 \%$ do sexo feminino.A idade média que eles acreditam que se inicia a adolescência é de 12,8 anos.Dos adolescentes avaliados $85,4 \%$ relataram já ter percebido alguma modificação em seu corpo.Conversas sobre sexualidade foram relatadas por $83,3 \%$ deles,sendo o ambiente familiar,a escola e os amigos as principais fontes de esclarecimento de dúvidas.No momento da avaliação apenas $22 \%$ dos jovens referiram questionamentos a serem esclarecidos. Conclusão: É de extrema importância que os adolescentes tenham liberdade para esclarecer suas dúvidas e receber orientações seja na consulta médica,no ambiente escolar e no familiar tornando-os progressivamente responsáveis sobre sua saúde e conscientes sobre suas atitudes e conseqüências.

Descritores: Adolescentes, Desenvolvimento puberal, Sexualidade, Prevenção de riscos à saúde.
Tratamento endovascular da oclusão arterial aguda com dispositivo de aspiração de trombos angiojet ultra

Almeida RC, Barros HPC, Silva CMR, Golfetti MG, Higashitani DY, Correa JA, Coffler GEG, Galego SJ

Introdução: O sistema ANGIOJET usa uma mistura complexa de fluidos de rápida transmissão e força hidrodinâmicas com a finalidade de fragmentar o trombo, permitindo sua extração por pressão negativa através da ponta do cateter. Esta técnica tem mostrado resultados promissores no tratamento da oclusão arterial aguda e está emergindo rapidamente como uma primeira linha de opção terapêutica e uma alternativa a pacientes que apresentem alto risco para o procedimento cirúrgico aberto. Relato de caso: Paciente, 60 anos 4 dias com quadro de dor de repouso no MIE, de início subto, com limitação da deambulação, associado a frialdade, parestesia e palidez do membro, com movimentos preservados, ausência de pulsos Po, Pd e TP. Pulso Femoral 4+/4+.MID: Aquecido, bem perfundido, sem edema, sem empastamento, sem déficits neurológicos, Pulsos F:4+/4+, Po: 3+, Pd: $2+$ e TP: $2+$. Tinha hipertensão arterial sistêmica e era cardiopata.O paciente recebeu tratamento endovascular,sendo realizada trombectomia e retitrada dele através do sistema ANGIOJET. Discussão: O dispositivo de aspiração de trombos ANGIOJET, mostrouse efetivo no tratamento da oclusão arterial aguda.

Descritores: Angiojet, Trombolise, Aterosclerose, Oclusão arterial aguda.

\section{Temas Livres: Epidemiológico}

7 Avaliação da densidade mineral óssea em portadores de doença de Crohn: resultados preliminares

Cordeiro RA, Amadeu NA, Moreno R, Catapani WR

Introdução: Pacientes com Doença de Crohn (DC) apresentam elevado índice de perda de massa óssea. Vários fatores têm sido relacionados a esta alteração como tratamento com corticosteróides e má absorção intestinal. Objetivo: Determinar a prevalência e os fatores relacionados à baixa densidade mineral óssea (DMO) em pacientes portadores de DC. Método: Foram estudados 24 pacientes ambulatoriais com diagnóstico de DC. Para cada paciente foi aplicado um questionário que contemplava as seguintes informações: idade, sexo, etnia, tabagismo, menopausa, terapia de reposição hormonal, medicamentos em uso, uso pregresso de corticóides, índice de atividade física, índice de massa corpórea, ingestão de leite/ laticínios e café, localização e extensão da doença, índice de atividade de Harvey Bradshaw, antecedentes cirúrgicos e de internações, tempo de diagnóstico da DC e tempo de sintomas antes do diagnóstico. Todos os pacientes foram submetidos ao exame de densitometria óssea e classificados de acordo com os critérios da Sociedade Brasileira de Densitometria Clínica. Resultados: Dos 24 pacientes, 15 (62,5\%) apresentaram baixa DMO. Entre os fatores estudados, tiveram associação com baixa DMO a idade e a raça. A raça parda teve $10 \%$ menos chance de ter baixa massa óssea do que a raça branca (OR: $0.1 ; \mathrm{p}=0.028$, IC95\% 0.01-0.8). Quanto à idade, pacientes com 51 a 74 anos tiveram 14,7 vezes mais chance de terem baixa DMO do que os pacientes entre 21 e 50 anos (OR: 14.7; $\mathrm{p}=0.008$, IC95\% 2.0-109.2). Os demais parâmetros não apresentaram associação. Conclusão: Constatou-se alta prevalência de baixa DMO $(62,5 \%)$ entre os pacientes portadores de DC estudados. Deve-se ressaltar o tamanho pequeno da amostra, que pode ter mascarado alguma possível associação com outro parâmetro.

Descritores: Doença de Crohn, Densidade óssea, Densitometria, Osteoporose.

\section{Câncer colorretal: uma análise exploratória sobre seu conhecimento em pacientes ambulatoriais da Faculdade de Medicina do ABC}

Moreno R, Cordeiro RA, Manaia GF, Saba GT, Silva JO, Ciancaglini JV, Madeira MG, Catapani WR

Introdução: O Câncer Colorretal(CCR)é a terceira maior causa de câncer no mundo,o quarto tipo de neoplasia mais prevalente em homens brasileiros e o terceiro em mulheres. Antecedentes familiares,dieta hipergordurosa,idade,consumo excessivo de álcool,tabagismo, baixa ingesta de frutas,vegetais e fibras são os principais fatores de risco.Pesquisa de sangue oculta nas fezes e colonoscopia podem detectar a doença precocemente. Objetivo: Análise exploratória sobre o conhecimento de sintomas,fatores de risco e exame envolvidos no CCR em uma população proveniente dos Ambulatórios de Especialidades da Faculdade de Medicina do $\mathrm{ABC}$ (FMABC). Método: Um questionário sobre dados demográficos, hábitos alimentares e perguntas sobre sintomas do CCR foi aplicado a 796 pacientes ambulatoriais da FMABC. Foram criados dois grupos: os que foram capazes de citar corretamente 3 sintomas do CCR e conhecem o procedimento de colonoscopia ("Grupo informado") e aqueles que não citaram corretamente nenhum sintoma e não conhecem colonoscopia ("rupo desinformado"). Resultados: No grupo desinformado, havia $276(44,23 \%)$ mulheres e $348(55,76 \%)$ homens, com média de idade de $48,8( \pm 17,0)$. No grupo informado, $14(26,4 \%)$ mulheres e $39(73,6 \%)$ homens, com média de idade de $49,8( \pm 14,5)$. O teste do qui quadrado não mostrou associação significante entre ser ou não informado e faixa etária $(\mathrm{p}=0,2)$, raça $(\mathrm{p}=0,06)$, padrão alimentar (gorduras: $p=0,8$; carne vermelha: $p=0,2$; frutas: $p=0,5$; verduras: $p=0,1$; fibras: $p=0,08$ ). Houve associação significante com sexo e com ter parentes de primeiro grau com CCR. Conclusão: Em uma amostra de 677 indivíduos, 624 (92\%) não foram capazes de citar corretamente 3 sintomas do CCR. Conhecer os sintomas do CCR não influencia o padrão alimentar dos indivíduos, o qual não difere entre indivíduos dos 2 grupos.

Descritores: Câncer colorretal, Epidemiologia, Análise exploratória. 


\section{Causas de infertilidade em casais atendidos no centro de reprodução assistida em situações especiais da Faculdade de Medicina do ABC (CRASE)}

Menezes SG, Evo CPR, Santos AA, Kayaki EA, Bianco B, Christofolini DM, Barbosa CP, Carvalho WAP

Introdução: É crescente o número de casais com doenças infecciosas que decidem engravidar. O Centro de Reprodução Assistida em Situações Especiais (CRASE) da Faculdade de Medicina do ABC atende tais casais para assegurar uma gestação segura. A infertilidade pode ser primária - quando o casal nunca teve uma gestação - ou secundária - quando o casal já teve uma gestação anterior. Objetivo: Procurou-se com esse estudo avaliar o tipo de infertilidade - e suas causas - em pacientes que procuram nosso serviço. Método: Analisamos os prontuários de 133 casais, avaliando se a infertilidade do casal era primária ou secundária, além de verificamos a frequêencia das seguintes causas de infertilidade: fatores femininos (tuboperitoneal, ovulatório ou uterino), fator masculino, fator indeterminado e fatores concomitantes masculino e feminino. Resultados: A taxa de infertilidade primária foi de $73,2 \%$, e secundária foi de $26,8 \%$. Entre as causas, o fator masculino foi predominante, com taxas de $51,1 \%$. Entre os fatores femininos, que representam $35,2 \%$ dos casos, tendo como maior causa o fator tuboperitoneal, com taxas de $22,5 \%$, seguido de fator ovulatório com $10,5 \%$ e por último fator uterino, com apenas $2,2 \%$. A concomitância de fatores feminino e masculino ocorre em $10,5 \%$ dos casais. Verificou-se ainda que $13,7 \%$ das causas são indefinidas. Conclusão: Concluiu-se que a infertilidade é, na maioria das vezes, um problema primário do casal. As taxas de causas masculinas são maiores que as femininas, mostrando uma desproporção entre os sexos. Chama a atenção também a porcentagem significativa de casais que têm infertilidade de causa ainda indefinida.

Descritores: Infertilidade feminina, Reprodução, Fertilização, Infertilidade masculina.

\section{Dispepsia não investigada: fato ou mito?}

Hirai CCG, Segre JM, Silva PA, Machado MP, Brunetti K, Chehter EZ

Introdução: Dispepsia não investigada é definida, pelos critérios de ROMA III, como dor ou desconforto em trato digestivo superior. Objetivo: Traçar perfil epidemiológico de pacientes portadores de dispepsia não investigada, referendados a ambulatório de Gastroenterologia, e estabelecer hipótese diagnóstica mediante exames complementares. Método: Aplicou-se questionário elaborado pelos pesquisadores e foram requisitados endoscospia digestiva alta com biópsia, sorologia para $\mathrm{H}$. pylori, ultrassonografia abdominal e protoparasitológico de fezes para investigação do quadro dispéptico. Os resultados foram avaliado segundo sua significância. Resultado: Foram incluídos 93 pacientes, 85 deram seguimento a pesquisa e 44 obtiveram diagnóstico. A média de idade da amostra foi de 42 anos, sendo $74 \%$ do sexo feminino e $26 \%$ do sexo masculino. A dor abdominal estava presente em $69 \%$ dos pacientes e, em $85 \%$ deles se localizava em epigástrio. O desconforto abdominal aparecia em $31 \%$ dos pacientes e em $73 \%$, se localizava em epigástrio. Dos 44 pacientes que obtiveram diagnóstico $70 \%$ foram considerados como dispepsia funcional e $30 \%$ como orgânica. Conclusão: $\mathrm{O}$ protocolo evidenciou prevalência de dispepsia funcional, coincidente com a literatura. Consensos internacionais indicam que portadores de dispepsia não-investigada devem receber teste terapêutico anteriormente a exames complementares, e Endoscopia Digestiva Alta deve ser sempre indicada em maiores de 55 anos ou em falha do teste terapêutico. Desta forma, os pacientes referendados ao ambulatório da especialidade deveriam ter permanecido em acompanhamento no nível primário de atenção em saúde.

Descritores: Dispepsia, Diagnóstico, Dispepsia, Epidemiologia, Gastroenteropatias etiologia, Helicobacter pylori, Questionário.

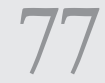

Elevado percentual de desnutrição em crianças com encefalopatia crônica não evolutiva (ECNE) à admissão em ambulatório de terapia nutricional

Matar MR, Santos JPM, Rocha LFL, Ricci R, Sarni ROS, Santiago SN, Souza FIS

Introdução: a encefalopatia crônica não evolutiva (ECNE) caracteriza-se por um conjunto de alterações motoras associadas ou não ao comprometimento coonnitivo e da fala. São causas frequentes a prematuridade e anóxia neonatal. Faz parte da reabilitação a preservação da condição nutricional para se garantir melhor qualidade de vida em curto e longo prazo. Objetivo: descrever as características gerais e a condição nutricional de crianças com ECNE encaminhados para acompanhamento ambulatorial. Método: Por mei de estudo retrospectivo, foram levantados todos os prontuários das crianças, com PC em acompanhamento no Ambulatório de Nutrologia do Departamento de Pediatria da Faculdade de Medicina do ABC nos últimos 2 anos. Coletou-se os seguintes dados da primeira consulta: idade, diagnóstico, peso ao nascer e idade gestacional e dados antropométricos (peso e estatura) utilizados para classificação da condição nutricional por meio do escore z da estatura/idade (ZEI) e do índice de massa corporal (ZIMC) Análise estatística: tabelas de frequêencia e teste do Qui-quadrado. Resultados: Incluiu-se 27 pacientes, sendo $17 / 27(63 \%)$ do sexo masculino e a média de idade foi de 3,2\&\#61617:2, 8 . Destes $17 / 27(63 \%)$ foram bebês prematuros (idade gestacional: 32,2\&\#61617;5 semanas). Todas as crianças tinham algum comprometimento nutricional grave (ZEI; -7,1\&\#61617;2,2 e ZIMC; -1,9\&\#61617;1,8). Observou-se baixa estatura em 25/27 (92,6\%) e desnutrição (ZIMC < -2) 13/27 (48,1\%). Conclusão: Observou-se intenso comprometimento nutricional nas crianças avaliadas, especialmente, estatural. O diagnóstico e intervenção mais precoce em crianças com ECNE deve ser realizado em paralelo as outras estratégias de reabilitação para que se reduza o impacto na saúde da criança.

\section{Correlação clínico-endoscópica na moléstia diverticular dos cólons}

\section{Trevizan LLB, Pachon S, Gomes Junior CAR, Catapani WR}

Introdução: A moléstia diverticular dos cólons (MDC) é diagnóstico comum em colonoscopias. Seu sintomas são de difícil avaliação, pela existência de portadores assintomáticos não diagnosticados. Objetivo: realizar correlação entre diagnóstico endoscópico de MDC e dor abdominal, consistência e frequiência de evacuações. Método: Avaliação de 127 colonoscopias. Instrumento: questionário sobre os dados clínico e posterior correlação com resultado do exame. Exclusão: exames incompletos, mau preparo, cirurgia digestivas prévias e concomitância de lesões de outras com MDC. Resultados: Incluídos 47 pacientes, 61,7\% sexo feminino. 23 pacientes apresentaram colonoscopia normal, e $24 \mathrm{MDC}$ isolada. A distribuição etária foi 17 indivíduos entre 17 e 45 anos ( $34,4 \pm 9,0), 16$ entre 46 a 59 anos $(55,1 \pm 3,3)$ e 14 entre 60 e 89 anos $(70,7 \pm 8,8)$. Na faixa etária mais baixa, predomina MD do cólon $\mathrm{E}$ ( 5 casos), na intermediária e na mais alta predominou a MD pancolônica (com 6 e 5 casos respectivamente). Não há diferença significante na prevalência de MDC entre as faixas etárias $(\mathrm{p}=0,38)$. Tomando-se o diagnóstico de MDC "in totum", sem distinção de localização anatômica, a dor abdominal foi mais prevalente no grupo com MDC do que com colonoscopia normal $(\mathrm{p}=0,026)$. Comparando-se pacientes com dor abdominal e colonoscopia normal, com aqueles com dor abdominal e portadores de MDC, não houve diferença significante quanto às características da dor. A consistência das fezes e a frequiência de evacuações também não diferiram entre os grupos. Conclusão: Em pacientes submetidos à colonoscopia, a frequência da queixa de dor abdominal foì significantemente maior em pacientes com MDC do que em pacientes com colonoscopia normal, porém as características da dor não diferenciaram os grupos.

Descritores: Dor abdominal, Diagnóstico, Divertículo colônico, Colonoscopia.

\section{6}

Efeitos colaterais do tratamento da hepatite $\mathrm{C}$ em centro de referência do grande $A B C$

\section{Garcia TJ, Lara PHS, Morimoto TP, Higasiaraguti M, Perejão AM, Ayub MA}

Introdução: A hepatite C é importante causa de hepatopatia crônica. O tratamento é longo, com índice de cura variável $(40-70 \%)$, com diversos efeitos colaterais que muitas vezes inviabilizam a terapia. Objetivo: Analisar os efeitos colaterais do tratamento da hepatite $\mathrm{C}$ com interferon peguilado e ribavirina no CRIE do Hospital Mario Covas (Santo André), de 23/2 a 5/5/11. Método: Estudo transversal, por questionário, com amostra não probabilística composta por 340 pacientes que tenham recebido pelo menos uma dose da medicação. Resultados: Os efeitos colaterais apresentados foram cansaço ( $82,9 \%)$, artralgia e/ou mialgia $(76,8 \%)$, emagrecimento $(71,8 \%)$, cefaléia $(67,6 \%)$, desânimo $(65,9 \%)$, depressão e/ou irritabilidade $(64,4 \%)$, prurido $(60,6 \%)$, febre $(59,1 \%)$, alopécia $(51,5 \%)$, tosse seca $(34,1 \%)$, náuseas $(11,7 \%)$, inapetência $(11,7 \%)$ e tontura $(7,9 \%)$. Foram relatados até 19 sintomas durante o tratamento (média: 7,74$)$. Apena 4 pacientes $(1,2 \%)$ negaram efeitos colaterais. Ao comparar os dois interferons observamos que os pacientes em uso do alfa $2 \mathrm{~b}$ apresentaram uma média de 8,01 sintomas por paciente enquanto que o alfa $2 \mathrm{a}$ foi responsável por uma média de 7,50 sintomas por paciente. Os pacientes em uso do interferon alfa $2 \mathrm{~b}$ apresentaram mais febre, emagrecimento, cefaléia, artralgia e/ou mialgia, cansaço, desânimo, depressão e/ou irritabilidade e tosse seca em relação aos em uso do alfa 2a, que por sua vez, tiveram mais alopécia e prurido. Conclusões: $\mathrm{O}$ estudo mostra uma grande morbidade relacionada ao tratamento, já que apenas $1,2 \%$ dos pacientes não apresentaram efeitos colaterais. Em nossa amostra o interferon peguilado alfa $2 \mathrm{~b}$ foi responsável por maior incidência de febre e emagrecimento quando comparado ao alfa 2a, sendo esta relação estatisticamente significante $(\mathrm{p}<0,05)$

Descritores: Hepatite C, Tratamento, Efeitos colaterais, Interferon peguilado.

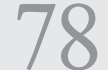

Epidemiologia dos pacientes em tratamento da hepatite $C$ em um centro de referência do grande $A B C$

\section{Garcia TJ, Lara PHS, Morimoto TP, Higasiaraguti M, Perejão AM, Ayub MA}

Introdução: A hepatite $\mathrm{C}$ é um desafio à saúde pública mundial. Objetivo: Análise epidemiológica do pacientes em tratamento da hepatite $\mathrm{C}$ com interferon peguilado e ribavirina no CRIE do Hospital Mario Covas (Santo André), de 23/2 a 5/5/11. Método: Estudo transversal, por um questionário, com amostra não probabilística de 340 pacientes que receberam pelo menos uma dose da medicação. Resultados: A amostra foi composta por $55,5 \%$ homens e $44,5 \%$ mulheres, de etnia branca $(69,1 \%)$, parda $(23,7 \%)$, negra $(5,6 \%)$ e amarela (1,5\%), com 23 a 83 anos de idade (média: 48,9$)$. Residentes em São Bernardo do Campo (36,2\%), Santo André (33,5\%), Diadema (11,8\%), São Caetano do Sul $(5,6 \%)$ e outros $(12,9 \%)$. Declararam-se analfabetos $(2,4 \%)$, com $1^{\circ}$ grau completo $(32,1 \%)$, com $2^{\circ}$ grau completo $(40,3 \%)$, com nível superior incompleto $(8,8 \%)$ e com nível superior completo $(16,5 \%)$. A renda de $20,5 \%$ dos pacientes é menor ou igual a 1 salário mínimo, $67 \%$ de $2-6$ e $12,5 \%$ com 6 ou mais. Possuem convênio médico $45,9 \%$. Contágio por transfusão de sangue $(28,2 \%)$, tatuagem/piercing $(6,5 \%)$, drogas injetáveis $(5,0 \%)$, contato sexual $(2,6 \%)$, outras $(13,5 \%)$ e $43,2 \%$ não informaram. Os genótipos referidos foram $1(69,2 \%), 2(17 \%)$, $3(12,1 \%), 4(1,6 \%)$ e desconhecido $(46,5 \%)$. Há doenças associadas em $31,2 \%$, entre elas: HAS $(28 \%)$, DM (17\%), HIV+ (5\%). O interferon alfa $2 \mathrm{~b}$ é utilizado por $55,5 \%$ dos doentes e $44,5 \%$ usam o alfa $2 \mathrm{a}$. o primeiro tratamento para $81,1 \%$. Conclusão: A maioria é do sexo masculino, branca, com média de 48,9 anos, de São Bernardo do Campo, com renda de 2-6 salários mínimos, sem convênio médico, sem doenças associadas, utiliza o interferon alfa $2 \mathrm{~b}$ e está no primeiro tratamento. A transfusão sanguínea foi relatada como a principal forma de contágio e o genótipo 1 o mais prevalente.

Descritores: Hepatite C, Interferon peguilado, Efeitos colaterais, Tratamento. 


\section{Estudo da prevalência de câncer de pele não melanoma no Ambulatório de Dermatologia da FMABC, Santo André, SP, Brasil, de 2005 a 2010}

\section{Yamada AT, Fonseca ABF, Daher MBSE, Abdalla BMZ, Machado Filho CDS, Costa PS}

Introdução: A incidência do câncer de pele não melanoma vem aumentando nos últimos anos. Estima-se que, atualmente, corresponde a 25\% de todos os tumores malignos registrados no país. Exposição solar excessiva, predisposição genética e alta sensibilidade solar são alguns dos fatores de risco encontrados. Por ser uma neoplasia altamente prevalente, medidas preventivas, tais como: uso de filtro solar e auto exame em busca de lesões são fundamentais. O Carcinoma Basocelular (CBC) e o carcinoma Espinocelular (CEC) são, respectivamente, a primeira e segunda neoplasia de pele mais comuns. Objetivo: Este trabalho visa apresentar uma análise crítica dos dados de CBC e CEC do ambulatório de dermatologia da Faculdade de Medicina do $\mathrm{ABC}$ e correlacionar os resultados com a literatura. Método: Estudo retrospectivo unicêntrico baseado em prontuários dos anos de 2005 a 2010, em que foram coletadas informações sobre casos de CBC e CEC relacionando-os com a identificação do paciente (idade e sexo), ao quadro clínico (localização cutânea) e aos laudos anatomopatológicos (histopatologia) de forma que possamos estabelecer futuramente algumas normas preventivas para essas neoplasias cutâneas, bem como contribuir com o melhor conhecimento do comportamento epidemiológico destas neoplasias na região. Resultados: Observou-se uma maior frequêencia nos pacientes na faixa etária acima de 40 anos, do sexo feminino. Com relação à topografia houve maior prevalência de lesões na região da face, também classificamos as neoplasias segundo o seu comportamento histopatológico. Conclusão: Observou-se uma correlação entre os dados encontrados e os da literatura internacional auxiliando nas medidas preventivas, diagnóstico precoce, tratamento e orientações de pacientes com altos fatores de risco.

Descritores: Carcinoma basocelular, Carcinoma espinocelular, Neoplasia, Epidemiologia.

\section{Evolução de pacientes idosos internados em instituição de longa permanência em vigência de colonização}

Matushita DKO, Fina R, Massari LM, Biondi BG, Manchini $C V$, Silva CDKM, Silva Junior EB

Introdução: Com o crescimento da população idosa, surgiram inúmeras instituições de longa permanência a fim de prestar serviços de saúde a essa população. Entretanto, não raramente, as instituições permitem que haja transmissão de microorganismo entre os pacientes, a chamada infecção cruzada ${ }^{3}$. Ao transportar essa bactéria, o transmissor faz com que o outro paciente torne-se colonizado por esta, tornando o fato $\mathrm{d}$ o paciente ser institucionalizado, um fator de risco para colonização ${ }^{3}$. Não se sabe atualmente, quais são as consequiências dessa colonização. Objetivo: $\mathrm{O}$ presente estudo busca verificar a evolução do paciente idoso institucionalizado que vem colonizado por qualquer bactéria. Método: Foram inclúdos no estudo, todos pacientes idosos provenientes de instituição de longa permanêcia admitidos no hospital Albert Sabin em São Caetano do Sul, cujas culturas de swab nasal, axilar ou anal, foram positivos para alguma bactéria. Resultados: O presente estudo incluiu 33 pacientes no qual $42,4 \%$ evoluíram com infecção, sendo que $50 \%$ das infecções foram causadas pelo mesmo agente que o colonizava previamente, e $50 \%$ foram causadas por outras bactérias. As únicas bactérias que colonizavam e evoluíram para um quadro infeccioso foram o Staphylococcus aureus resistente a meticilina (MRSA) e a Klebsiella pneumoniae, responsáveis por $42,8 \%$ e $71,4 \%$ das infecções respectivamente. Conclusão: Os pacientes previamente colonizados apresentaram um considerável desenvolvimento para um quadro infecciso (42\%). Existem bactérias com mais facilidade para a instalação de infecção. Os protocolos de descolonização mostram-se como uma medida interessante para a prevenção da infecção já que $21,4 \%$ dos pacientes colonizados, foram infectados pelos mesmos agentes que os colonizavam.

Descritores: Institucionalizados, Descolonização, Infecção, Idosos.

\section{Q2 Implantação do Serviço de Retinopatia da Prematuridade no hospital Municipal Universitário de São Bernardo do Campo}

\section{Pachon S, Mota RT, Hamermesz B, Lima LP, Toloi GC, Towata F, Farah ML, Salomão GHA}

Introdução: A retinopatia da prematuridade (ROP) é definida como retinopatia bilateral que ocorre tipicamente em lactentes tratados com altas concentrações de oxigênio. Com a evolução dos cuidados neonatais, recém nascidos cada vez mais prematuros foram capazes de sobreviver, aumentando assim o número de casos de ROP. Objetivo: Descrever os resultados do programa de prevenção a cegueira po retinopatia da prematuridade após implantação de serviço de diagnóstico e tratamento de oftalmologia neonatal nos hospitais vinculados a Fundação ABC. Método: Foram avaliados recém nascidos de acordo com os seguintes critérios: 1 - peso ao nascer menor que $1500 \mathrm{~g}$, 2 -idade gestacional menor que 32 semanas, 3- terceiro critério (indicação do neonatologista por intubação orotraqueal prolongada, sepses, transfusões sanguíneas, gemelaridade, entre outros critérios que justifiquem a avaliação por "sofrimento" neonatal). Resultados: Foram avaliados 141 recém nascidos prematuros entre janeiro de 2009 e dezembro de 2010 , destes $133(94.32 \%)$ apresentaram quadro de retinopatia da prematuridade com crescimento retiniano espontâneo sem necessidade de intervenção cirúrgica. Oito (5.67\%) crianças necessitaram de tratamento a laser para fotocoagulação de retina por risco de descolamento de retina e em $100 \%$ dos casos o sucesso terapêutico foi alcançado, evitando-se a evolução para cegueira. Não foi necessário tratamento cirúrgico por vitrectomia ou qualquer outra técnica para tratamento da retinopatia. Conclusão: A implantação do serviço de retinopatia da prematuridade foi eficaz em prevenir a cegueira em recém nascidos de risco para o descolamento de retina. Este serviço deve ser difundido para todos os hospitais com berçários que recebam recém nascidos prematuros.

Descritores: Retinopatia da prematuridade/terapia, Prematuro, Retinopatia da Prematuridade/prevenção \& controle, Cegueira/prevenção \& controle.
Estudo epidemiológico dos corredores da $10^{\mathrm{a}}$ meia maratona de Santo André: avaliação de 187 participantes

Bisson G, Ferreira GF, Towata F, Chiota FL, Yamauti LS, Yamamoto AYP, Beltrani Filho CA, Navarro MS Introdução: Acompanhando a busca progressiva pela saúde física e melhora na qualidade de vida, literatura busca avaliar o perfil dos corredores de rua. Objetivo: Identificar o aspecto físico, comorbidade associadas, acompanhamento médico, obtendo assim o perfil dos competidores de rua e embasamento cientifico para medidas profiláticas necessárias. Método: Os dados foram recolhidos, via questionário aplicado em 187 participantes da $10^{\circ}$ meia maratona de Santo André; subdividido em três provas: caminhada, $10 \mathrm{~km}$ e meia maratona $(21 \mathrm{~km})$. Resultados: meia maratona: $89.2 \%$ eram do sexo masculino, $6.2 \%$ são tabagistas $60 \%$ vão ao médico rotineiramente, apresentavam um índice de massa corporal (IMC) médio de 23.29 e circunferência abdominal (CU) de 82,35 . Prova de $10 \mathrm{Km}$ : observou-se maior participação do sexo feminino $(20.3 \%), 3.8 \%$ tabagistas, $72.2 \%$ vão ao médico rotineiramente. Apresentavam um IMC médio de 24.72 e CU de 82,44. Caminhada: a média de idade foi menor ( 40.55 anos contra 44.23 nos $10 \mathrm{~km}$ e 44.62 nos $21 \mathrm{~km}$ ), $77.5 \%$ do sexo feminino, sendo $15 \%$ dos participantes com hipertensão arterial sistêmica (HAS), contra $10.1 \%$ nos $10 \mathrm{~km}$ e $9.2 \%$ na meia maratona. Tabagistas compunham $5 \%, 82.5 \%$ vão ao médico rotineiramente, $27.5 \%$ faziam acompanhamento profissional (contra $24.6 \%$ nos $21 \mathrm{~km}$ e $38 \%$ nos 10km). Apresentaram uma média de IMC de 24.14 com 80.82 de CU. Conclusão: O perfil físico é similar, com predomínio feminino na caminhada, apesar das maiores taxas de HAS, temos menores índices de tabagismo e maior preocupação quanto ao acompanhamento profissional nesta prova. Os participantes dos 10 e $21 \mathrm{~km}$ apresentam os piores resultados quanto à assistência médica e ao tabagismo, sendo necessário o acompanhamento profilático para a prevenção de futuros eventos cardiovasculares.

Descritores: Antropometria, Atleta, Treinamento, Exercício.

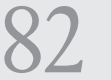

Fatores maternos, gestacionais e neonatais associados a internação do recém-nascido em unidade de terapia intensiva neonatal

Zlochersky AM, Munhoes DA, Samos FM, Trigo LFB

Objetivo: Avaliar fatores maternos, gestacionais e neonatais que justifiquem necessidade de internação do RN em UTI Neonatal. Método: Estudo transversal descritivo com 357 parturientes e seus 361 RN admitidos na UTI Neonatal do HMU-SBC, SBC, SP, BR entre 03 de outubro de 2008 e 21 de novembro de 2010. Foram coletadas informações maternas, do RN e da gestação em prontuários médicos. Resultados: Em relação às consultas de pré-natal, parturientes que realizaram menos de três tiveram idade gestacional (IG) de $31 \pm 4$ semanas, prevaleceu parto normal (64\%), peso de seus RN foi $1506 \pm 692$ gramas. As que realizaram mais de 6 consultas tiveram IG de $37 \pm 4$ semanas, prevaleceu parto cesárea (53\%), peso de seus RN foi $2656 \pm 878$ gramas. Dos RN que foram a óbito na UTI neonatal (34\%), IG foi $30 \pm 6$ semanas, Apgar de $1^{\circ}$ minuto $4 \pm 3$, de $5^{\circ}$ minuto $7 \pm 3$, peso $1495 \pm 976$ gramas. Dos que receberam alta da UTI neonatal ( $66 \%$ ), IG foi $34 \pm 5$ semanas, Apgar de $1^{\circ}$ minuto $6 \pm 3$, de $5^{\circ}$ minuto $8 \pm 2$, peso 2276 \pm 915 gramas. $41 \%$ das parturientes apresentaram pelo menos uma patologia durante a gestação. Mais prevalentes: tabagismo (21\%), infecção de trato urinário (20\%), doença hipertensiva específica da gestação (18\%). Conclusão: O estudo mostrou que quanto mais consultas de pré-natal, maior idade gestacional e peso ao nascer, portanto menor possibilidade de prematuridade e baixo peso. OR entre pré-natal e óbito foi $1.272 \mathrm{com} p=0.000$, demonstrando que, a fim de reduzir mortalidade neonatal precoce no Brasil, um recurso é investir na melhoria do atendimento pré-natal. A diferença de Apgar de $1^{\circ} \mathrm{e} 5^{\circ}$ minutos entre RN que foram a óbito e os que obtiveram alta da UTI, sendo o do primeiro grupo menor do que o do segundo, demonstrou a validade da classificação Apgar como método prognóstico do RN.

Descritores: Unidade de terapia intensiva, Neonatal, Materno, Recém-nascido.

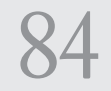

Incidência de sintomas da doença do refluxo gastroesofágico em pacientes com doença pulmonar obstrutiva crônica e sua relação com a qualidade de vida

Trevizan LLB, Herbst LG, Munhoes DA, Fiss E

Introdução: A alta taxa de morbi-mortalidade de portadores de DPOC é um grande problema de saúde pública. Sintomas como dispnéia, tosse e cansaço, levam a limitação funcional e impacto na qualidade de vida. Segundo a literatura, há relação entre distúrbios pulmonares e DRGE, é comprovado a exacerbação/ desencadeamento da asma pelo refluxo o que dificulta o tratamento. Pouco se estudou sobre a relação entre DPOC e DRGE. Objetivo: Verificar a incidência de sintomas de DRGE em pacientes DPOC e avalia impacto na qualidade de vida. Método: Estudo transversal, prospectivo. Entrevistados 44 pacientes em tratamento para DPOC. Instrumentos: questionário de aspectos demográficos e clínicos, Questionário de Sintomas de DRGE (QS-DRGE) e Questionário do Hospital Saint George na Doença Respiratória (SGRQ) que avalia qualidade de vida. Resultados: A média de idade foi de 71,07 anos (45 - 86). Estadiados, $29,3 \%$ apresentava distúrbio pulmonar moderado e $43,9 \%$ grave. O tabagismo foi referido por $90,9 \%$. Interferência no trabalho pelo DPOC referida em $36,4 \%$ dos casos. Sintoma de DRGE mencionados por $25 \%$, a maior queixa foi azia. Dos que apresentaram sintomas de refluxo, $20 \%$ referiram insatisfação em relação ao estado de saúde. Não houve correlação entre sintomas de refluxo e estadio avançado de DPOC. Sintomas de DRGE estiveram associados à pontuação elevada do $\mathrm{SGRQ}(\mathrm{p}=0,05)$. Alta pontuação no domínio de impactos $p$ sicossociais (SGRQ) apresentou associação $(\mathrm{p}=0,02)$ com pontuação no $\mathrm{QS}-\mathrm{DRGE}$. Conclusão: Portadores de DPOC apresentam relevante incidência de sintomas de DRGE, associados a impacto significativo na qualidade de vida desses sobretudo na avaliação psicossocial. Estudos devem descrever essa relação e analisar possível melhoria na qualidade de vida com o tratamento da DRGE.

Descritores: Doença pulmonar obstrutiva crônica, Refluxo gastroesofágico, Qualidade de vida. 


\section{Q5 0 uso de drogas ilícitas em casais que procuram o centro de reprodução assistida em situações especiais da Faculdade de Medicina do ABC (CRASE)}

Menezes SG, Cavalheiro CM, Paiva CP, Brandes A, Bianco B, Christofolini DM, Barbosa CP, Carvalho WAP

Introdução: O Centro de Reprodução Assistida em Situações Especiais (CRASE) atende casais que são portadores de doenças infecciosas que podem ser transmitidas durante a gestação. Usuários de drogas são expostos a dupla via de transmissão de doenças infecciosas e, alem disso, o uso de drogas ilícitas pode estar relacionado com a diminuição da fertilidade. Objetivo: $\mathrm{O}$ intuito desse estudo foi avaliar quantos dos casais atendidos fazem uso dessas substâncias ilícitas. Método: Foram analisados retrospectivamente 133 prontuários de casais que procuraram o serviço do CRASE, verificando o uso das seguintes drogas: maconha, cocaína, crack e o uso concomitante de mais de uma dessas substâncias. Resultados: Entre as mulheres, $100 \%$ negaram o uso de qualquer droga ilícita. Já entre os homens, $10,5 \%$ afirmaram fazer uso de alguma droga ilícita. Destes, 53,4\% faziam uso regular apenas de maconha, $20 \%$ usavam apenas cocaína e nenhum relatou usar apenas crack. $\mathrm{O}$ uso concomitante de maconha e cocaína foi relatado por $20 \%$, enquanto o uso concomitante de cocaína, maconha e crack foi relatado por $6,6 \%$. Conclusão: Tendo em vista o alto número de parceiros usuários de drogas, torna-se imprescindível o questionamento desse hábito durante a anamnese do casal, tanto para que se faça uma investigação das causas da infertilidade -e se o uso de drogas influencia - quanto para que se oriente o quanto o uso de drogas - ou o convívio com quem usa - pode influenciar no bom andamento da gestação.

Descritores: Drogas ilícitas, Infertilidade, Reprodução, Doenças transmissíveis.

\section{7}

Oficina do lanche saudável: avaliação de hábitos alimentares na adolescência

\section{Melo LRC, Lucca NS, Melo PM, Cintra RMB, Reato LFN}

Introdução: A afirmação plena do potencial de crescimento e desenvolvimento com qualidade de vida e cidadania depende da alimentação e nutrição como requisitos básicos para a promoção e proteção da saúde. As diversas mudanças ocorridas na adolescência também estão associadas a novas escolhas alimentares que podem tornar os jovens vulneráveis a uma série de agravos nutricionais. Estudos sobre a nutrição de adolescentes indicam o consumo excessivo de alimentos de alto teor calórico e fácil preparo, apesar da ampla disponibilidade de alimentos saudáveis. Objetivo: Avaliar hábito alimentar, preferências e aversõe alimentares de adolescentes participantes da Feira de Saúde da região do grande ABC. Método: O estudo de caráter quantitativo foi realizado com 67 adolescentes em que foi aplicado um questionário com 22 questões que abordam: estrutura familiar; quantidade, qualidade e frequiência das refeições realizadas durante o dia. Resultados: Observou-se o déficit de macro e micronutrientes e vitaminas devido ao baixo consumo de frutas e vegetais e o grande aporte calórico decorrente do consumo freqüente de refrigerantes e frituras. A escola foi local onde houve maior consumo de alimentos inadequados devido à permanência prolongada do jovem no ambiente escolar. Conclusão: Para corrigir tais erros na alimentação é de extrema importância que seja instituída uma reeducação alimentar aliando a equipe multiprofissional de atendimento ao adolescente a família e a escola visando à formação de hábitos alimentares saudáveis prevenindo assim inúmeras comorbidades.

Descritores: Adolescentes, Hábitos saudáveis, Comorbidades relacionadas à alimentação, Equipe multidisciplinar de atendimento ao adolescente.

\section{QC Percepção dos agentes comunitários de saúde do programa de Saúde da Família sobre a violência contra a mulher}

\section{Melo LRC, Conchão S}

Introdução: Segundo a Lei Maria da Penha, configura como violência doméstica qualquer tipo de ato hostil que ocorre no âmbito doméstico e entre indivíduos unidos por laços naturais, por afinidade ou po vontade.Sendo o serviço de saúde a principal porta de entrada para essas vitimas, pode-se considerá-lo umas das armas mais importantes no diagnostico da violência contra mulher.Como o agente comunitário de saúde(ACS) é o que tem maior contato direto com as famílias,é mais fácil que eles façam a identificação primaria dos casos. Objetivo: Identificar problemas encontrados pelos ACSs no reconhecimento e encaminhamento de casos de violência doméstica contra a mulher e indicar melhorias para estas ações. Método: Trata-se de um estudo quantitativo e qualitativo com 24 ACSs de 2 unidades de saúde vinculadas ao Programa Saúde da Família, localizadas em Santo André (SP).Entrevistas semi-estruturadas foram conduzidas, as quais continham questões referentes à percepção dos ACS sobre os tipos de violência, conseqüências dessa e fatores determinantes para identificação e condução dos casos de agressão contra a mulher, além de analisar seu ponto de vista sobre quais são as dificuldades do sistema de saúde em atuar e intervir nesses casos. Resultados: A análise dos resultados demonstrou que a maioria dos agentes consegue identificar os atos violentos, porém encontram empecilhos na hora de colocar seus conhecimentos em pratica, por parte da vítima ou por sua insegurança. Conclusão: Por fim, se constatou a necessidade de ter um programa de aperfeiçoamento do ACS e campanhas informativas para a população.

Descritores: Violência doméstica contra mulher, Agentes comunitários de saúde do Programa de Saúde da Família, Lei Maria da Penha, Epidemia silenciosa.

\section{6 \\ Obesidade infantil e determinantes alimentares no tempo de permanência dos estudantes nas escolas públicas estaduais do município de Santo André, Estado de São Paulo}

Menezes SG, Zanellato RM, Kakumoto MH, Balderi TZ, Marino MAZ

Introdução: Obesidade infantil é considerada, atualmente, verdadeira epidemia mundial, e no Brasil, houve aumento da prevalência de $4,1 \%$ para $13,9 \%$ nos adolescentes. Objetivo: verificar se a permanência em período integral dos estudantes de escolas públicas estaduais, exerce influência nos hábitos alimentares e sua relação com a incidência de obesidade. Método: foram avaliados 5652 estudantes entre março de 2007 e maio de 2011 de sete escolas públicas estaduais no Município de Santo André, SP, de ambos os sexos, de 11 a 17 anos, através do peso $(\mathrm{Kg})$ e altura $(\mathrm{m})$. O índice de massa corporal (IMC $=\mathrm{Kg} / \mathrm{m} 2)$ com percentis (PIMC) fo classificado de acordo com a idade e sexo, a partir do padrão de referência da National Center Health Statistic in colaboration with the National Center for Chronic Disease Prevention and Health Promotion 2000, e PIMC \&\#8805; 95 considerado obesidade. As escolas foram classificadas como A, B, C, D, E, F e G, sendo quatro $(\mathrm{A}, \mathrm{B}, \mathrm{C}$ e E) com dois períodos, das 7:00h às 12:00h e das 13:00h às 17:00h, e três $(\mathrm{D}, \mathrm{F}$ e G) das 7:00h às 17:00h. Resultados: dos 5652 estudantes, observamos obesidade nos períodos matutino e vespertino respectivamente nas escolas: A (21,63\% e 23,36\%); B (16,09\% e 14,09\%); C (12,03\% e 15,07\%); E (17,05\% e $18,04 \%)$ e nas escolas: D (2,78\%); $F(2,66 \%) ; G(2,99 \%)$. Não observamos diferenças significativas entre os períodos matutino e vespertino $(p>0,85)$. Observamos diferenças significativas $(p<0,01)$ entre as escolas de período integral e as de meio período. Conclusão: Os hábitos alimentares saudáveis orientados e realizado durante o período escolar integral, podem diminuir a incidência da obesidade, prevenindo as co-morbidades associadas, e a reeducação alimentar deve ser compartilhada com todos os integrantes da família.

Descritores: Adolescentes, Estudantes, Obesidade, Santo André.

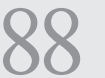

Percepção da Medicina não tradicional, alternativa ou complementar por estudantes de Medicina

\section{Cudizizio FFP, Machado MP, Baldassin SP}

Introdução: Segundo a literatura, há um aumento da procura dos pacientes por práticas como acupuntura, homeopatia e fitoterapia por destaque dessas na relação médico-paciente. O ensino dessas práticas na graduação gera polêmica. Objetivo: avaliar a percepção do estudante de medicina sobre seu preparo para lidar com homeopatia, acupuntura e fitoterapia. Método: Estudo transversal, multicêntrico. Instrumento: questionário, com 35 perguntas, aplicado a alunos do curso de Medicina do primeiro, terceiro e sexto ano da FMABC, Unifesp e Santa Casa. Resultados: Participaram do estudo 714 estudantes, 248 do primeiro, 248 do segundo e 218 do sexto ano. Desses $93 \%$ considera importante saber explicar ao paciente sobre acupuntura, $87 \%$ sobre homeopatia e fitoterapia, porém apenas $22 \%$, $15 \%$ e $9 \%$ se sentem seguros para tal, respectivamente. Há prejuízo na relação médico paciente para $53 \%$, caso o médico não tenha conhecimento sobre o tema, $75 \%$ acha que poderia perder pacientes. $26 \%$ referiu ter tido mais de uma aula sobre medicina alternativa. $57 \%$ afirma ter ouvido depreciaçõe por professores sobre homeopatia. $81 \%$ gostaria de ter os temas no currículo e $80 \%$ indicaria as técnicas as seus pacientes, sobretudo acupuntura (78\%). Justificando a não inclusão das técnicas no currículo básico se destacam 38\% que acredita que acupuntura não tem espaço na grade curricular; $61 \%$ e $45 \%$ que acreditam que a homeopatia e fitoterapia têm carência de comprovação cientifica. Quanto à função da acupuntura $6 \%$ acha que esta nunca deve substituir a medicina tradicional contra $32 \%$ da homeopatia e $25 \%$ da fitoterapia. Conclusão: Estudantes não se sentem seguros para lidar com dúvidas sobre medicina alternativa, consideram o tema importante e gostariam de ter mais acesso a este.

Descritores: Acupuntura, Homeopatia, Fitoterapia, Estudantes.

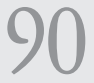

Prevalência das afecções oftalmopediátricas com tratamento cirúrgico no Serviço de Oftalmopediatria da Faculdade de Medicina do ABC

\section{Mota RT, Pachon S, Toloi GC, Lima LP, Hamermesz B, Gomes MLR, Salomão GHA}

Introdução: Atualmente, há cerca de 1,4 milhões de cegos no mundo que apresentam menos de quinze anos de idade, sendo que, $70-80 \%$ das crianças cegas morrem durante os primeiros anos de vida em consequência de doenças associadas ao comprometimento visual. Objetivo: Estabelecer a prevalência das afecções oculare com tratamento cirúrgico em crianças no Serviço de Oftalmopediatria da Faculdade de Medicina do ABC nos anos de 2010 e 2011. Método: Estudo retrospectivo no qual foram inclú́dos os pacientes submetidos à cirurgia oftalmológica no Hospital Estadual Mario Covas no período compreendido entre janeiro de 2010 e maio de 2011. Resultados: Foram submetidas à internação para procedimento oftalmológico no período referido 123 crianças, e destas, 27 (21,95\%) foram examinadas sob sedação pela necessidade de um exam minucioso, impossível de se realizar em consultório. A cirurgia de maior prevalência foi a correção do estrabismo, correspondendo a 40 casos $(32,52 \%)$, seguida da cirurgia para remoção da catarata com 18 casos $(14,63 \%)$. Do restante, 15 crianças $(12,20 \%)$ foram operadas por quadro de glaucoma do desenvolvimento, $9(7,31 \%)$ foram vitrectomizadas por diversas causas de retinopatias e $5(4 \%)$ que apresentavam quadro de retinopatia da prematuridade com risco de descolamento de retina foram fotocoaguladas. O implante secundário de lente intraocular (LIO) foi realizado em $5(4 \%)$ crianças que tiveram a remoção do cristalino pela técnica de lensectomia sem implante de LIO e 3 (2,4\%) olhos de duas crianças foram enucleados pela presença de retinoblastoma. Conclusão: Os dados encontrados são compatíveis com os encontrados na literatura médica, com maior prevalência dos casos de estrabismo e menor de tumores intraoculares entre as crianças.

Descritores: Procedimentos cirúrgicos oftalmológicos/estatística \& dados numéricos, Criança, Oftalmopatias/tratamento, Cegueira/prevenção \& controle. 


\section{Q 1 Prevalência das infecções virais em casais atendidos no Centro de Reprodução Assistida em Situações Especiais da FMABC - CRASE}

Menezes SG, Brandes A, Teles JS, Lerner TG, Bianco B, Christofolini DM, Barbosa CP, Carvalho WAP

Introdução: O Centro de Reprodução Assistida em Situações Especiais (CRASE) atende casais portadores de doenças infecciosas que tomam a decisão de engravidar, mas para que seja uma gestação segura, procuram a reprodução assistida. Verificou-se que grande parte dos casais são portadores de doenças virais. Objetivo: $O$ objetivo desse estudo foi verificar a prevalência das infecções virais nos casais atendidos, verificar quais são os vírus mais prevalentes entre os homens e as mulheres. Método: Foram analisados retrospectivamente 133 prontuários de casais atendidos em nosso serviço, verificando a prevalência de HIV, hepatite B, hepatite C, HTLV, HPV e as co-infeções entre estes vírus. Resultados: Entre as mulheres, $37,6 \%$ são portadoras de alguma doença viral. Destas, $43,5 \%$ referiram possuir HIV, $13,4 \%$ hepatite B, $20 \%$ hepatite C, 3,3\% referiram HTLV 1 ou 2 e 3,3\% referiram HPV. Na análise dos dados masculinos, $69,9 \%$ eram portadores de doenças virais. Destes, $60 \%$ possui HIV, $18,2 \%$ hepatite B, $12,7 \%$ hepatite C, 5,5\% HIV e hepatite C e 1,8\% HTLV e hepatite C. Conclusão: O HIV é a maior infecção viral tanto em homens quanto em mulheres entre os casais que necessitam de reprodução assistida por terem alguma doença infecciosa. Chamam atenção os altos índices de hepatite B - doença passível de prevenção po vacina - e de hepatite C. Além disso, é surpreendente a baixa prevalência de HPV nesses casais, o que talvez seja explicado pela alta incidência de HPV subclínico.

Descritores: Fertilidade, Reprodução, Doenças transmissíveis, Viroses.

\section{Q Prevalência do câncer em dois serviços públicos atendidos pela Faculdade de Medicina da Fundação ABC (FMABC)}

Oliveira MM, Lera AT, Lerner TG, Guariento RT, Giglio ABD, Barbosa RP, Cubero D, Giglio AD

Introdução: $O$ câncer é uma patologia cada vez mais prevalente no Brasil e atualmente representa a segunda causa de mortalidade no país. A população do Grande $\mathrm{ABC}$ conta com dois serviços públicos terciário para cuidados oncológicos, ambos coordenados pela Disciplina de Oncologia da FMABC: Hospital Mário Covas e o Hospital de Ensino Anchieta (CACON). Objetivo: Analisar as características dos pacientes que freqüentam os serviços de Oncologia da FMABC e comparar com as estatísticas nacionais e da região. Método: Um levantamento conduzido de 14/9/2010 a 18/5/2011 nos ambulatórios de oncologia dos dois supramencionados serviços tabulou de forma sistemática as características clínicas dos pacientes presentemente atendidos. Resultados: Do total de 2367 pacientes avaliados, $60 \%$ eram oriundos do Hospital Mário Covas, 63\% eram mulheres, com idade média de 60,25 (12-105) anos. Os tumores mais prevalentes foram: mama (44\%), colorretal (22\%), próstata (15\%), Linfoma não Hodgkin (8\%) e estômago (5\%). Do total de pacientes (excetuando-se Linfoma não Hodgkin), 15,3\% apresentaram metástase no momento da sua inclusão. Conclusão: Em comparação com os dados do INCA para o Brasil e Região Sudeste de 2010 nosso serviço apresenta significativamente mais casos de câncer de mama (44\% FMABC versus 13\% Brasil e $13,6 \%$ Sudeste) e menor número de casos de câncer de pulmão (2,5\% FMABC versus 7,36\% Brasil e $6,7 \%$ Sudeste). Volumes diferentes de cirurgias oncológicas nos diversos serviços de referência de nossa instituição, assim como maior intensidade de medidas preventivas para câncer de mama podem explicar parte das diferenças observadas. Não podemos excluir, todavia, fatores epidemiológicos específicos regionais para explicar a alta prevalência de câncer de mama na região do $\mathrm{ABC}$.

Descritores: Câncer, Epidemiologia do câncer, Câncer de pulmão, Câncer de mama.

\section{Crostituição $\mathrm{x}$ violência doméstica: análise do histórico de vida das profissionais do sexo em Santo André}

\section{Goulart LFVV, Bertoldo BF, Cabral FHR, Alencar MS, Nicolau RN, Vitoria WO, Conchão S}

Introdução: Trata-se de uma pesquisa extremamente interessante do ponto de vida social e humano, pois aborda um tema inédito e velado perante toda a sociedade brasileira. O objeto de estudo da pesquisa são mulheres que, por motivos diversos, optaram por ingressar na profissão do sexo. Objetivo: $\mathrm{O}$ objetivo principal desse trabalho é a investigação sobre a vida das mulheres profissionais do sexo, procurando por um possível histórico de violência doméstica, focando as que atuam no município de Santo André no ABC Paulista. Método: A pesquisa foi feita através de um roteiro de perguntas elaboradas pelos próprios pesquisadores que serviu como base para uma conversa realizada com as profissionais do sexo, mulheres, com mais de 18 anos e que já atuam há algum tempo. Resultados: Analisamos várias questões dentre elas a não regulamentação desta profissão em nosso país. A maioria das mulheres entrevistadas relatou ter sofrido algum tipo de violência doméstica dentre as enumeradas pelo grupo. Apesar de negarem inicialmente, com o decorrer da conversa, elas admitiam e revelavam ter sofrido um tipo de violência doméstica. Conclusão: Concluímos que apesar de todas as dificuldades de obtenção de dados pudemos confirmar a nossa hipótese. A violência doméstica está presente no histórico de vida das profissionais do sexo entrevistadas. Podemos dizer que a presença de um histórico de violência doméstica influencia na procura por esta profissão.

Descritores: Prostituição, Violência doméstica, Histórico de vida, Profissionais do sexo. Santo André

Ferreira GF, Bisson G, Carvalho FL, Bianchi RM, Astolfi AH, Fernandes HPA, Monteiro MIC, Barrôco RS Introdução: A análise da impressão plantar é útil para identificar as variedades dos pés existentes e seus arcos fisiológicos, de modo que é conhecida a relação entre o equilíbrio e o alinhamento de várias articulações. Objetivo: Verificar e avaliar a prevalência de pé plano associada as características físicas, hábitos e comorbidades. Método: Os autores avaliam 142 adultos da população geral de ambos os sexos participantes da Feira de Saúde de Santo André em 2009. A medida do pé plano foi feita a partir do cálculo algébrico do índice do arco plantar (IP) e seu valor limite. Este índice estabele uma relação entre a região central e posterior da impressão. Resultados: A prevalência de pé plano ficou em $4.9 \%$, sendo que não houve diferença entre os pés esquerdo e direito, entre os sexos, e entre os grupos etários. Não se provou relação entre pé plano e IMC, tabagismo, etilismo, tipo de calçado e dor em membro inferior. Conclusão: $\mathrm{O}$ índice do arco plantar (IP) é uma medida simples e variável segundo a população estudada, não existindo diferença estatística entre os sexos, e faixas etárias, e que o valor médio do índice do arco plantar (IP) foi 0.71 , sendo acima de 0.85 devem ser considerados como indicativos de pé plano.

Descritores: Pé plano, Adulto, Avaliação, Antropometria.

\section{Brito GM, Lera AT, Lerner TG, Borba TM, Aževedo RGS, Cordeiro RA, Cubero D, Giglio AD}

Introdução: A assistência oncológica está hoje entre as mais dispendiosas, contribuindo com custos diretos, por meio de exames preventivos, testes diagnósticos e tratamentos, além de custos indiretos, decorrentes da incapacidade produtiva do doente e da morbi-mortalidade da doença. A prevenção primária (PP) do câncer consiste na limitação da exposição a agentes causais ou fatores de riscos como o fumo, sedentarismo, vírus e exposição solar. Objetivo: Revisar sistematicamente a literatura e descrever características de estudos que tenham investigado a relação entre PP e custos sociais ou econômicos do câncer, identificando os tipos de câncer para os quais existem medidas de PP, e comparar os resultados aos dados de prevalência de câncer em dois serviços públicos de oncologia atendidos pela FMABC. Método: Foram analisadas publicações nas bases MEDLINE (PubMed) e LILACS (BVS), a partir dos descritores MeSH/DeCS: Primary Prevention, Neoplasms e Costs and Cost Analysis, uscando-se artigos em espanhol, inglês ou português publicados nos últimos dez anos. Levantamento prévio conduzido nos ambulatórios de oncologia do Hospital Mário Covas e do Hospital de Ensino Anchieta computou as características clínicas dos pacientes presentemente atendidos de $09 / 2010$ a 05/2011. Resultados: Do total de 118 artigos, $63,6 \%$ tratavam de câncer de colo de útero e $55 \%$ tinham como país de origem os Estados Unidos. Analisado o perfil epidemiológico do câncer em nosso serviço, observou-se que para $28,9 \%$ do total de 2367 pacientes existiriam medidas de PP que poderiam ter sido empregadas. Conclusão: Poucos artigos na última década investigaram a relação entre custos e prevenção primária do câncer. A maioria avaliou custos e benefícios da vacinação contra HPV na PP de câncer de colo de útero.

Descritores: Prevenção primária, Câncer, Custos e análise de custo, Epidemiologia.

\section{Q Qualidade da informação na internet disponível para pacientes em páginas em português em relação à diabetes mellitus, hipertensão arterial e infarto agudo do miocárdio}

Giglio ABD, Gomiero FPR, Matsubayashi CO, Amado DK, Abdalla BMZ, Shiroma MARDV, Giglio AD

Introdução: É cada vez mais comum que os pacientes e seus familiares procurem na internet informações a respeito de suas doenças. Diabetes Mellitus (DM), Hipertensão Arterial Sistêmica (HAS) e Infarto Agudo do Miocardio (IAM) são muito comuns na população brasileira, desta forma estas comorbidades são bastante procuradas na internet. Objetivo: Tivemos como objetivo avaliar a qualidade da informação em relação a estas doenças disponíveis em Português. Método: Selecionamos as primeiras 20 (vinte) páginas escritas em português para cada uma das doenças escolhidas, através da página de busca do Google. Como ferramentas para avaliar a qualidade da informação foram utilizadas o DISCERN Questionnarie (DQ) e o Health on the Net (HON). Para saber se as informações eram adequadas utilizamos as diretrizes brasileiras e internacionais para as diferentes comorbidades. Resultados: Ao avaliar o conteúdo das informações disponíveis, $45 \%, 95 \%, 85 \%$ das páginas continham a definição de DM, HAS e IAM, respectivamente. Em relação ao diagnóstico e tratamento, somente $25 \%$ das páginas das 3 (três) comorbidades possuíam esta informação específica. Somente $15 \%, 20 \%$ e $10 \%$ das páginas tinham a certificação pelo HON, respectivamente. Em função do DQ as páginas obtiveram notas maiores que $50 \%$ em $70 \%$ das páginas de DM, $65 \%$ de HAS e 55\% de IAM. Conclusão: A informação disponível na internet sobre as três comorbidades escolhidas (DM, HAS e IAM), em português, é frequentemente inadequada e insuficiente. Os médicos devem orientar seus pacientes de forma adequada para que suas dúvidas sejam atendidas e que eles saibam buscar outros eventuais questionamentos em páginas de qualidade.

Descritores: Internet, Qualidade da informação, Informação em saúde, Doenças prevalentes. 

pacientes atendidos no Ambulatório de Neurologia Vascular da FMABC

Tae B, Kuster GW

Introdução: $\mathrm{O}$ acidente vascular cerebral (AVC) é a primeira causa de mortalidade e morbidade no Brasil a terceira causa de mortalidade no mundo, e está relacionado com importante limitação funcional e prejuízo nas relações sociais. $\mathrm{O}$ ambulatório de neurologia vascular da Faculdade de Medicina do ABC atende pacientes da região visando estudar e adequar as medidas de tratamento das doenças cerebrovasculares aplicadas a esta população. Objetivo: O presente estudo visa caracterizar clínica e demograficamente os pacientes atendidos por este serviço nos anos de 2010 e 2011. Método: Foi realizado estudo retrospectivo descritivo de 111 pacientes, através de levantamento de dados clínicos e epidemiológicos presentes em prontuários. Resultados: Foi observado que dos 111 pacientes atendidos a média de idade era de 56,19 anos ( $\mathrm{dp} \pm 16,05)$, destes $58(52,25 \%)$ eram mulheres e $53(47,75 \%)$ eram homens. $78,38 \%$ dos pacientes eram hipertensos, $23,42 \%$ diabéticos, $27,03 \%$ dislipidêmicos, $36,94 \%$ tabagistas, $21,62 \%$ etilistas, $13,51 \%$ obesos, $84,68 \%$ sedentários, $10,81 \%$ possuíam fibrilação atrial, $83,78 \%$ tiveram um AVCi e $10,81 \% \mathrm{AVCh}$ Conclusão: Verificou-se que a população atendida no ambulatório da FMABC é de forma geral a população com maior presença de fatores de risco para o AVCi: mulheres, $>50$ anos, sedentários e hipertensos, evidenciando uma falha na detecção e tratamento precoce dos determinantes do AVC, já bem estabelecidos internacionalmente.

Descritores: AVC, Fatores de risco, Epidemiologia, Doenças cerebrovasculares.

\section{9}

Sondagem da prevalência de distúrbios neurobiológicos em crianças com desempenho escolar comprometido

\section{Barletta HM, Pedroso C, Bereta BD, Mattos LM, Bejerra DF}

Introdução: Diversos fatores influenciam no desempenho escolar de uma criança, entre eles os emocionais, os ambientais e também os neurobiológicos. Com a disseminação da informação, é cada vez mais comum ouvirmos de professores e pais que suas crianças têm um desempenho escolar insatisfatório por serem hiperativas ou disléxicas, por exemplo, ainda que, em grande parte dos casos, seus problemas sejan puramente fruto do espírito desatento e bagunceiro variável de criança a criança. Objetivo: O presente trabalho teve por objetivo sondar quantas das crianças apontadas pela escola como tendo distúrbios de aprendizagem realmente apresentavam alterações biológicas que os justificassem. Método: Participaram do estudo 67 alunos de uma escola situada no município de São Bernardo do Campo - SP e considerados pela coordenação da escola crianças com dificuldades de aprendizagem. A eles foram aplicados o YSR (Inventário de Auto-Avaliação para idade de 11-18 anos), teste de Snellen, um questionário aos pais (sondando possíveis problemas visuais ou auditivos das crianças) e atividades para avaliação do nível de aprendizado nas diferentes matérias escolares. Houve posterior tabulação e análise dos dados obtidos. Resultados: A maior parte dos alunos não apresentava distúrbios neurobiológicos, mas sim comportamentais, e houve um hiato entre o número de crianças que apresentavam dificuldades visuais as que faziam acompanhamento oftalmológico. Conclusão: $\mathrm{O}$ estudo mostrou que a abordagem de uma criança com mau desempenho escolar deve ser multifatorial e multidisciplinar, e que, por isso, crianças que aparentemente têm dificuldade de aprendizagem devem ter uma avaliação de maneira integral, levando em consideração, além da dificuldade em si, os fatores sociais, familiares e etc.

Descritores: Dificuldade Escolar, Crianças, Adolescentes, Aprendizagem.

\section{Uso da vitamina e na profilaxia de neuropatia periférica induzida pela oxaliplatina: estudo piloto de fase II}

\section{Okawara M, Lera AT, Lerner TG, Rodrigues NP, Souza LF, Cruz FM, Afonseca SO, Giglio AD}

Introdução: A oxaliplatina é um dos quimioterápicos mais utilizados no tratamento do câncer colorretal. É um composto derivado da cisplatina e tem como toxicidade limitante a neuropatia periférica. Grande parte dos pacientes apresentam parestesias e disestesias em extremidades e peri-orais, que freqüentemente levam à suspensão do tratamento. Estudos evidenciaram redução de $50 \%$ na incidência de neuropatia em pacientes tratados com cisplatina que fizeram reposição oral profilática de vitamina E. Objetivo: Avaliar o uso da vitamina E na profilaxia da neuropatia periférica induzida pela oxaliplatina. Método: Foram incluídos 38 pacientes no estudo, aleatoriamente randomizados para receber Vitamina E ou placebo por 5 dias antes do início do tratamento com oxaliplatina e até o término do regime de quimioterapia. A avaliação do desfecho foi realizada pela escala de neurotoxicidade dos Critérios Comuns de Toxicidade do Câncer (CTCAE). Estudo eletrofisiológico de superfície (sem agulhamento) avaliou neuropatia sensorial antes e após dois ciclos da quimioterapia. Resultados: Quatro pacientes foram excluídos por dificuldades de contato. Dos 34 pacientes que completaram o estudo, 18 pertenciam ao grupo da vitamina E, enquant que 16 pertenciam ao grupo placebo. Observou-se incidência cumulativa de $83 \%$ das classes I / II de neuropatia periférica no grupo da vitamina $\mathrm{E}$, contra $68 \%$ no grupo placebo $(\mathrm{p}=0,45)$. Observou-se maior tendência à diarréia em pacientes que receberam vitamina $\mathrm{E}(55,6 \%$ versus $18,8 \%, \mathrm{p}=0,06)$. Não houve outras diferenças significativas quanto às toxicidades entre os grupos. Conclusão: Não foi demonstrada diminuição significativa na incidência de neuropatia periférica aguda induzida por oxaliplatina, com o uso de vitamina $\mathrm{E}$.

Descritores: Vitamina E, Neuropatia, Quimioterapia, Câncer.
Síndrome metabólica em adolescentes em Serviço de Ambulatório Didático

\section{Zlochersky AM, Job ACG, Job LCG, Hirata AM}

Objetivo: Avaliar prevalência de Síndrome Metabólica (SM) em adolescentes (ADC). Método: Estudo retrospectivo de 159 ADC do Ambulatório de ADC do CSE-Capuava, SA, SP, BR em 2009. Selecionados ADC com índice de massa corpórea (IMC) Z score $>1$. Excluídos ADC com síndrome genética, obesidade de causa 2ária, Diabetes Mellitus (DM) e medicamento que modifique pressão arterial (PA), glicemia ou lípides. Coletados: idade, sexo, IMC, PA, glicemia de jejum (GJ), insulina basal (IB), triglicérides e HDL colesterol. SM, segundo critério do Instituto da Criança HC-FMUSP, foi considerada quando $\geq 3$ critérios estavam presentes: IMC Z score $>2$; GJ $>100 \mathrm{mg} / \mathrm{dL}$ ou relação GJ/IB p95; HDL 100mg/ dL. ADC foram divididos em 2 grupos (sobrepeso e obesidade) de acordo com IMC Z score. Avaliadas diferenças entre os grupos por teste t e associação entre variáveis por teste qui-quadrado/teste Fisher. Avaliada associação entre IMC e SM por coeficiente de Pearson. Nível de significância estatístico: 5\%. Resultados: SM prevaleceu em 57\% dos ADC obesos e 22\% dos ADC com sobrepeso. 76\% dos ADC com SM apresentaram resistência insulínica (RI), 52\% triglicérides elevado e 48\% HDL alterado. Conclusão: Os resultados demonstram alta prevalência de SM nos 2 grupos, principalmente nos obesos, valor superior ao encontrado na literatura ( $40 \%$ em ADC obesos, $4 \%$ em ADC sobrepeso). Demonstrado que quanto maio a RI, mais prevalente SM, fatores de risco cardiovasculares, desenvolvimento prematuro de DM tipo $2 \mathrm{e}$ doença cérebro-vascular. Apesar de não haver critério diagnóstico definitivo, pode-se determinar ADC de risco para SM com simples exames clínicos e laboratoriais e promover intervenção individualizada, juntamente com mudança no estilo de vida dos ADC.

Descritores: Síndrome metabólica, Adolescente, Obesidade, Sobrepeso.

\section{Trabalho de parto prematuro: casos do Hospital Municipal Universitário de São Bernardo do Campo x dados da literatura}

Vaccari NL, Job ACG, Job LCG, Silva RPS

Introdução: Nascimento pré termo, assim definido por ocorrer com menos de 37 semanas (259 dias) de idade gestacional, é responsável por maior morbimortalidade neonatal quando comparado aos nascidos termo Morbidades que se estendem à vida adulta, resultando em custos físicos, sociais e econômicos. As taxas de nascimentos pré termo estão em crescimento, apesar dos conhecimentos avançados sobre fatores de risco, mecanismos de trabalho de parto prematuro (TPP) e da introdução de políticas de saúde pública e intervençõe médicas. A etiologia do TPP é multifatorial. Os fatores contribuintes para o aumento dos nascimentos pré termo incluem: maiores taxas de gestações múltiplas, aumento do uso de técnicas de reprodução assistida, da proporção de parturientes acima dos 34 anos de idade e do parto cesárea eletivo. Objetivo: Expor os dados encontrados em cada caso de TPP ocorrido no Hospital Municipal Universitário de São Bernardo do Campo (HMU-SBC) no período estudado e compará-los com dados existentes na literatura. Método: Foram examinados 52 prontuário e realizadas entrevistas com puérperas internadas no HMU-SBC, no período de agosto a outubro de 2010 cuja gestação fora interrompida antes de 37 semanas. Resultados: O estudo revelou taxa de 5,8\% de casos de prematuridade no HMU-SBC no período analisado, próximo ao valor de prevalência no Brasil em 2006 (6,5\%). Semelhante, também, 'as taxas de nascimento prematuro no mundo desenvolvido (5\% a 15\%). Em 75\% dos casos os nascimentos prematuros são espontâneos, nos demais são resultantes de indicação médica, o que está de acordo com os achados deste trabalho. Conclusão: $O$ presente estudo expôs os dados encontrados em cada caso de TPP ocorrido no HMU-SBC no período estudado e os comparou com os dados existentes na literatura.

Descritores: Nascimento prematuro, Trabalho de parto pré-termo, Trabalho de parto prematuro, Prematuridade. estudantes de medicina brasileiros de 2001 a 2006

\section{Machado MP, Alves TCTF}

Introdução: Muitos estudos revelam uma alta prevalência de sintomas depressivos em estudantes de medicina durante a graduação em comparação a população geral e isso tem sido atribuído a fatore ambientais, tais como estresse e dificuldades inerentes ao curso médico. Apesar disso, ainda não existe un consenso sobre qual a época de maior estresse, tampouco sobre os fatores etiológicos e desencadeantes tendo alguns estudos mostrado dados discordantes em relação a outros. Objetivo: analisar a variação de sintoma depressivos entre estudantes de medicina durante um período de seis anos e os possíveis fatores associados, tais como trotes e atividades sociais. Método: fase quantitativa - teste do qui-quadrado e modelos de regressão logística foram usados para examinar as diferenças nos escores de Depressão de Beck em todos os ciclos da escola médica (básico, intermediário e internato), entre 2001 e 2006 ( $n=732$ ), estratificados po grupos de gênero e idade. Fase qualitativa - Quatro informantes-chave, pessoas que tiveram importantes funç̃oes acadêmicas e que representam diferentes grupos sociais entre 2001 e 2006, foram entrevistados para a busca de informações relevantes sobre mudanças no ambiente durante esse período. Resultados: Os estudantes do sexo masculino que cursavam o ciclo básico em 2006 apresentaram uma tendência de aumento dos sintomas depressivos em comparação aos do mesmo sexo do ciclo básico de 2001 (OR = 7,36 [IC 95\% =0,85-63,5], $\mathrm{p}=0,07)$. Conclusão: $\mathrm{O}$ aumento do trote e o declínio da participação dos alunos nas atividades sociais durante a curso médico podem influenciar no aumento de sintomas depressivos em estudantes do sexo masculino dos primeiro e segundo anos do curso de Medicina.

Descritores: Depressão, Estudante de Medicina, O trote, Envolvimento social. 


\section{Monografia}

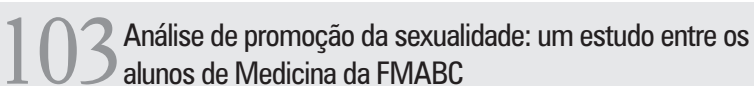

Blumetti AMC, Fonseca ABF, Carneiro CEL, Jeremias EG, Romero $M C$, Akerman $M$

Introdução: A promoção da sexualidade tem como objetivos conseguir com que uma pessoa tome decisõe autônomas sobre suas atividades sexuais e fazer com que ela manifeste sua identidade sexual de forma plena. Objetivo: Este trabalho visa identificar a quais estratégias de promoção da sexualidade (como mídia, familia, religião, saúde) os alunos da FMABC foram submetidos bem como a maneira que estes meios influenciam seu desenvolvimento. Método: A partir da realização de um questionário piloto (elaborado pelas autoras a partir de modelos efetivos) com dez estudantes, o projeto foi enviado e aprovado pelo Comitê de Ética da FMABC. Este foi então ampliado par 50 indivíduos de cada sexo, visando avaliar as possíveis diferenç̧as no desenvolvimento da sexualidade por gênero. Resultados: Foi verificado que a religião dos estudantes não influencia nas escolhas tomadas em relação ao assunto. Grande parte da amostra não tem restrições quanto à temática sexo em casa, inclusive muitos obtiveram informações a partir de suas familias, sendo que esta é a principal fonte de informação ao lado da escola. Estas são informativas, porém falhas uma vez que as únicas pessoas do estudo que usam a pílula do dia seguinte ou coito interrompido foram orientadas por tais meios. Observa-se também que as mulheres frequentam mais o médico e esclarecem mais sua dúvidas do que os homens. Apenas uma pequena parcela diz ter se informado com o parceiro. Conclusão: Conclui-se que os principais meios de promoção da sexualidade durante o desenvolvimento dos estudantes que responderam o questionário foram: escola, família e amigos. Também foram importantes o médico para as mulheres, e a televisão para os homens, contribuindo entre outros fatores para uma diferença na promoção da sexualidade entre os gêneros.

Descritores: Promoção da sexualidade, Estudantes da FMABC, Agentes de promoção à saúde, Diferenças de gênero.

\section{Consequências individuais e coletivas da apnéia obstrutiva do sono: revisão da literatura}

\section{Neto LCS, Strufaldi VP, Canto BES, Cunha LLG, Matos LI}

Introdução: A apnéia obstrutiva do sono (AOS) é definida como a obstrução da passagem de ar pelas via aéreas superiores durante o sono. Assim,o paciente apresenta episódios repetidos de hipoxemia e hipercapnia, e com eles o sono torna-se superficial e fragmentado, resultando em complicações para o indivíduo e para a coletividade. Objetivo: Realizar revisão da literatura quanto às consequências individuais, econômicas e sociais causadas pela AOS. Método: Revisão de literatura de artigos publicados nas bases de dados Lilacs e Medline. Resultados: Identificaram-se diversas complicações da AOS relacionadas ao indivíduo: (1) alterações físicas e comportamentais: sono excessivo, fadiga, ansiedade, irritabilidade, depressão, redução da libido, diminuição da qualidade de vida, astenia, e consequências metabólicas (ganho de peso, diabetes e dislipidemia) e cardiovasculares (hipertensão arterial sistêmica, aterosclerose e doença coronariana); (2) disfunção cognitiva: déficits de atenção, percepção, memória, raciocínio, juízo, pensamento e linguagem. Em relação à AOS e repercussões socioeconômicas, tem-se: (1) aumento do número, proporção e gravidade de acidentes automobilísticos devido à diminuição da concentração do motorista; (2) prejuízo ocupacional com queda na produtividade, demissões e acidentes de trabalho; (3) prejuízo social:o individuo com AOS representa também um perigo para a sociedade por aumento de imperícias; (4) aumento de gastos públicos e privados:manutenção de rodovias e estrutura de fiscalização e apoio, gastos previdenciários,custos diagnósticos,terapêuticos e hospitalares. Conclusão: A AOS deve ser considerada como uma doença de saúde pública, dados os seus inequívocos prejuízos individuais, sociais e econômicos. Políticas específicas devem ser implementadas visando a redução do impacto dessas consequências.

Descritores: Apnéia, Transtornos do sono, Saúde pública, Revisão.

\section{Vídeo}

\section{Abordagem extraperitoneal pode simplificar a laparoendoscopia por única porta (LESS) na correção de hérnia inguinal associada a ligadura de varicocele}

Longuino LFF, Peixoto GA, Ferreira AACM, Manchini CV, Silva II JL, Silva EG, Pompeu ACL, Machado MT

Introdução: Em algumas condições cirúrgicas urológicas, a hérnia inguinal ocorre concomitantemente e pode ser corrigida no mesmo ato cirúrgico. A correção por LESS desta hérnia é um procedimento novo, em desenvolvimento e poucos relatos descritos. Objetivo: O objetivo deste vídeo é demonstra a técnica extraperitoneal de correção de herniorrafias inguinais e ligadura varicocele através da LESS. Método: Posicionou-se o paciente em litotomia modificada, realizou-se uma incisão de 3,5 centímetro infraumbelical e posterior acesso extraperitoneal. Locou-se o balão de dilatação na aponeurose do músculo reto abdominal. Promoveu-se a locação do afastador percutâneo e da porta de gel com três trocartes convencionais. Após identificação dos pontos de referência,realizou-se a separação do saco herniário do cordão inguinal com instrumentos convencionais. A tela de PTFE foi fixada com grampeador de titâneo pigtail. Resultados: Realizou-se 15 correções de hérnias por LESS em 10 pacientes. Em 2 casos,operou-se uma varicocele concomitante por este acesso no mesmo procedimento.O tempo operatório médio foi de 70 minutos,a média de perda de sangue foi de $70 \mathrm{ml}$ e apenas um caso apresentou seroma periumbelical tratado de forma conservadora.A permanência hospitalar média foi de 22 horas e o tempo médio de recuperação foi de 2,5 semanas. Conclusão: A abordagem do espaço extraperitoneal através da dissecção por balão de dilatação facilitou a dissecação do espaço,a identificação dos pontos de referência e das veias dilatadas dentro do cordão espermático.Além disso,a colocação de tela de PTFE na hernioplastia inguinal por LESS com ligadura da varicocele concomitante é uma excelente alternativa cirúrgica.

Descritores: Laparoendoscopia por Única Porta (LESS), Hérnia Inguinal, Varicocele, Abordagem Extraperitoneal.

\section{$14 \begin{aligned} & \text { Bulindo com a Universidade: um estudo sobre o trote na } \\ & \text { Medicina }\end{aligned}$}

Kharmandayan S, Feo LB, Alencar MS, Conchão S, Akerman M

Introdução: O trote violento considerado um fenômeno social, cultural e histórico, não é especifico de um carreira, e muito menos de uma universidade. No entanto, é curioso notar que o curso de medicina tem despontado ao longo dos anos como sendo um dos mais agressivos. Indagações despertaram e mobilizaram alunos iniciantes do curso de medicina da FMABC em 2010. Posteriormente, o grupo cresceu e passou a contar com a ajuda de alunos do então segundo ano. Objetivo: Aprofundar historicamente na faculdade de Medicina levantando possíveis explicações à submissão dos alunos (as) ao trote abusivo. Método: Realizamos 2 grupos focais, que foram a base para nossas analises e conclusões finais. Resultados: Com base no depoimento dos participantes do grupo focal, percebemos que os principais motivos a submissão ao trote são: desejo de praticar um esporte tanto pela atividade em si como para ser parte de um time, procura por inclusão em um grupo e medo do futuro profissional sem a ajuda dos veteranos. Conclusão: As analises, ainda em curso, dos grupos focais nos permite realizar conclusões preliminares. Os anseios criados pelos alunos antes da faculdade fazem com que eles não vejam a linha tênue entre agressão e brincadeira e por vezes ignorem a própria agressão explicita. A faculdade nesse aspecto pode servir como um microcosmo da juventude do século XX e XXI. Uma juventude focada no $\mathrm{Eu}$, a quem pouco foi passada questões como cidadania, ética e moral. Um grupo que só se reconhece como tal quando fazer parte de um todo lhe traz benefícios. Mesmo que estes sejam futuros.

Descritores: Trote, Bulling, Abuso psicológico, Calouros.

\section{Vaporização fotosseletiva de próstata: revisão de literatura}

Bruniera FR, Pessoa GB, Lara PHS, Kataguiri A, Chiota FL, Golfetti MG, Cabral PRAC, Julio AD

Introdução: A hiperplasia prostática benigna (HPB) apresenta incidência crescente de acordo com a idade, acometendo até $90 \%$ dos homens octagenários. Esta condição caracteriza-se pela restrição de esvaziamento vesical adequado, sendo responsável por sintomas do trato urinário inferior, e podendo evoluir com complicações. O tratamento medicamentoso é indicado para os pacientes com quadro clínico de obstrução infravesical com impacto na qualidade de vida, reservando-se o tratamento cirúrgico para casos refratários ou quando associados a complicações. Objetivo: Comparar os resultados da vaporização fotosseletiva de próstata (VFP) e ressecção transuretral prostática (RTU) para o tratamento da HPB. Método: Realizou-se uma revisão de literatura dos principais artigos publicados. Resultados: A vaporização fotosseletiva de próstata é um método de tratamento endoscópico da HPB, realiza ablação de tecido prostático, apresentando resultados consistentes de melhora do fluxo urinário, diminuição do resíduo pós miccional e melhora dos sintomas, apresentando-se como alternativa factível à ressecção transuretral da próstata. Estudos comparativos demonstram menor morbidade relacionada à vaporização, havendo menor sangramento per-operatório, menor necessidade de irrigação vesical e portanto menor tempo de cateterização vesical e de internação, podendo ser realizada inclusive na vigência de anticoagulação sistêmica. Entretanto, pode levar a maior incidência de sintomas irritativos no pós operatório precoce. Conclusão: As evidências atuais demonstram que a vaporização prostática é uma opção segura à ressecção transuretral da próstata, porém não há estudos com seguimento a longo prazo, demonstrando a manutenção dos seus benefícios ao longo dos anos.

Descritores: Hiperplasia prostática benigna (HPB), Vaporização fotosseletiva de próstata (VFP), Ressecção transuretral prostática (RTU), Próstata.

\section{Artroplastia da articulação trapézio-metacárpica com implante de piocarbono no tratamento da rizartrose - apresentação da técnica cirúrgica}

Longuino LFF, Vanzin AM, Mota RT, Ikeuti DH, Moraes GBB, Gasparotti E, Alves RS, Aita MA

Introdução: A artroplastias de ressecção e interposição no tratamento da rizartrose estão bem estabelecidos e apresenta bons resultados em $85 \%$ dos pacientes. Atualmente, inúmeros implantes e técnicas de substituição da articulação trapézio-metacárpica são desenvolvidas como alternativa no tratamento da rizartrose. Objetivo: Apresentar o procedimento cirúrgico de artroplastia de ressecção da articulação trapézio-metacárpica com a interposição, não cimentada, de uma prótese de piocarbono R (Ascension R). Método: Foram documentadas através de filmagem, a descrição cirúrgica, passo-a-passo, desta técnica de artroplastia. Utilizou-se de máquina filmadora SONY e as imagens obtidas são do procedimento da paciente R.P.L., que assinou o termo de consentimento livre e esclarecido. Resultados: Na avaliação subjetiva da dor (VAS), ocorreu uma redução de 8,75 para 1 na escala utilizada. Com relação a força de prensão, aumentou-se de 2,28 Kgf para 3,4 Kgf após o sexto mês pós-cirúrgico. Neste mesmo período, 0 arco de movimento (abdução e adução palmar) aumentou de 64,45 para 78,75. Aplicou-se o questionário DASH e obteve-se 59,05 no período pré-operatório e 8,68 no pós-operatório. Não houve nenhuma complicação pós-cirúrgica. Conclusão: Após a análise dos dados obtidos após o sexto mês pós-operatório, pode-se concluir que este método é eficaz e seguro, além de apresentar uma significativa melhora clínica e funcional, o que proporcionou uma melhora na qualidade de vida da paciente.

Descritores: Mensuração da qualidade de vida, Artroplastia da articulação trapézio-metacárpica, Rizartrose, Piocarbono. 
19 Canulação da artéria axilar para uso na circulação extracorpórea em cirurgias da aorta ascendente

\section{Ulrych BK, Silva AMA, Moraes FA, Shiroma ETM, Moreno R, Horiuti L, Pires AC}

Introdução: Atualmente, a aorta ascendente distal é o sítio de canulação arterial mais frequentemente utilizado no retorno do sangue oxigenado proveniente da máquina de circulação extracorpórea na cirurgia cardiovascular. Em situações em que não é aconselhável a utilização da aorta ascendente distal, tem-se optado pela canulação da artéria axilar. Objetivo: O presente vídeo tem por objetivo apresentar a técnica de canulação da artéria axilar direita bem como apresentar suas vantagens, contra indicações e complicações mais freqüentes. Método: filmagem de cirurgia da equipe de Cirurgia Cardiovascular FMABC demonstrando a técnica de dissecção da artéria axilar. Resultados: Nos últimos anos, alguns estudos demonstraram benefícios da canulação da artéria axilar. Apesar de ser tecnicamente mais difícil que a aorta ou artéria femoral, a canulação da artéria axilar promove um fluxo sangüíneo anterógrado por um vaso usualmente livre de doença aterosclerótica, além de baixas taxas de complicações. Conclusão: A artéria axilar é uma boa alternativa à impossibilidade de canulação da aorta ascendente na instalação de circulação extracorpórea.

Descritores: Aneurisma de aorta ascendente, Cirurgia cardiovascular, Artéria axilar, Circulação extracorpórea.

\section{Correção das doenças da raiz da aorta pela técnica de Bentall de Bono}

\section{Silva AMA, Moraes FA, Shiroma ETM, Ulrych BK, Moreno R, Machado LN, Pires AC}

Introdução: $\mathrm{O}$ aneurisma ou dissecção da aorta ascendente freqüentemente se associa à ectasia do anel valva aórtico e, conseqüentemente, à insuficiência aórtica grave. Nesses casos é necessário reparo cirúrgico do aneurisma de aorta ascendente e da insuficiência valvar. Objetivo: Demonstrar a técnica cirúrgica proposta por Hugh Bentall e Antony de Bono por meio da substituição valvar aórtica e da aorta ascendente por um tubo valvulado com reimplante dos óstios coronários no tubo. Método: Filmagem de cirurgia realizada pela equipe de Cirurgia Cardiovascular da FMABC para demonstração da técnica. Resultados: Dentre as comorbidades mais prevalentes no pré-operatório, apresentam-se a hipertensão, doença coronariana, tabagismo e dissecção aguda de aorta. Em relação ao intra-operatório, aproximadamente um terço dos pacientes são submetidos a intervenção posterior, sendo a revascularização do miocárdio a mais recorrente. Tal técnica apresenta, na literatura, uma mortalidade geral em média de 3\%. Conclusão: O procedimento descrito por Bentall e De Bono ainda se mostra eficaz no tratamento de doenças que acometem a raiz aórtica,constituindo técnica de escolha nos dias atuais.

Descritores: Bentall-de-Bono, Cirurgia cardiovascular, Aneurisma aórtico, Insuficiência da valva aórtica.

\section{Derivação bílio-digestiva paliativa em paciente com neoplasia avançada de cabeça de pâncreas}

\section{Towata F, Ikeuti DH, Bastelli MM, Chien V, Brito GM, Henriques AC, Fuhro FE}

Introdução: $O$ adenocarcinoma pancreático é a segunda principal causa de morte dentre as neoplasias do aparelho digestivo. Acomete com maior frequência a porção cefálica do pâncreas $e$ frequentemente é acompanhada das síndromes de icterícia obstrutiva e de obstrução antro-pilórica. A gastroduodenopancreatectomia cefálica (GDP) é a cirurgia curativa indicada em casos de doença não avançada locoregionalmente, sem disseminação à distância e em pacientes com bom performance status. A cirurgia paliativa é realizada em pacientes com condições clínicas mínimas, associada às síndromes ictérica e/ou de obstrução antro pilórica, ou seja, em pacientes que apresentam algum sintoma a ser paliado. Objetivo: Apresentar um vídeo de um procedimento cirúrgico paliativo visando ao alívio da icterícia obstrutiva causada. por neoplasia de cabeça de pâncreas com envolvimento dos vasos mesentéricos (critério de irressecabilidade). Método: Derivação biliar interna por meio de colédoco-jejuno-anastomose láterolateral em Y-de-Roux por laparotomia. Resultados: Paciente evoluiu sem complicações no intra e pósoperatório. No último seguimento, um ano após a cirurgia, o paciente tem sido submetido ao tratamento quimioterápico paliativo com satisfatória evolução. Conclusão: Pacientes portadores de malignidades do tubo digestivo que apresentem sintomas como obstrução, icterícia, sangramento e perfuração, e que se enquadrem nos casos considerados sem indicação de tratamento cirúrgico radical devem, sempre que possível, ser submetidos a alguma forma de tratamento paliativo a fim de aliviar seu sofrimento.

Descritores: Icterícia, Neoplasia de pâncreas, Paliação, Derivação bilio-digestiva.

\section{Esofagectomia subtotal transiatal em paciente com carcinoma espinocelular de esôfago}

\section{Amaro DMC, Blumetti AMC, Fonseca ABF, Yamada FB, Henriques AC, Fuhro FE}

Introdução: O carcinoma espinocelular é uma neoplasia epitelial que representa $90 \%$ dos tumores esofageanos, acomete principalmente os terços médio e superior de homens acima de 50 anos, com incidência maior em negros. Os fatores de risco para seu desenvolvimento podem ser nutricionais, genéticos, patológicos (afeccões prévias do esôfago) e relativos aos hábitos (tabagismo, etilismo). São neoplasias insidiosas, de modo que até $2 / 3$ dos casos não são ressecáveis ao diagnóstico, reduzindo sua sobrevida A esofagectomia é um procedimento de alto risco com complicações pós-operatórias sérias e taxa de mortalidade entre 2 e $6 \%$. A abordagemtransiatal é menos invasiva, e por isso é a via de escolha em casos de função respiratória comprometida e contra-indicação de toracotomia. Objetivo: Apresentar um caso cirúrgico, por meio de vídeo, enfatizando as técnicas cirúrgicas empregadas no tratamento de carcinoma espinocelular de esôfago. Métodos: Esofagectomia subtotal com gastrectomia polar superior e confecção de trato gástrico pela grande curvatura utilizando grampeador linear cortante para reconstrução do trânsito alimentar e piloroplastia. Os pedículos vasculares pilórico e gastroepiplóico direito foram preservados. Via de acesso transhiatal com frenotomia mediana (conforme preconizado pelo professor Pinotti) e cervicotomia esquerda associada à esternotomia parcial em "L". Resultados: O paciente evoluiu sem complicações após a cirurgia. Conclusão: Quando o CEC é localizado e em pacientes hígidos, seu principal tratamento é sua ressecção cirúrgica. A possibilidade da utilização da via de acesso transiatal, menos invasiva, diminui o risco de complicações peri e pós-operatórias.

Descritores: Esofagectomia transiatal, Carcinoma espinocelular, Carcinoma de esôfago, Terço médio. 


\section{Nefrectomia parcial laparoscópica sem clampeamento do hilo renal}

\section{Almeida RC, Abdalla TE, Arrym TP, Yamauti LS, Kataguiri A, Alves CDM, Cabral PRAC, Neves Neto OC}

Introdução: A nefrectomia parcial é o tratamento de eleição para tumores renais menores do que $4 \mathrm{~cm}$. A nefrectomia parcial realizada pela via laparoscópica (NPL) é uma técnica complexa, e normalmente realizada com clampeamento quente temporário dos vasos do hilo renal. Entretanto trabalhos recentes mostram que cada minuto de clampeamento quente pode ter consequiências deletérias futuras ao parênquima renal. Nesse sentido, alguns autores têm tentado desenvolver técnicas com redução do tempo de isquemi renal. Relato de caso: Paciente de 55 anos, masculino com tumor renal exofitico de $3 \mathrm{~cm}$ diagnosticad incidentalmente como achado de tomografia abdominal. Estádio clínico pTla. Rim contralateral normal. Foi optado pela nefrectomia parcial laparoscópica, onde o pedículo renal não foi clampeado e o parênquima renal de proximidade foi incisado com bisturi ultrassonico e o parênquima renal hemostasiado através de sutura e surgicel. Tempo operatório de $120 \mathrm{~min}$, sangramento de $200 \mathrm{ml}$, alta hospitalar no 2. ${ }^{\circ}$ pósoperatorio. Discussão: A NPL pode ser feita sem o clampeamento do hilo, evitando a isquemia quente e assim preservando melhor a função renal. Está técnica tem maior relevância em pacientes com rins únic ou quando o paciente tem comorbidades como HAS e DM, as quais podem trazer prejuízo a função renal de longo prazo

Descritores: Nefrectomia, Isquemia Quente, Rim.

\section{Prostatectomia videolaparoscópica extraperitoneal}

Muller S, Almeida DV, Chicoli FA

Introdução: A prostatectomia radical laparoscópica é uma opção minimamente invasiva estabelecida par o tratamento do câncer de próstata localizado. Relato de caso: Paciente masculino de 72 anos, sem queixas urinárias, PSA $=8,0 \mathrm{ng} / \mathrm{ml}$ e toque retal revelando uma prostata de 50 gramas com nódulo endurecido de $2,0 \mathrm{~cm}$ em base direita. A biópsia transretal revelou adenocarcinoma Gleason 7 ( 2 de 12 fragmento acometidos). Exames de estadiamento (TC de abdome total e cintilografia óssea) sem evidência de doença metastática. Estadiamento clínico cT2aN0M0. Com um diagnóstico de câncer de próstata localizado, foi optado pelo tratamento cirúrgico radical pela técnica laparoscópica extraperitoneal. Discussão: O emprego desta técnica evidenciou vantagens como: 1) cirurgia realizada através de pequenas incisões com menos dor pós-operatória, 2) não invasão da cavidade peritoneal com consequente diminuição de lesão de órgãos intracavitarios, 3) menor perda sanguínea durante o ato operatório, 4) uma melho visualização das estruturas que permitiu uma completa ressecção do tumor, 5) excelente preservação do plexo neurovascular (função erétil), 6) ótima preservação do aparelho esfincteriano e do comprimento uretral (continência urinária), 7) magnificação da imagem permitindo uma anastomose vesico-uretral muco-mucosa bastante segura.

Descritores: Prostatectomia/métodos, Laparoscopia/métodos, Extraperitoneal, Procedimentos cirúrgicos minimamente invasivos.

\section{Sacrocolpopexia laparoscópica endoscópica por porta única (less): passo a passo de uma técnica simplificada sem nós}

Longuino LFF, Ferreira AACM, Peixoto GA, Toneto BR, Chicoli FA, Costa Junior RMM, Pompeu ACL, Machado $M T$

Introdução: O tratamento cirúrgico de prolápso de cúpula vaginal após histerectomia total envolve sacrocolpopexia abdominal ou vaginal. Objetivo: $\mathrm{O}$ objetivo deste trabalho é relatar um caso de prolápso de cúpula vaginal completo tratados com sacrocolpopexia laparoscópica por um único trocater. Método: Mulher branca,52 anos,apresentou prolápso de cúpula vaginal grau 3 associada à incontinência urinária de esforço. Tratada com sacrocolpopexia por LESS transumbilical com afastador de acesso per-cutâneo através de uma incisão de $3,5 \mathrm{~cm}$ na cicatriz umbilical e 3 trocartes ligados a uma luva cirúrgica. Posicionou-se a paciente em litotomia e usou-se apenas instrumentos laparoscópicos convencionais para as dissecções intrabdominais.Fixouse a tela de polipropileno em formato de $\mathrm{Y}$ ao fundo de saco vaginal utilizando 3 suturas contínuas contendo em suas extremidades grampos poliméricos.A última sutura foi fixada por grampos ao periósteo sacral a partir do promontório obtendo-se um posicionamento vaginal sem tensão. Fechou-se o peritônio posterior recobrindo toda tela. Resultados: O tempo cirúrgico foi de 2,5 horas com perda sanguínea inferior a $100 \mathrm{~mL}$.O pósoperatório hospitalar foi de $18 \mathrm{~h}$ e não houveram complicações. A paciente ficou satisfeita com sua cicatriz e con os resultados cirúrgicos. A operação resultou em sucesso anatômico, resolução a curto prazo da incontinência urinária. Conclusão: A Sacrocolpopexia por LESS realizada com instrumentos convencionais é uma técnica difícil, mas viável e eficiente para tratar o prolápso de cúpula vaginal.O afastador de acesso per-cutâneo associado às suturas sem nós são as opções técnicas que simplificam as manobras de reconstrução através da LESS.

Descritores: Laparoscopia endoscópica por porta única (LESS), Sacrocolpopexia, Prólapso de cúpula vaginal, Técnica simplificada sem nós.

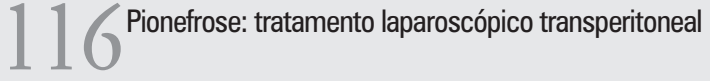

Golfetti MG, Soares GA, Almeida RC, Yamauti LS, Alves CDM, Okamoto ECG, Julio AD

Introdução: Denomina-se pionefrose a infecção do parênquima renal associada a um processo obstrutivo ureteral, evoluindo com coleção de urina purulenta em um rim não funcionante. A nefrectomia é a cirurgia empregada no seu tratamento, com o objetivo de evitar a progressão do processo infeccioso e sua evolução para septicemia e óbito. É considerado um procedimento de alta complexidade nesses casos, pois o processo inflamatório se extende além do parênquima renal, acometendo órgãos e estruturas adjacentes. Desta forma, causa fibrose, aderências e neovascularização perirenal, elevando-se os riscos de ressecção, independente da via de acesso empregada. Os benefícios da laparoscopia são amplamente descritos na literatura, como menor requerimento de analgésicos, menor tempo de internação e convalescência, porém, a utilização desta técnica em rins inflamatórios permanece controversa. Objetivo: Relatamos a nefrectomia laparoscópic transperitoneal de rim excluso $(10,5 \mathrm{~cm})$ a esquerda, com ureterolitíase proximal obstrutiva complicada com pionefrose. Método: Video demonstrativo de quadro clinico, laboratorial e radiológico de paciente com pionefrose, seguido de edição do tratamento cirúrgico pormenorizado. Resultados: $\mathrm{O}$ vídeo demonstra o status intra-operatorio do retroperitoneo, com intensas aderências perirenais, alteração dos plano cirúrgicos e espessamento da fascia de Gerota. A ligadura e secção do hilo renal foi realizada em bloco, através de disparo único de grampeador endoscópico endo-GIA, devido a dificuldade de individualização das estruturas hilares. Conclusão: A nefrectomia laparoscopica transperitoneal é um procedimento factivel e resolutivo, podendo ser empregada em condições inflamatórias, como na pionefrose.

Descritores: Pionefrose, Nefrectomia laparoscópica, Ureterolitíase, Rim inflamatório.

\section{Ressecção de adenocarcinoma de cárdia Siewert I por meio de esofagectomia subtotal associada à gastrectomia polar superior e reconstrução do trânsito alimentar por meio de esôfagogastroplastia por via transiatal}

Delena PJ, Lee LEJ, Job LCG, Urata CN, Azevedo RGS, Henriques AC, Fuhro FE

Introdução: $\mathrm{O}$ carcinoma gástrico é a segunda principal causa de morte por câncer no mundo. A incidência do adenocarcinoma de cárdia é cinco vezes maior no homem do que na mulher. Siewert classifica a neoplasia de cárdi em três tipos. O tipo I corresponde àquela de $1 \mathrm{~cm}$ acima da junção gastroesofágica (JGE) até $5 \mathrm{~cm}$ proximal; O tipo II, de $1 \mathrm{~cm}$ acima a $2 \mathrm{~cm}$ abaixo da JGE (verdadeiro carcinoma da cárdia) e o tipo III, de $2 \mathrm{~cm}$ a $5 \mathrm{~cm}$ abaixo da JGE (carcinoma gástrico subcárdico). O tipo de ressecção cirúrgica varia com a localização das lesões. Nas do tipo I, propõe-se a esofagectomia por acesso transmediastinal seguida de linfadenectomia subcarinal, remoção do tecido frouxo do mediastino, gastrectomia proximal e linfadenectomia do território abdominal correspondente. Objetivo: Apresentar um caso cirúrgico, por meio de vídeo, enfatizando as técnicas cirúrgicas empregadas no tratamento de adenocarcinoma de cárdia (Siewert I). Método: Esofagectomia subtotal com gastrectomi polar superior e confecção de trato gástrico pela grande curvatura utilizando grampeador linear cortante para reconstrução do trânsito alimentar e piloroplastia. Os pedículos vasculares pilórico e gastroepiplóico direito foram preservados. Via de acesso transhiatal com frenotomia mediana (conforme preconizado pelo professor Pinotti) e cervicotomia esquerda associada à esternotomia parcial em "L". Resultados: As complicações mais frequentes - fístula da esofagogastroanastomose, necrose do tubo gástrico, pneumonia, pneumotórax e tromboembolismo pulmonar - não foram observadas. Conclusão: No Siewert tipo I propõe-se a ressecção supracitada, pois não altera a mortalidade pós-operatória e as complicações são controláveis.

Descritores: Carcinoma gástrico, Adenocarcinoma de cárdia Siewert I, Esofagectomia subtotal, Gastrectomia polar superior.

\section{Transplante renal para tratamento de pacientes com insuficiência renal crônica em fase terminal}

Towata F, Ferreira FAY, Oliveira LO, Shiroma ETM, Yamada FB, Yamashita ET, Miranda MP, Genzini T Introdução: Transplante renal (TR) é uma importante opção terapêutica para pacientes, dialíticos ou prédialíticos, com insuficiência renal crônica em fase terminal. O doador pode ser vivo relacionado (parente), vivo não-relacionado (não-parente) ou doador cadáver (DC). Em 2010, foram realizados 4630 TR no Brasil, sendo 1641 de doadores vivos (35,44\%) e 2989 de doadores falecidos (64,55\%). Objetivo: Descrever técnic cirúrgica de TR utilizada em nosso serviço. Método: Escolha do doador vivo (DV) envolve a avaliação de diversos parâmetros, principalmente relacionados à idade, condição clínica, compatibilidade ABO/HLA e prova cruzada - cross-match. Para seleção do DC, é fundamental a qualidade do órgão transplantado, o que depende da idade, da história clínica pregressa e dos cuidados de terapia intensiva no momento da constatação da morte encefálica. Todos esses critérios, tanto para o DV quanto para o DC, devem ser rigorosament analisados para o sucesso do TR. A técnica cirúrgica empregada na cirurgia do doador consiste na nefrectomia aberta ou laparoscópica. No caso de DC, os princípios gerais incluem o controle da aorta e da cava acima dos órgãos a serem removidos, a perfusão in situ com soluções de preservação e a obtenção de tecido para estudos de histocompatibilidade. Na cirurgia do receptor, a anastomose arterial pode ser término-terminal n artéria hipogástrica ou término-lateral nas artérias ilíacas. Já a anastomose venosa é término-lateral na vei ilíaca externa. Resultados: Uso de DC, além das dificuldades na obtenção do órgão, oferece menor sobrevida para enxerto e paciente. Conclusão: Apesar de seu elevado índice de sucesso e sobrevida, o TR está sujeito a complicações, como fístulas e estenoses, mas é uma importante alternativa para pacientes com doença rena terminal, retirando-os da diálise, em que ocorre elevada mortalidade.

Descritores: Doença renal terminal, Transplante renal, Terapia dialítica, Doação de órgãos. 


\section{Simpósio de Iniciação Científica}

\section{Utilização da via videolaparoscopia no tratamento de carcinoma renal de células claras} 12 Imunoexpressão da via de sinalização Wnt canônica no
Chiota FL, Silva AMA, Shimanoe VH, Chicoli FA, Machado MT

Introdução: $\mathrm{O}$ carcinoma de células claras renal é o tumor maligno renal mais prevalente em adultos, acometendo em média $80 \%$ dos casos de carcinoma de células renais. Seu tratamento é cirúrgico e é preferencialmente realizado pela via videolaparoscópica. Relato de caso: paciente masculino, 45 anos, durante exame de rotina foi encontrada uma massa suspeita em rim esquerdo. Mediante investigação e biópsia foi diagnosticado carcinoma de células claras e como conduta foi realizada nefrectomia videolaparoscópica extraperitoneal cujos tempos foram: incisão da fáscia de Gerota, dissecção da gordura perirrenal, mobilização do rim para cima, clipagem e secção da artéria, veia renal e ureter e a retirada da peça pela incisão de pfanestiel. O paciente evoluiu sem complicações e recebeu alta no 1\&\#8304; pós operatório. Discussão: a incisão lombar (Bergman-Israel) para a retirada da peça cirúrgica acarreta em maior morbidade ao paciente devido à necessidade de seccionar músculos. A incisão de Pfanestiel por sua vez evita essa morbidade por utilizar o afastamento dos músculos abdominais para acessar a cavidade abdominal.

Descritores: Videolaparoscopia, Carcinoma renal de células claras, Uro-oncologia, Cirurgia.
Vanzin AM, Waisberg J

Introdução: $\mathrm{O}$ trato gastrintestinal é um dos locais mais freqüentes de carcinogênese em função do rápido turnove celular e da exposição diária a toxinas. A quebra da homeostase da célula epitelial leva à perda das características e aquisição de um fenótipo potencialmente metastático, processo conhecido como transição epitélio-mesenquimal regulado pelas vias embrionárias fundamentais: via Wnt e fator de crescimento tumoral beta. A ativação inapropriada dessa via desempenha papel crítico no câncer gástrico. Objetivo: Detectar e verificar as proteínas integrantes da via de sinalização Wnt: Wnt-1, APC, glicogênio sintase quinase-3, receptor de quemoquina, $\beta$-catenina e ubiquitina. Método: Estudo retrospectivo analisando Grupo 1: 70 doentes com carcinoma gástrico operados no serviço. Grupo 2: 40 doentes com gastrite enantemática. Serão acrescidos os anticorpos Wnt-1, APC, glicogênio sintase quinase-3, receptor de quemoquina, beta-catenina e ubiquitina, sobre os cortes de tecido e será realizada a revelação com cromógeno e contracoloração. O método aplicado será o da quantificação digital da imunoexpressão de marcadores biológicos pela técnica de imuno-histoquímica. Resultados: Considerados 70 laudos anatomopatológicos, 43 do sexo masculino e 27 do feminino. Com idade média de 63,78 e 67,40 anos respectivamente. O predomínio das lesões ocorreu no terço médio do estômago $48,2 \%$. Para todos os paciente foram feitas a classificação TNM, tendo um predomínio de T3, 57,5\% e N1 52\%. Conclusão: O pico de incidência no sexo masculino ocorre por volta dos 70 anos. Os dados obtidos estão em acordo com as informações divulgadas pelo INCA. O material foi enviado para estudo imuno-histoquimico e aguardamos resultados.

Apoio financeiro: $\mathrm{PIBIC} / \mathrm{CNP}$

\section{Funcionalidade dos pacientes portadores da doença de Parkinson atendidos no Hospital Estadual Mário Covas de Santo André}

Taha A, Sato MA

Introdução: $\mathrm{O}$ apetite ao sódio é caracterizado como um comportamento que leva o animal a ingerir sódio, em condições em que há falta do mesmo no organismo. No entanto, pouco se sabe sobre os componente afetivos ou motivacionais envolvidos neste comportamento. Não está esclarecido se o Núcleo Accumbens (NAcc), estrutura do sistema mesolímbico que possui importante função na regulação de comportamentos motivados participaria do controle do comportamento ingestivo. Objetivo: Verificar o efeito da inibição GABAérgica do NAcc sobre o apetite ao sódio em ratos. Metódo: Foram utilizados ratos Wistar (N = 6/grupo, $\sim 320 \mathrm{~g}$ ), submetidos à estereotaxia para implante de cânulas-guia bilateralmente no NAcc (porção shell), 7 dias antes dos experimentos, para posterior injeção de solução salina ou muscimol (agonista GABAérgico, $6 \mathrm{mM}, 1 \mathrm{uL}$ ). O teste do apetite ao sódio foi feito em ratos depletados de sódio com furosemida S.C $24 \mathrm{~h}$ antes do experimento e a ingestão cumulativa de água e $\mathrm{NaCl} 1,8 \%$ foram mensuradas aos 15, 30, 60, 120 e 180 min. Resultados: Observou-se que, após a injeção de muscimol no NAcc, houve redução da ingestão de $\mathrm{NaCl} 1,8 \%(5,3 \pm 1,9 \mathrm{~mL} / 180 \mathrm{~min})$ comparado ao grupo que recebeu salina no NAcc $(17,7 \pm 2,7 \mathrm{~mL} / 180 \mathrm{~min})$. Não se observou diferença na ingestão de água após muscimol no NAcc $(1,2 \pm 0,7 \mathrm{~mL} / 180 \mathrm{~min})$ em comparação ao grupo que recebeu salina no NAcc $(3,4 \pm 1,1 \mathrm{~mL} / 180 \mathrm{~min})$. Conclusão: A inibição do NAcc com muscimol reduziu a ingestão de sódio em ratos depletados de sódio com furosemida, o que sugere que o NAcc constitui parte de um circuito motivacional central necessário para induzir o apetite ao sódio.

Descritores: Núcleo Accumbens, Sódio, Furosemida, GABA.

\section{Estudo dos polimorfismos dos receptores de estrógeno alfa e beta em homens brasileiros com infertilidade idiopática}

\section{Paiva CP, Mafra FA, Bianco B, Christofolini DM, Barbosa CP}

Introdução: Os estrogênios desempenham um importante papel no sistema reprodutivo humano. Sua ação é mediada por dois receptores: ER alfa e ER beta. Variantes polimórficas nestes genes foram previamente associadas a distúrbios reprodutivos. Um estudo realizado com pacientes Iranianos com oligoastenoteratozoospermia idiopática encontrou associação dos genótipos do ER alfa e ER beta com o alto risco de infertilidade. Entretanto, um estudo Grego encontrou associação positiva apenas entre os polimorfismos do ER alfa com a motilidade e a concentração espermática em homens oligozoospérmicos. Objetivo: Determinar a distribuição dos polimorfismos de ER alfa e ER beta em pacientes inférteis e controles férteis brasileiros. Método: Foram avaliados 78 homens com azoospermia não-obstrutiva (NOA), 119 com oligozoospermia grave (SO) e 216 homens férteis. Os polimorfismos do ER alfa (PvuII e XbaI) e ER beta (AluI e RsaI) foram detectados através de TaqMan PCR. Os resultados foram analisados estatisticamente e o valor de $\mathrm{p}<0.05$ foi considerado significante. Resultados: A análise individual de cada polimorfismo revelou que nem PvuII nem Xbal estavam associados com o grupo NOA ( $\mathrm{p}=0.662$ e $\mathrm{p}=0.527$ ) ou com o grupo $\mathrm{SO}(\mathrm{p}=0.777 \mathrm{ep}=1.0)$. Nenhuma diferença estatística foi observada entre os polimorfismos AluI e Rsal o grupo NOA ( $\mathrm{p}=1.0 \mathrm{e} \mathrm{p}=0.740)$ ou com o grupo $\mathrm{SO}(\mathrm{p}=0.423 \mathrm{ep}=0.920)$ e controles. Os genótipos combinados do ER alfa e ER beta não demonstraram associação de haplótipos com a infertilidade masculina. Conclusão: $\mathrm{O}$ presente estudo mostrou que os polimorfismos PvuII, XbaI, AluI e Rsal não estão associados com a infertilidade idiopática em homens brasileiros. As variações étnicas e geográficas na distribuição dos polimorfismos nos genes receptores de estrógeno sugerem a heterogeneidade genética na infertilidade masculina.

Descritores: Infertilidade masculina, Polimorfismos, Receptor de estrógeno.

\section{Gomes $\mathrm{CO}$, Squarcino IM}

Introdução: Caracterizada por redução das células dopaminérgicas do núcleo da base, a doença de Parkinson causa tremores, dificuldade na movimentação voluntária e na manutenção da postura. Tais características da doença podem ser minimizadas com a Fisioterapia, podendo interferir para a melhoria das atividades funcionais. Objetivo: Avaliar se a Fisioterapia alterou a funcionalidade do paciente, a ser mensurada com a escala da Medida de Independência Funcional (M.I.F.). Método: Os pacientes com marcha comunitária em atendimento em grupo no Centro de Reabilitação do Hospital Estadual Mário Covas de Santo André foram avaliados antes e após 6 meses da intervenção fisioterapêutica do serviço, com a escala de M.I.F.; outra avaliações para complementação da análise foram realizadas nos mesmos períodos: Escala de Equilíbrio de Berg. Escala de Estágios de Incapacidade de Hoehn e Yahr, SF-36, Mini-exame do estado mental e testes de coordenação motora. A Fisioterapia foi realizada uma vez por semana durante 30 minutos, associada a tarefas domiciliares para treino de coordenação motora fina. Resultados: Participaram do estudo, 10 pacientes em tratamento, cujos valores de MIF não tiveram significativas alteraç̃es, porém, o mesmo não parece ter ocorrido com todas as dimensões do questionário de qualidade de vida (SF-36), que apresentaram melhora. Também houve alteração na Escala de Estágios de Incapacidade de Hoehn e Yahr, com $30 \%$ dos casos apresentando melhora do nível de comprometimento (de 2,5 para nível 2). Quanto à Escala de Equilíbrio de Berg, também houve alterações, sendo o escore inicial de 533 e o final de 542 . Conclusão: A pesquisa está em fase de conclusão, com análise estatística de dados correlatos.

Descritores: Mielomeningocele, Locomoção, Fisioterapia.

Apoio financeiro: NEPAS/FUABC FE(III)/ácido nitroso-2-naftol-3,6-dissulfônico em espécies vegetais

\section{Silva DX, Souza $M W$, Moya $H D$}

Introdução: Compostos polifenólicos estão presentes em extratos vegetais e apresentam capacidade antioxidante. Verificou-se que a adição de ácido pirogálico (AP) em solução contendo Fe(III) e ácido nitroso-2-naftol-3,6dissulfônico (NRS) em tampão TRIS pH 8, promoveu o aparecimento de coloração verde, devido à formação dos complexos de $\mathrm{Fe}(\mathrm{II}) / \mathrm{NRS}$. Assim, investigou-se o uso dessa reação na quantificação do teor de polifenol total (PFT) em extratos vegetais, não utilizada até então. As espécies P. major, A. muricata e C. sylvestris, foram escolhidas como modelo. Para efeito de comparação os mesmos extratos foram analisados utilizando o reagente Folin Denis (FD), recomendado pela Farmacopéia Brasileira (FB) e ambos os resultados foram expressos em $\%$ de AP. Objetivo: Determinar o teor de PFT em extratos vegetais utilizando os complexos Fe(III)/NRS Método: O procedimento para obtenção dos extratos vegetais aquosos seguiu o recomendado pela FB, os quai foram adicionados a uma solução contendo complexos de Fe(III)/NRS. Ambas as medições após 30 min., foram realizadas em $715 \mathrm{~nm}$ (método oficial) e em $730 \mathrm{~nm}$ (método proposto). Resultados e Conclusão: Embora os valores de PFT obtidos com os complexos Fe(II)/NRS (P. major 0,44\%; A.muricata 0,35\% e C.sylvestris $0,38 \%$ ) sejam menores que os valores encontrados pelo método oficial (P. major 1,3\%; A. muricata 1,8\% e C. sylvestris $1,8 \%$ ), o uso desses complexos mostrou-se adequado para estimar o teor de PFT. As diferenças de PFT podem ser atribuídas ao fato de que diferentes compostos polifenólicos presentes nas espécies analisadas respondem diferentemente à reação de redução de $\mathrm{Fe}(\mathrm{III})$ a $\mathrm{Fe}(\mathrm{II})$. O tipo de estrutura química e as massas moleculares dos polifenóis são fatores determinantes nessa reação química e deverão ser investigados.

Descritores: Ácido nitroso-2-naftol-3,6-dissulfônico, Polifenóis, Extratos vegetais.

Apoio financeiro: CNPq-PIBIC, FAPESP 
Impacto da cirurgia bariátrica da sintomatologia psiquiatrica, qualidade de vida e parâmetros clínicos em obesas mórbidas

Pelaggi ER, D'Elia G

Introdução: A obesidade mórbida é uma condição clínica com prevalência crescente nas últimas décadas, com evidências de ser determinante de diversas comorbidades clínicas, além de haver correlação com pior qualidade de vida, sintomatologia depressiva e alteraç̃oes de comportamento. A cirurgia bariátrica é amplamente aceita para seu tratamento, sendo que o conhecimento de suas repercussões psicológicas e o seu impacto na qualidade de vida poderia beneficiar os pacientes submetidas a cirurgia. Objetivo: Avaliar o impacto da cirurgia bariátrica na sintomatologia depressiva, ansiosa e de compulsão alimentar; na qualidade de vida; no uso de substâncias psicoativas e dos parâmetros clínicos de pacientes obesas mórbidas submetidas a cirurgia bariátrica. Método: Foram aplicados questionários, um mês antes e 6 meses após a cirurgia, para 23 mulheres com idade entre 18 e 65 anos e Índice de Massa Corpórea (IMC) $\geq 40 \mathrm{~kg} / \mathrm{m} 2$, aguardando a cirurgia bariátrica. Questionário usados: Inventário de Depressão de Beck (IDB), Inventário de Ansiedade Traço-Estado (IDATE-T), Teste de investigação bulímica de Edinburgh (BITE), Escala de qualidade de vida (WHOQOL-Bref), Inventário sobre o uso de substâncias psicoativas. Os dados foram tabulados e estão sendo analisados com o programa estatístico EPI-INFO 6,utilizando teste paramétricos e não paramétricos.O nível de significância é de 5\%. Resultados: Os resultados parciais tendem para a diminuição dos escores de depressão e ansiedade; aumento do padrão regula de alimentação; melhoras da capacidade de locomoção e da aceitação da aparência física e da qualidade do sono. Não houve alteração significativa no padrão do uso de substâncias psicoativas. Conclusão: Os resultados apresentados são parciais e a análise comparativa dos dados coletados está em andamento.

Descritores: Cirurgia bariátrica, Obesidade mórbida, Psiquiatria.

Apoio financeiro: NEPAS/ FUABC

120 Percepção da Medicina não tradicional, alternativa ou complementar por estudantes de Medicina

\section{Cudizizio FFP, Machado MP, Marafanti I, Silva NR, Baldassin SP}

Introdução: Segundo a literatura, há um aumento da procura dos pacientes por práticas como acupuntura, homeopatia e fitoterapia por destaque dessas na relação médico-paciente e suas vantagens econômicas. O ensino dessas práticas na graduação gera polêmica. Objetivo: avaliar a percepção do estudante de medicina sobre seu preparo para lidar com homeopatia, acupuntura e fitoterapia. Método: Estudo transversal, multicêntrico. Instrumento: questionário, com 35 perguntas, aplicado a alunos do curso de medicina do primeiro, terceiro e sexto ano da FMABC, Unifesp e Santa Casa. Resultados: Participaram do estudo 714 estudantes, 248 do primeiro, 248 do segundo e 218 do sexto ano. Desses $93 \%$ considera important saber explicar ao paciente sobre acupuntura, $87 \%$ sobre homeopatia e fitoterapia, porém apenas $22 \%, 15 \%$ e $9 \%$ se sentem seguros para tal, respectivamente. Há prejuízo na relação médico paciente para $53 \%$, caso o médico não tenha conhecimento sobre o tema, $75 \%$ acha que poderia perder pacientes. $26 \%$ referiu te tido mais de uma aula sobre medicina alternativa. $57 \%$ afirma ter ouvido depreciações por professore sobre homeopatia. $81 \%$ gostaria de ter os temas no currículo e $80 \%$ indicaria as técnicas as seus pacientes, sobretudo acupuntura (78\%). Justificando a não inclusão das técnicas no currículo básico se destacam $38 \%$ que acredita que acupuntura não tem espaço na grade curricular; $61 \%$ e $45 \%$ que acreditam que a homeopatia e fitoterapia têm carência de comprovação científica. Quanto à função da acupuntura $6 \%$ acha que esta nunca deve substituir a medicina tradicional contra $32 \%$ da homeopatia e $25 \%$ da fitoterapia. Conclusão: Estudantes não se sentem seguros para lidar com dúvidas sobre medicina alternativa, consideram o tema importante e gostariam de ter mais acesso a este.

Descritores: Acupuntura, Homeopatia, Fitoterapia, Estudantes.

Apoio financeiro: NEPAS/FUABC

\section{Estudo experimental da migração melanocítica em halos pigmentares}

\section{Bittencourt F, Machado Filho CDS}

Introdução: Estudo experimental em cobaias com o objetivo de desenvolver modelo de migração celula com halos pigmentares em animal. Sabe-se que as cobaias malhadas possuem a propriedade de formar halo pigmentares por difusão de melanócitos quanto se enxerta pele pigmentada em pele não pigmentada. Esse fenômeno é utilizado em humanos para tratamento cirúrgico do vitiligo, porém faltam estudos na literatura sobre os fenômenos envolvidos na migração de melanócitos. Objetivo: Desenvolver modelo experimental da migração celular de halos pigmentares em cobaias; determinar a migração temporal dos melanócitos no halo pigmentar e sua relação com a expressão visual dos halos pigmentares. Método: Cinco cobaias da espécie Cavia porcellus, bicolores. Na área pigmentada (doadora) foi coletado um fragmento de pele de 3 $\mathrm{mm}$. Na área despigmentada (receptora) foi removido um fragmento de $2 \mathrm{~mm}$ de diâmetro, o fragmento pigmentado da área doadora foi colocado na área branca receptora e fixado com cola de metacrilato. A partir do fragmento central implantado foi traçado um círculo com $0,5 \mathrm{~cm}$ de raio em cuja superfície serão coletadas biópsias de $5 \mathrm{~mm}$ em pontos distintos em: D0, D7, D15, D30, D60. Em D60 será também coletada uma amostra com $1 \mathrm{~cm}$ de raio totalizando 7 amostras. Todos os fragmentos são coletados em frascos com formol. Resultados: Ocorre a formação do halo pigmentar. Conclusão: Foi comprovado que as cobaias malhadas possuem a propriedade de formar halos pigmentares por difusão de melanócitos quanto se enxerta pele pigmentada em pele não pigmentada.

Descritores: Migração celular, Halos pigmentares, Difusão melanocítica

Apoio financeiro: $\mathrm{PIBIC} / \mathrm{CNPq}$
12 Avaliação da frequência de polimorfismos de genes 20 relevantes ao metabolismo do folato na infertilidade masculina

Kayaki EA, Christofolini D, Bianco B, Barbosa CP, Gava MM

Introdução: Deficiências crônicas de folato têm sido associadas com metilação anormal do DNA, não-disjunção por hipometilação, alterações na recombinação do DNA e aberrantes segregaç̃es cromossômicas. As vias do metabolismo do folato podem ser modificadas por polimorfismos nos genes MTHFR, MTR e MTRR, podendo levar à infertilidade. Objetivo: Identificar polimorfismos nos genes MTHFR (C677T, A1298C e C1793T), MTRR (A66G) e MTR (A2756G) em homens inférteis e do grupo controle e correlacionar os achados à infertilidade masculina. Método: O estudo envolveu 306 homens, sendo 133 inférteis (oligospermia grave e azoospermia não-obstrutiva) do Ambulatório de Andrologia do Serviço de Reprodução Humana da Faculdade de Medicina do ABC (FMABC) e 173 homens férteis. Os polimorfismos foram identificados por PCRq com ensaio Taqman. Os resultados foram analisados estatisticamente através do teste qui-quadrado e valores de $\mathrm{p}<0,05$ foram considerados significantes. Resultados: Na análise do polimorfismo de $M T R$ encontrou-se uma frequência elevada do genótipo mutado em inférteis em relação à encontrada nos controles $(\mathrm{p}=0,0008)$. Para o polimorfismo de $M T R R$ não foi estabelecida associação com infertilidade $(\mathrm{p}=0,1794)$. O polimorfismo $\mathrm{C} 677 \mathrm{~T}$ de $M T H F R$ foi mais encontrado entre homens com oligospermia ( $\mathrm{p}<0,0001)$. Já o polimorfismo A1298C, o alelo mutado foi mais encontrado entre os afetados, mostrando forte relação do alelo com infertilidade $(\mathrm{p}=0,0011)$. O polimorfismo $C 1793 \mathrm{~T}$ desse gene não apresentou associação $(\mathrm{p}=0,3543)$. Conclusão: As associações encontradas entre os polimorfismos estudados e infertilidade masculina corroboram os achados de outros estudos. Tais descobertas permitem o delineamento dos mecanismos genéticos envolvidos na infertilidade masculina.

Descritores: Infertilidade masculina, Polimorfismo, Folato.

Apoio financeiro: CNPq-PIBIC, NEPAS

12 Padronização da cultura de mioblastos para transplante em pacientes portadores de distrofia muscular

Introdução: Mioblastos são células do tecido muscular esquelético que quando estimuladas originam novas fibras musculares ou se fundem às já existentes. Este estímulo pode ser fisiológico ou patológico. Nas distrofias de Duchenne e Becker há degeneração do músculo, levando o indivíduo a morte na adolescência ou quando adulto jovem. Estas distrofias são causadas por mutação no gene da distrofina, presente no cromossomo X. A distrofina faz parte do citoesqueleto da fibra muscular, sendo responsável pela manutenção da integridade da fibra muscular frente às forças aplicadas no processo de contração muscular. A falta desta proteína causa enfraquecimento e rompimento da fibra muscular durante a contração, o que leva à degeneração da musculatura. $\mathrm{O}$ transplante de mioblastos em pacientes portadores de distrofia induziria à expressão normal da distrofina, cessando a degeneração e recuperando a mass muscular. Objetivo: Estabelecimento de método de cultura de mioblastos que permita atender à demanda dos transplantes em pacientes com distrofia. Método: Biópsias de músculo esquelético de camundongos foram tratadas com colagenase/tripsina e submetidas a ciclos de centrifugação a fim de se obter suspensão de células. Estas são cultivadas em meio HAM-F12, 10\% FBS e 1\% antibiótico e plaqueadas várias veze para separar os mioblastos das fibras esqueléticas. Os mioblastos são testados para verificar o potencial de diferenciação e tumorigenicidade. Estando satisfatórias, são coletadas de 3 a $4 \times 10^{8}$ céls para o transplante em músculo de camundongos MDX. Resultados e conclusão: Um protocolo eficiente para a cultura dos mioblastos ainda não foi estabelecido. O manejo e transporte das biópsias e a separação dos mioblastos das fibras musculares são os pontos de maior dificuldade no momento.

Descritores: Mioblastos esqueléticos, Distrofia muscular de Duchenne, Transplante de células.

Apoio financeiro: NEPAS/FUABC

\section{Perfil da locomoção de crianças portadoras de mielomeningocele atendidas no Hospital Estadual Mário Covas de Santo André}

Oliveira GP, Squarcino IM

Introdução: Mielomeningocele (MMC) é uma malformação complexa do tubo neural que ocorre devido à falha na fusão dos elementos posteriores da coluna vertebral, cursando com lesão neurológica que afeta a locomoção da criança. Se a locomoção de forma independente é restringida, a exploração do ambiente diminui, podendo afetar o conhecimento sobre o corpo no espaço e defasar o desenvolvimento neuropsico-motor em relação à idade cronológica. Objetivo: Este estudo tem como finalidade verificar o tipo e a idade de início da locomoção atingido por crianças com MMC em reabilitação no Hospital Estadual Mário Covas (HEMC). Método: Análise retrospectiva de prontuários das crianças com MMC atendidas no Centro de Reabilitação do HEMC no período de 2004 a 2011; foram excluídos os prontuários de crianças que interromperam o tratamento na instituição, que já tinham iniciado a reabilitação em outro serviç̧o e que apresentavam diagnóstico associado. Resultados: No período, foram elegíveis 10 prontuários, sendo 9,5 meses a idade média em que as crianças iniciaram a Fisioterapia e 17,8 meses em que iniciaram o treino de locomoção compatível com o melhor prognóstico funcional; destes, $80 \%$ realizou treino de marcha com dispositivos auxiliares e 20\% iniciou treino em cadeira de rodas. Conclusão: Pesquisa em processo de análise e discussão de resultados.

Descritores: Mielomeningocele, Locomoção, Fisioterapia.

Apoio financeiro: NEPAS/FUABC 
122 Influência de solução salina hipertônica na variabilidade da frequência cardiaca

\section{Farah HMAT, Almeida RL, Sato MA, Colombari E}

Introdução: A ativação dos osmorreceptores centrais ou periféricos induz a liberação de vasopressina e modifica a atividade nervosa simpática. Não é claro se alterações autonômicas poderiam ocorrer mesmo na ausência de alteracões da pressão arterial (PA). Objetivo: Investigar os efeitos agudos de infusões de salinas hipertônicas (SH) sobre a PA, frequência cardíaca (FC) e modulação cardiovascular autonômica avaliada por meio de análise espectral. Método: os ratos foram divididos em 2 grupos: 1.Ratos de infusão central (RIC, n=5) - uma cânula guia foi implantada no ventrículo lateral (VL) para infundir soluções ( $\mathrm{NaCl} 0,9 \%, 1,8 \%, 3,6 \%$ e 7,2\%) 2. Ratos de infusão periférica (RIP, $\mathrm{n}=9$ ) - infusões salinas foram feitas pela veia femoral direita. A PA e a FC foram avaliadas pela artéria femoral direita em ratos não anestesiados, usando o sistema Windaq, $2000 \mathrm{~Hz}$. A FC fo avaliada pela análise espectral usando o programa CardioSeries. Resultados: Não foram observadas alterações da PA ou FC depois das infusões de SH nos RIC, mas soluções de $\mathrm{NaCl} 0,9 \%$ e 1,8\% determinaram aumento no componente LF da PA sistólica. Nos RIP, observou-se aumento da FC e redução da variabilidade da FC no domínio do tempo após a infusão de soluções de $\mathrm{NaCl} 3,6 \%$ e 7,2\%. Quando se comparou RIC vs. RIP, notouse aumento no componente LF da PA sistólica depois da infusão das soluções de $\mathrm{NaCl} 0,9 \%, 1,8 \%$ e 7,2\%, aumento no componente LF e HF da variabilidade da FC no domínio da frequência após a infusão da solução de $\mathrm{NaCl} 7,2 \%$. Conclusão: As soluções infundidas no grupo RIP alteraram a FC e suas modulações, enquanto as soluções infundidas no VL modificaram apenas a modulação simpática da PA. Os volumes injetados foram muito pequenos ( $2 \mu \mathrm{L}$ no RIC e $0,1 \mathrm{~mL}$ no RIP) para causar alteração na FC ou na PA.

Descritores: Frequência cardíaca, Pressão arterial, Análise espectral.

Apoio financeiro: PIBIC/CNPq, FAPESP, NEPAS acadêmico de formandos de Medicina

Marafanti I, D'Elia G, Alves TCTF

Objetivo: O objetivo desse trabalho foi correlacionar sintomas de ansiedade e desempenho no concurso de residência médica da Faculdade de Medicina do ABC (FMABC). Método: Trata-se de um estudo de coorte, na qual alunos do sexto ano matriculados na Faculdade de Medicina do $\mathrm{ABC}$ e que preencheram os critérios de inclusão foram avaliados quanto ao traço de ansiedade e comparados quanto à aprovação no concurso de residência Médica da FMABC. O instrumento utilizado para avaliação dos sintomas de ansiedade foi o inventário de ansiedade de Spielberger em sua forma traço (IDATE-T). Resultados: A amostra foi composta por 67 por alunos, sendo que 69 alunos responderam os questionários, porém 2 foram excluídos por não terem prestado a prova do concurso de residência médica da FMABC 2011. Dessa amostra, 22 alunos (32,8\%) eram do sexo masculino e 45 alunos $(67,2 \%)$ eram do sexo feminino. A idade dos alunos variou de 23 a 32 anos com a média de idade de 25,6 e um desvio padrão de 1,8 anos. Na amostra, nenhum aluno apresentou ansiedade leve, variando entre 57 alunos (85\%) que apresentaram ansiedade moderada e 10 alunos (15\%) que apresentaram ansiedade grave segundo a escala IDATE-T do inventário de Spielberger. Dos 67 alunos, 44 (65\%) foram aprovados contra $23(35 \%)$. Dos alunos com ansiedade moderada, $35,08 \%$ não foram aprovados; dos alunos com ansiedade grave $30 \%$ não foram aprovados. Quando comparamos o grau de ansiedade dos alunos com seu desempenho na prova não se tem diferenças estatisticamente significante quanto ao grau dos sintomas ansiosos. Conclusão: Este trabalho demonstrou um alto índice de alunos apresentando ansiedade moderada e grave, porém estas quando analisadas isoladamente não parecem ser preditoras de diferença nos desempenhos nas provas de ingresso no curso de residência médica.

Apoio financeiro: NEPAS/FUABC

\section{Níveis e fontes de estresse psicológico entre funcionários de saúde de um hospital}

\section{Vilanova LCR, Martins NR, Castelli MS, Almeida NR, Alemida IB, Baldassin SP}

Introdução: Atualmente percebemos a grande influência do trabalho na qualidade de vida de um indivíduo. O relato da presença de estresse por profissionais da área da saúde, como enfermeiros, médicos, auxiliare e outros, é bastante presente em fonte de estudos e pesquisas. Em vista disto, a escolha de se trabalhar com esta população tem sido relacionada à ocorrência de sintomas de depressão e estresse referentes à rotina profissional dessa área. Objetivo: Estudar a freqüência de sintomas de estresse entre profissionais de saúde, que trabalham no Hospital Estadual Mário Covas. Método: os profissionais de saúde do Hospital Estadual Mário Covas (HEMC) foram solicitados a responder aos questionários utilizados no estudo, anônimos, de autopreenchimento, sem prévio conhecimento, mas sob consentimento. Os instrumentos utilizados para o estudo foram: Inventário de Depressão de Beck, versão em português. Questionário sócio-demográfico desenvolvido especialmente para este estudo. Inventário de Burnout de Maslach - MBI, versão em português. Resultados: Distribuímos a pesquisa nos setores do hospital, nos turnos da manhã, tarde e noite. Em sete setores do hospital. O total de questionários respondidos foram cem, as quais foram utilizados pelo estudo. Conclusão: $\mathrm{O}$ produto da coleta não foi equivalente aos anseios iniciais, com objetivo de atingir quantidades maiores da amostra, porém, as experiências adquiridas neste processo permitirão a execução da pesquisa. O planejamento das próximas etapas dar-se-á por uma tabulação da amostra, que está sendo realizada, contribuindo para a análise, suas categorias e discussões dos dados obtidos na pesquisa.

Descritores: Intervenção na crise, Ansiedade, Serviço hospitalar.

Apoio financeiro: NEPAS/FUABC
121 Estudo histoquímico do efeito da glicosamina sulfato e associada ao condroitim sulfato no metabolismo do ácido hialurônico em cartilagem articular de ratas ooforectomizadas

\section{Barletta HM, Petri G, Veridiano JM, Correa OMT}

Introdução: A glicosamina e o condroitim sulfato, açúcares constituintes da matriz extracelular das cartilagen hialinas têm sido empregados na terapia de doenças que afetam a cartilagem articular do joelho. Dado que, estudo em humanos mostram uma melhora dos sintomas como dor e deficiência na motilidade mediante o tratamento com estes compostos e o papel importante no ácido hialurônico (HA) na composição das cartilagens articulares, Objetivo: esse trabalho tem por objetivo analisar o comportamento do ácido hialurônico na cartilagem articular de ratas ooforectomizadas (oof) após a administração por gavagem da glicosamina sulfato associada e não associada ao condroitim sulfato. Ratas não ooforectomizadas (noof) foram utilizadas como controle; a ooforectomia foi realizada devido ao conhecido efeito da falta dos hormônios sexuais no envelhecimento das cartilagens. Método: Utilizou-se ratos fêmeas Wistar $(\mathrm{n}=40)$ divididos nos seguintes grupos: animais oof que tomaram glicosamina associado ao condroitim sulfato (Dinaflexß) por 60 dias (G60oof), animais oof que tomaram condroitim sulfato (Condroflex $($ ) por 60 dias (C60oof), animais oof que tomaram água (sham) e animais noof. Resultados: A análise histoquímica revelou uma menor quantidade de HA nos grupos oof quando comparados ao grupo noof, porém essa diferença não foi significativa. Além disso, quando comparados os grupos oof 60 dias entre si (G60oof, C60oof e sham) uma maior quantidade de HA foi observada com a administração de glicosamina; porém não houve diferença significativa. Conclusão: Esses resultados mostraram uma tendência da glicosamina em aumentar a quantidade do HA na cartilagem articular uma vez que os resultados não foram estatisticamente significativos.

Descritores: Ácido hialurônico, Cartilagem articular, Ooforectomia, Rato.

Apoio financeiro: $\mathrm{PIBIC} / \mathrm{CNPq}$

136 Efeito do óleo de semente de uva na aterosclerose em coelhos

\section{Dantas JF, Petri G, Fonseca FLA, Feder D}

Introdução: A aterosclerose é uma das principais causas de morte e incapacitação nos países ocidentais. O desenvolvimento de ateromas em coelhos tem se mostrado um modelo eficaz para o estudo da aterogênese, sendo esta lesão induzida por dieta hipercolesterolêmica. O óleo de semente de uva é constituído por, dentre outras substâncias, tocoferol e flavonóides, podendo assim ter um caráter antioxidativo. O seu uso poderia impedir a oxidação do LDL causada no processo de formação do ateroma, possivelmente adquirindo um caráter preventivo. Objetivo: Análise dos efeitos do óleo de semente de uva sobre a aterosclerose em modelo animal. Método: Seis coelhos Nova Zelândia, machos, foram submetidos a uma dieta hipercolesterolêmica por dois meses; três deles foram tratados com o óleo de semente de uva, $5 \mathrm{ml}$ diariamente por gavagem. A dieta hipercolesterolêmica foi obtida através da mistura de óleo de milho e gema de ovo com a ração. O efeito do óleo foi medido através de comparações das dosagens plasmáticas dos lipídeos e quantidade de gordura na aorta. Resultados e Conclusão: A dieta hipercolesterolêmica tem se mostrado eficaz já que todos os animais apresentaram aumento significativo $(\mathrm{p}<0,01)$ do colesterol plasmático após um mês de dieta. Os animais continuam em tratamento e após a medida dos lipídeos plasmáticos e da gordura na placa de ateroma poderemos concluir a cerca do efeito do óleo de semente de uva sobre a aterogênese.

Descritores: Aterosclerose, Coelhos, Colesterol na dieta, Extrato de sementes de uva.

Apoio financeiro: NEPAS/FUABC extracelular após infarto agudo do miocárdio

\section{Garcia LF, Pinhal MAS}

Introdução: Neste estudo, ratos foram submetidos á transferência gênica com VEGF e foram divididos de acordo com o tamanho do infarto em grande (LMI), pequeno (SMI), com ou sem tratamento com transferência gênica. O grupo controle também foi analisado. Objetivo: Investigar quais as células envolvida no remodelamento da matriz extracelular após o IAM. Para isso, serão analisados anticorpos de células indiferenciadas (fibronectina, vimentina e CD-44), diferenciadas (E-caderina) e marcadores de proliferação celular (PCNA). Método: Imunohistoquímica. Os anticorpos anti-fibronectina, anti-vimentina, anti-Ecaderina e anti-PCNA, foram diluídos, respectivamente, na proporção 1:300, 1:700, 1:700 e 1:1000. O anticorpo anti-CD44 não precisa ser diluído. Quantificação Digital da IH. Os parâmetros obtidos do programa digital serão: porcentagem de células (IP), intensidade de coloração digital (ItE) e indicador de expressão digital (IE). Análise estatística. Os resultados serão expressos como média e erro padrão. Resultados: O grupo controle e grupo que sofreu infarto grande sem tratamento apresentaram maior quantidade de células indiferenciadas do que diferenciadas. Os demais grupos apresentaram uma maior quantidade de células diferenciadas em relação às células indiferenciadas. Conclusão: Os marcadores avaliados até o momento permitem concluir que possivelmente células diferenciadas (como os miócitos) participam do remodelamento da matriz extracelular, tanto nos grupos tratados quanto não tratados, após IAM.

Descritores: Terapia gênica, VEGF, Infarto agudo do miocárdio, Anticorpos.

Apoio financeiro: $\mathrm{PIBIC/CNPG}$ 
12 Estudo do reflexo esôfago-brônquico em pacientes portadores de doença pulmonar obstrutiva crônica

\section{Trevizan LLB, Herbst LG, Sperling S, Fiss E}

Introdução: A DPOC caracteriza-se pela limitação progressiva e irreversível do fluxo aéreo por resposta inflamatória anormal nos pulmões. Pesquisas demonstram relação entre os distúrbios pulmonares e doenças do sistema digestivo. Sabe-se que DRGE pode estimular o reflexo da tosse por irritação dos tratos respiratórios ou por estímulo vagal. Segundo FISS, esse reflexo esôfago-brônquico é responsáve por redução da função pulmonar em asmáticos. Pouco foi estudado sobre o efeito do refluxo em paciente com DPOC. Objetivo: Evidenciar a relação entre o refluxo gastroesofágico e o reflexo esôfago-brônquico comprovando a relação entre DRGE e o agravamento dos sintomas pulmonares do DPOC. Método: Estudo clínico. Serão estudados 20 pacientes portadores de DPOC em tratamento. Foram aplicados questionários, um contendo informações gerais e outro sobre Sintomas na Doença do Refluxo Gastroesofágico (QS DRGE). Os pacientes foram submetidos ao teste de BERSTEIN modificado por $\mathrm{Fiss}(\mathrm{HCl}$ a $0,1 \mathrm{~N})$ seguido de testes espirométricos seriados. $\mathrm{O}$ controle foi realizado com os mesmos pacientes com espirometrias seriadas na ausência do teste. Resultados: Completaram o teste 11 pacientes, sendo $90 \%$ do sexo masculino. A média de idade foi de 68 anos (60-82). Na avaliação do QS-DRGE 45,45\% dos pacientes apresentaram queixas de refluxo gastroesofágico. $\mathrm{Na}$ análise das espirometrias seriadas, $54,54 \%$ apresentou piora da função pulmonar em pelo menos um dos períodos de análise (variação de 2-10\% do inicial). No entanto, o restante $(45,45 \%)$ apresentou melhora no padrão pulmonar em relação ao inicial. Conclusão: A prévia dos resultados sugere uma relação entre DPOC e DRGE e deve ser melhor avaliada com a finalização do estudo objetivando a melhoria no tratamento da doença e a qualidade de vida dos portadores.

Descritores: DPOC, DRGE, Espirometria, Qualidade de vida.

Apoio financeiro: NEPAS/FUABC

\section{Violência sexual no município de Mauá-SP: retrato de 142 casos}

\section{Oliveira MM, Oliveira Filho MM, Fernandes CE, Oliveira E}

Introdução: A violência sexual é um grave problema de saúde pública que atinge todas as classes sociais, etnias, culturas e religiões de todos os países no mundo. Estima-se que $18 \%$ das mulheres sofrerão pelo menos um episódio de violência sexual durante sua vida. Infelizmente, as vítimas são assistidas em apenas 2,7\% dos municípios. Objetivo: O presente estudo objetiva analisar os casos de violência sexual ocorridos no município de Mauá-SP. Método: Foram analisadas, 142 mulheres vítimas de violência sexual em Mauá entre 2008 e 2009. Todos os casos foram assistidos no Hospital Nardini, instituição vinculada à Faculdade de Medicina do ABC. Resultados: A média de idade foi de 22 anos e $74,2 \%$ das vítimas eram de etnia branca. Não possuíam relacionamento estável 101 mulheres (78,7\%). Tinham vida sexual ativa 107 mulheres $(75,4 \%)$. O período em que mais ocorreram os crimes foi o noturno $(76 \%)$ e que a violência nesse momento teve maior probabilidade de ser praticada por mais de um agressor ( $\mathrm{OR}=2,856$ IC 1,089 $-7,487 ; \mathrm{P}=0,0361)$. A maioria, 108 mulheres $(76 \%)$, procurou auxílio médico em até 72 horas após o ocorrido. 89 mulheres $(62,7 \%)$ usaram medicações protocolares e $133(93,7 \%)$ fizeram exames de rotina previstos. Houve único agressor em 115 casos $(80,9 \%), 61$ pacientes (42,9\%) fizeram boletim de ocorrência e 31 (21,8\%) submeteram-se ao exame de corpo de delito. Em 58 casos (40,8\%) foi utilizado algum tipo de arma. Somente 3 agressores $(2,1 \%)$ foram presos. As pacientes que utilizaram contracepção de emergência não engravidaram. Apenas 4 acabaram engravidando. Conclusão: Os casos de violência sexual que foram assistidos no Hospital Nardini foram tecnicamente bem conduzidos, entretanto, os índices de denúncia para as autoridades competentes foram muito pequenos.

Descritores: Estupro, Violência sexual, Saúde da mulher.

Apoio financeiro: $\mathrm{CNPq}$ /PIBIC

\section{Distribuição do ácido hialurônico na remodelação do tecido interpúbico no pós-parto em camundongos}

\section{Rodrigues MCFS, Petri G, Veridiano JM, Correa OMT}

Introdução: Durante a gestação ocorre a formação de um ligamento na sínfise púbica de camundongo para possibilitar o parto normal. Sabe-se que neste período ocorre o aumento do ácido hialurônico (HA) promovendo o relaxamento deste ligamento. Após o parto, esse tecido precisa voltar rapidamente ao seu tamanho e morfologia original. Objetivo: $\mathrm{O}$ presente estudo quantificou o HA durante o pós-parto para permitir um melhor entendimento do papel do HA nas adaptações que ocorrem na sínfise púbica durante o período de involução do tecido interpúbico. Método: Camundongos Swiss fêmeas da mesma linhagem foram acasaladas e após o parto foram sacrificados nos dias 3, 5, 10,13,16, 19, 2, 31 e 42 pós-parto (n = 45). Cinco animais virgens foram utilizados para controle. O HA foi quantificado in situ por histoquímica, utilizando uma sonda HA-biotinilada e os dados foram submetidos à ANOVA two-way seguida pelo teste de Tukey. Resultados: A presença de HA foi observada nos tecidos interpúbicos dos animais virgens e nos dias 3, 5, 10, 13, 16, 19, 21, 31 e 42 pós-parto (dpp). Entretanto houve uma diminuição significativa a parti do $3^{\circ} \mathrm{dpp}(9,2 \pm 0,4)$ até $013^{\circ} \mathrm{dpp}(1,4 \pm 0,3)$. Essa quantidade se manteve nos dias pós-parto subsequente analisados $(16,19,21,31$ e 42), sendo semelhante a dos animais virgens. Conclusão: O HA regride no periodo pós-parto, sugerindo sua participação na remodelação do tecido interpúbico após o parto.

Descritores: Sínfise pubiana, Ácido hialurônico, Puerpério, Camundongo.

Apoio financeiro: $\mathrm{CNPq} / \mathrm{PIBIC}$

\section{Trote universitário: um olhar para o passado a partir de uma revisão bibliográfica}

\section{Feo LB, Kharmandayan S, Conchão S, Boaretto RC, Akerman $M$}

Introdução: Todos os anos observam-se matérias que a mídia divulga sobre trote violento nas universidades. O trote, como é chamado o que deveria ser um processo de recepção de calouros pelos veteranos se transforma num ritual de agressões físicas e morais. Aqueles que organizam essa "recepção" justificam ações abusivas como brincadeira ou ritual de passagem, como um processo "natural". O trote violento considerado fenômeno social, cultural e histórico, não é específico de uma carreira ou universidade. Mas o curso de medicina tem despontado ao longo dos anos como um dos mais agressivos. É nesse contexto que se encaixa o questionamento da pesquisa: por que existe a submissão ao trote? Objetivo: Durante o amadurecimento desse tema, este foi dividido em dois braços de pesquisa. Um braço se destina a coleta informações atuais sobre o assunto enquanto o outro - dessa pesquisa em questão - é direcionado para um levantamento bibliográfico sobre o tema. Método: Levantamento da bibliografia relacionada ao tema. A revisão bibliográfica foi realizada em algumas bases de dados nacionais indexadas. Resultados: O trote ainda é um fenômeno que há pouco material acadêmico publicado. Parte das publicações trata do ambiente de trabalho e escolar, especialmente o pré-universitário. Além de um breve mapeamento sobre o assunto, o levantamento contribuiu para a reflexão da relação entre alunos e entre estes e os professores, das relações de poder estabelecidas. Conclusão: Isso traz de volta a questão feita pelos alunos que deu origem à pesquisa: "por que nos submetemos ao trote?" É possível verificar como este processo de recepção, ao contrário de um "ritual de passagem", se revela um padrão de relações hierárquicas entre alunos, durante todo o curso a até no ambiente profissional.

Descritores: Abuso, Violência, Histórico, Universitário.

Apoio financeiro: $\mathrm{CESCO}$

\section{Variação da prevalência de sintomas depressivos em estudantes de Medicina brasileiros de 2001 a 2006}

Introdução: Muitos estudos revelam uma alta prevalência de sintomas depressivos em estudantes de medicina durante a graduação em comparação a população geral e isso tem sido atribuído a fatores ambientais, tais como estresse e dificuldades inerentes ao curso médico. Apesar disso, ainda não existe um consenso sobre qual a época de maior estresse, tampouco sobre os fatores etiológicos e desencadeantes tendo alguns estudos mostrado dados discordantes em relação a outros. Objetivo: analisar a variação de sintomas depressivos entre estudantes de medicina durante um período de seis anos e os possíveis fatores associados, tais como trotes e atividades sociais. Método: fase quantitativa - teste do qui-quadrado e modelos de regressão logística foram usados para examinar as diferenças nos escores de Depressão de Beck em todos os ciclos da escola médica (básico, intermediário e internato), entre 2001 e 2006 ( $n=732$ ), estratificados por grupos de gênero e idade. Fase qualitativa - Quatro informantes-chave, pessoas que tiveram importantes funções acadêmicas e que representam diferentes grupos sociais entre 2001 e 2006, foram entrevistado para a busca de informações relevantes sobre mudanças no ambiente durante esse período. Resultados: Os estudantes do sexo masculino que cursavam o ciclo básico em 2006 apresentaram uma tendência de aumento dos sintomas depressivos em comparação aos do mesmo sexo do ciclo básico de 2001 (OR = 7,36 [IC 95\% $=0,85-63,5], \mathrm{p}=0,07)$. Conclusão: $\mathrm{O}$ aumento do trote e o declínio da participação dos alunos nas atividades sociais durante a curso médico podem influenciar no aumento de sintomas depressivos em estudantes do sexo masculino dos primeiro e segundo anos do curso de Medicina.

Descritores: Depressão, Estudante de Medicina, O trote, Envolvimento social, de gênero.

Apoio financeiro: NEPAS/FUABC

\section{$144 \begin{aligned} & \text { Validação de novos métodos na detecção de hemoglobina } \\ & \text { glicosilada }\end{aligned}$}

\section{Carvalho MPF, Abdallah AM, Lambiasi A, Saviolli L, Fonseca FLA}

Introdução: A glicação é um processo de ligação não enzimática irreversível da glicose a resíduos lisina de uma proténa. Isto ocorre quando há altas concentrações de glicose no líquido extra celular (LEC).A hemoglobina glicada reflete a glicemia média ao longo de 2 meses antes de sua dosagem, isto é, a meia vida da hemoglobina. Objetivo: Validar o método de turbidimetria em amostra de pacientes adultos; determinar os valores de referência de hemoglobina glicada pelo método de turbdimetria; e relacionar os valores de hemoglobina glicada geradas pelo método de turbidimetria e LPLC. Método: A partir de $10 \mathrm{ml}$ de sangue em tubo de EDTA determinou-se a hemoglobina glicada pelo métodos propostos. $\mathrm{O}$ método turbidimétrico se baseia na interação de antígeno/anticorpo. Para determinação direta de HbAlc no sangue total adicionou-se um anticorpo anti-HbAlc, formando um complexo látex-HbAlc-anticorpo Após a adição do anticorpo secundário ocorreu a aglutinação. O LPLC foi baseado na permuta catiônica a baixa pressão para determinar a HbAlc. Resultados: Um total de 111 pacientes foram incluídos divididos por classes de acordo com a glicemia, onde para cada uma foram feitas médias do método de LPLC, turbidimetria e valores de glicemia.As classes com suas respectivas médias são: 70-100 com 5,95\%, $5,77 \%$ e $88,69 \mathrm{mg} / \mathrm{dL} ; 101-115$ com $5,50 \%, 5,03 \%$ e $107,6 \mathrm{mg} / \mathrm{dL} ; 116-130$ com $6,00 \%, 6,20 \%$ e $120,91 \mathrm{mg} /$ dL; $131-150$ com $6,69 \%, 6,16 \%$ e $136 \mathrm{mg} / \mathrm{dL} ; 151-170 \mathrm{com} 7,40 \%, 7,03 \%$ e $160,75 \mathrm{mg} / \mathrm{dL} ; 171-200 \mathrm{com}$ $8,49 \%, 7,59 \%$ e $184,4 \mathrm{mg} / \mathrm{dL}$; e maior que $200 \mathrm{com} 8,64 \%, 8,62 \%$ e $260,42 \mathrm{mg} / \mathrm{dL}$. Conclusão: Foi possível verificar que há equivalência significante entre os métodos turbidimétrico e o LPLC, podendo este ser usado para dosagem de hemoglobina glicada.

Descritores: Glicação, Diabetes mellitus, Métodos.

Apoio financeiro: PIBIC/CNPq 
$1 \sqsubset$ Resistência insulínica e sua relação com morbidades associadas à obesidade na faixa etária pediátrica

\section{Silva PA, Souza FIS, Sarni ROS}

Introdução: A obesidade em crianças e adolescentes é um problema mundial que se tornou epidemia no último século. $\mathrm{O}$ mecanismo central das morbidades associadas à obesidade é a resistência insulínica. Objetivo: avaliar os níveis de glicemia, insulina de jejum e HOMA-IR de crianças e adolescentes com obesidade e relacioná-los com gravidade da doença, cintura abdominal, perfil lipídico, provas de função hepática e pressão arterial. Método: Por meio de estudo transversal e retrospectivo foram avaliados 89 pacientes com obesidade exógena, entre os meses de fevereiro a dezembro de 2010. Elaborou-se um questionário para coleta de dados antropométricos e laboratoriais.Considerou-se HOMA-IR > 3,45 como sugestivo de resistência insulínica. Resultados: A mediana de idade foi de 9,5 anos, 59,6\% eram do sexo feminino e 52,8\% pré-púberes. A mediana do ZIMC foi de 3,2 e 59,5\% eram obesos graves (ZIMC > +3). HOMA-IR > 3,45 foi observada em $24,7 \%$ dos pacientes. Verificou-se cintura abdominal aumentada em 87,6\%; pressão arterial elevada em (39,3\%); alterações do perfil lipídico em 67,4\%. A presenç̧a de RI não se associou com cintura aumentada, alterações de pressão arterial e do perfil lipídico. A RI foi mais encontrada em pacientes com níveis maiores de TGP $>26,5 \mathrm{U} / \mathrm{L}(45,5 \%$ vs $18,2 \%, \mathrm{p}=0,021)$ e Gama-GT $>27,5 \mathrm{U} / \mathrm{L}$ $(63,3 \%$ vs $16,7 \% ; \mathrm{p}=0,004)$. Os níveis de TGP correlacionaram-se de forma estatisticamente significante com ZIMC $(r=0,294)$, cintura $(r=0,329)$, PAS $(r=0,414)$ e PAD $(r=0,375)$. Os níveis de Gama-GT correlacionaram-se, por sua vez, com a cintura $(r=0,513)$ e PAD $(r=0,324)$. Conclusão: A associação de elevação nas enzimas hepáticas com resistência insulínica aponta para a importância da avaliação desse índice em crianças e adolescentes com excesso de peso.

Descritores: Obesidade, Hiperinsulinismo, Fígado gorduroso e criança.

Apoio financeiro: $\mathrm{CNPq} / \mathrm{PIBIC}$

\section{Ação do tamoxifeno no sistema nervoso central e conseqüência desta ação sobre o efeito dos antidepressivos inibidores seletivos da recaptura de serotonina (ISRI)}

Chiovatto RD, Fukuda EY, Feder D, Nassis CDZ

Introdução: $\mathrm{O}$ câncer de mama teve nos últimos anos aumento na incidência e diminuição na mortalidade pelos avanços no tratamento e diagnóstico. O tamoxifeno é utilizado na terapia adjuvante e atua como modulador seletivo do estrógeno com ação antagonista competitiva, possui propriedades anti-estrogênicas no tecido mamário. Estudos indicam que aproximadamente $67 \%$ delas têm sintomas de depressão e ansiedade apresentam assim pior prognóstico em 5 anos de vida e aumento do risco de mortalidade. Estudos demonstram que os estrogênios influenciam nas funções cerebrais. Portanto, a possibilidade do uso concomitante de antidepressivos e tamoxifeno existe, porém a interação entre eles ainda é pouco estudada. Objetivo: Avaliar o efeito comportamental do tamoxifeno e sua interação com a fluoxetina no SNC. Método: Foram utilizados ratos wista fêmeas fornecidos pelo biotério da Faculdade de Medicina do ABC. Os animais foram mantidos no biotério com água e ração ad libitum e foram divididos em grupos de 5 , tratados por 21 dias, sendo: grupol controle (solução salina) -0,2mL de soro fisiológico; grupo 2-tamoxifeno $5 \mathrm{mg} / \mathrm{kg}$; grupo3-fluoxetina $10 \mathrm{mg} / \mathrm{kg}$;grupo4-fluoxetin $10 \mathrm{mg} / \mathrm{kg}+$ tamoxifeno $5 \mathrm{mg} / \mathrm{kg}$. A esquiva inibitória e a fuga do braço aberto foram avaliadas em labirinto en T elevado,antes e 21 dias após a administração das drogas. Resultados e Conclusão: Os resultados indicaram que o tratamento crônico com o tamoxifeno promoviam sintomas evidenciados no transtorno depressivo maior, que foram revertidos com o uso da fluoxetina, comprovados estatisticamente pela alteração no padrão da esquiva inibitória, mas não foram evidenciado comportamentos pânico-like através do parâmetro da fuga do braço aberto. Os níveis séricos de cortisol não demonstraram variações significativas ao longo do tratamento.

Descritores: Tamoxifeno, Fluoxetina, Interação.

Apoio financeiro: NEPAS/FUBAC

\section{Impacto da presença de stent metálico na expressão gênica do tecido adiposo epicárdico}

\section{Spener RF, Breda JR, Souto RP}

Introdução: O stent usado em cateterismo pode iniciar processo inflamatório no vaso, resultando em restenose e falha do tratamento. Além da resposta local do próprio vaso, é razoável supor que tecidos próximos ao stent possam participar desta restenose, entre eles o tecido adiposo epicáridico (TAE), reconhecida fonte de citocinas específicas (adipocinas) com efeito pró- e antiinflamatório. Objetivo: Determinar o perfil de expressão gênica do TAE e avaliar seu impacto sobre o processo inflamatório decorrente da presença de stent. Método: Duas amostras de TAE foram retiradas cirurgicamente de cada paciente com diagnóstico clínico-angiográfico de restenose coronária intra-stent, sendo uma amostra próxima local da restenose e outra próxima de artéria não afetada. RNA total foi obtido por meio da solução de Trizol. O cDNA específico de adiponectina, IL-6, MCP-1 e do controle gliceraldeído-3-fosfatodesidrogenase (GAPDH) foram amplificados por RT-PCR. A intensidade de expressão foi avaliada em gel de agarose $2 \%$ após coloração por brometo de etídio e quantificada por análise densitométrica com o software Scion Image. Resultados: Até o momento, 11 casos foram estudados, originando 22 amostras de TAE ( 2 sítios por paciente). Em 21 amostras houve expressão de GAPDH. Todas as amostras expressaram adiponectina sendo possível verificar uma tendência, não confirmada estatisticamente, que a expressão deste gene seja diminuída na amostra de TAE próximo a artéria com restenose em relação a amostra próxima a artéria não afetada do mesmo paciente. A amplificação de MCP-1 e IL-6 em TAE está sendo padronizada. Conclusão: Resultados preliminares obtidos até o presente momento sugerem que a expressão gênica de TAE próximo a artéria em processo de restenose possa encontrar-se alterada.

Descritores: Coronariopatia, Epicárdio, Tecido adiposo, Angioplastia. .

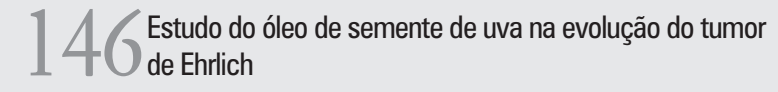

Costa RAR, Pavani KCP, Leger FS, Dantas JF, Fonseca FLA, Petri G, Feder D

Introdução: A semente de uva tem ação antitumoral comprovada, no entanto existem poucos e inconclusivos estudos sobre as ações do óleo de semente de uva e seu mecanismo de ação. Objetivo: Estudar a ação antitumoral do óleo de semente de uva, obtido por um processo inédito de extração a frio, analisando também sua ação na angiogênese e atividade fagocitária dos macrófagos. Método: Foram utilizados camundongos machos, balb-C, adultos, pesando entre 20 e $30 \mathrm{~g}$, mantidos com água e alimentação ad libitum. No estudo da angiogênese os animais foram divididos em dois grupos: grupo $1-0,01 \mathrm{ml} / \mathrm{g}$ de óleo de semente de uva por gavagem diariamente; grupo 2 - óleo mineral $0,01 \mathrm{ml} / \mathrm{g}$. Em ambos, os camundongos foram anestesiados com quetamina e xilasina sendo introduzida uma esponja estéril de $0,125 \mathrm{~cm}^{3}$ no subcutâneo do dorso do animal. Após sete dias as esponjas foram retiradas obtendo-se a quantidade de hemoglobina da esponja em relação a hemoglobina do sangue. O estudo da fagocitose dos macrófagos foi realizado em dois novos grupos de animais tratados com a mesma dose anterior; após 7 dias de tratamento uma amostra dos macrófagos peritoneais foi obtida por lavagem com soro fisiológico. Os macrófagos foram cultivados em solução com vermelho neutro $0,075 \%$; após 24 horas obteve-se a quantidade de corante fagocitado por espectrofotometria. No estudo da atividade antitumoral, dois novos grupos foram inoculados com tumor de Ehrlich na região dorsal e tratados da mesma forma anterior, medindo-se o tumor e pensando-se diariamente o animal durante 30 dias. Resultados e Conclusão: Nenhum dos estudos teve significância estatística. Dessa forma, fica claro que a efetividade demonstrada pelo óleo de semente de uva é devida a componentes que não estão presentes no método de extração do óleo estudado.

Descritores: Óleo de semente de uva, Tumor de ehrlich, Angiogênese, Macrófagos peritoneais.

Apoio financeiro: NEPAS/FUABC

\section{A ausência de reprodutibilidade da nanotecnologia na 4 dosagem de DNA plasmático livre em amostras de pacientes com câncer de próstata}

Moreno $R$, Delgado PO, Fonseca FLA

Introdução: O Câncer de Próstata (CP) afeta milhares de pessoas no mundo. Pacientes com afecções em que há aumento de morte celular possuem aumento da quantidade de DNA plasmático (DNAP), dando a ele um valioso valor de critério diagnóstico, resposta terapêutica e evolução do tumor. Objetivo: Validar a determinação de valores de DNAp por meio de nanotecnologia (NanovueTM-NV) em amostras de pacientes com CP. Método: Foram analisadas amostras de 80 pacientes do Ambulatório de Urologia da Faculdade de Medicina do $\mathrm{ABC}$ com diagnóstico de CP. Compararam-se as dosagens através da espectrofotometria tradicional (GeneQuant $\mathbb{R}-\mathrm{GQ})$ e do NV. Resultados: Das 80 amostras, realizou-se medição em 51(63,75\%) e optou-se por interromper os testes pela total discordância de resultados e ausência de reprodutibilidade. As dosagens de DNA plasmático pelo NV foram feitas em duplicata. Houve quantidade variável de diferença de valores entre a primeira e a segunda dosagem pelo NV. Apenas 2 amostras $(0,04 \%)$ tiveram diferença ZERO entre as duas medidas,a diferença média foi de $10,29 \mu \mathrm{g} / \mathrm{mL}$ e 21 (41,2\%) ficaram acima disso. Não houve correspondência direta entre valores crescentes de DNAp pelas duas técnicas. Apesar de haver alguns valores aceitáveis, num panorama geral isso não ocorre. Frente a isso, criou-se um relatório de testes, desta vez com medições em triplicata. Através de diversos testes e análises, considerou-se que os resultados não foram reprodutíveis. Após análise da fabricante, outros testes foram realizados, também sem reprodutibilidade. No gráfico de dispersão, o $r^{2}$ na análise de correlação foi 0,0044 . Conclusão: A nanotecnologia não se mostrou reprodutível na dosagem de DNAp em amostras de pacientes com CP.

Descritores: Câncer de próstata, DNA plasmático, Nanotecnologia

Apoio financeiro: CNPq-PIBIC

"Bulindo" com a universidade: um estudo sobre o trote na Medicina

Kharmandayan S, Feo LB, Chabaribery M, Santos LH, Pinto MG, Matos I, Matos P, Alencar M, Bertoldo B, Goulart LFVV, Cabral FHR, Nicolau RN, Vitória WO, Akerman M, Conchao $S$, Boaretto $R$

Introdução: $\mathrm{O}$ trote violento considerado um fenômeno social, cultural e histórico, não é especifico de uma carreira, e muito menos de uma universidade. No entanto, é curioso notar que o curso de medicina tem despontado ao longo dos anos como sendo um dos mais agressivos. Indagações despertaram e mobilizaram alunos iniciantes do curso de medicina da FMABC em 2010. Posteriormente, o grupo cresceu e passou a contar com a ajuda de alunos do então segundo ano. Objetivo: Aprofundar conhecimentos sobre o fenômeno do trote que ocorre historicamente na faculdade de Medicina levantando possíveis explicações à submissão dos alunos(as) ao trote abusivo. Método: Realizamos 2 grupos focais, que foram a base para nossas analises e conclusões finais Resultados: Com base no depoimento dos participantes do grupo focal, percebemos que os principais motivos a submissão ao trote são: desejo de praticar um esporte tanto pela atividade em si como para ser parte de um time, procura por inclusão em um grupo e medo do futuro profissional sem a ajuda dos veteranos. Conclusão: As analises, ainda em curso, dos grupos focais nos permite realizar conclusões preliminares. Os anseios criados pelos alunos antes da faculdade fazem com que eles não vejam a linha tênue entre agressão e brincadeira e por vezes ignorem a própria agressão explicita. A faculdade nesse aspecto pode servir como um microcosmo da juventude do século XX e XXI. Uma juventude focada no Eu, a quem pouco foi passada questões como cidadania, ética e moral. Um grupo que só se reconhece como tal quando fazer parte de um todo lhe traz benefícios. Mesmo que estes sejam futuros.

Descritores: Violência, Abuso, Bulling.

Apoio financeiro: CESCO 


\section{$36^{\circ}$ COMUABC - CONGRESSO MÉDICO UNIVERSITÁRIO DO ABC Índice remissivo por Autores}

\section{A}

Abdalla BMZ …............................................................. 115

Abdalla TE................................................105, 106, 121

Abdallah AM .

Afonseca SO

Agena J.....

Aita MA

Akerman $\mathrm{M}$.................................................119, 125, 126

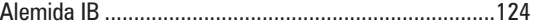

Alencar M .................................................117, 119, 126

Almeida DV ...........................................................

Almeida NR ........................................................... 124

Almeida RC ........................102, 105, 111, 113, 120, 121

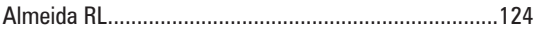

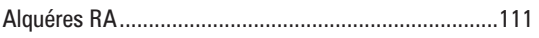

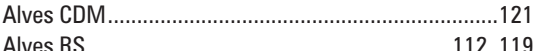

Alves TCTF .........................................118, 124, 125

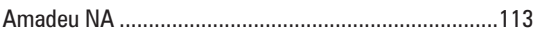

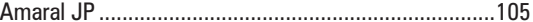

Amarante RDM ............................................................110

Amaro DMC ....................................................104, 120

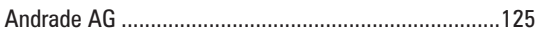

Andrade TM .............................................................

Arrym TP.......................................................104, 121

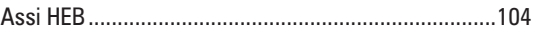

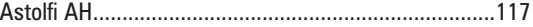

Ayub MA..........................................................114, 115

Azevedo RGS ..................................................117, 121

B

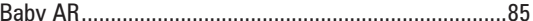

Baccaro BM ...............................................................104

Baldassin SP ..................................116, 123, 124, 125

Balderi TZ......................................................................116

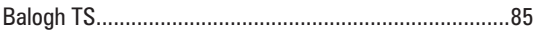

Bando AMN

Baptista MAFB..............................................103, 110

Barbosa CP .........106, 107, 108, 114, 116, 117, 122, 123

Barbosa RP .............................................................. 117

Barletta HM.............................................108, 118, 124

Barrôco RS.....................................................................117

Barros HPCB ...............................102, 105, 111, 113, 120

Barros LLF........................................................ 110

Barros RASA

Barsella AR .................................................................104

Bastelli MM …...................................................... 120

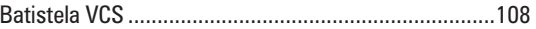

Beltrani Filho CA …...................................................115

Bereta BD.....................................................108, 118

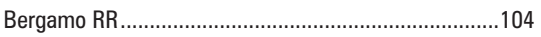

Bertoldo BF …......................................117, 126

Bezerra DF...................................................108, 118

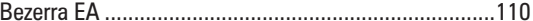

Bianchi RM .............................................................117

Bianco B ............106, 107, 108, 114, 116, 117, 122, 123

Biondi BG ..............................................112, 115, 117

Bittencourt F .....................................................107, 123

Blumetti AMC ….......................................113, 119, 120

Boaretto RC.......................................................125, 126

Bonadio CMA .............................................................. 110

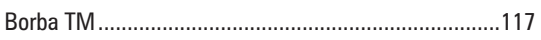

Bragatto FB ........................................................... 108

Brandes A ..........................................107, 108, 116, 117

Breda JR .

126

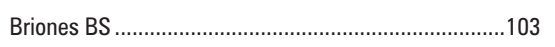
Brito GM ......................................................117, 120

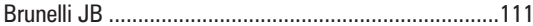

Brunetti K ......................................................... 114

Bruniera FR …........................................................... 119

Burlamaqui JCF..................................................103, 104

C

Cabral FHR ..........................................................117, 126

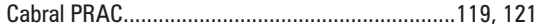

Campos MAM..............................................................104

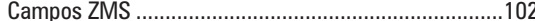

Canto BES ..............................................................119

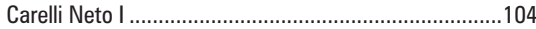

Carneiro CEL...................................................119, 120

Carvalho AAS .......................................................... 123

Carvalho FL ...................................................................117

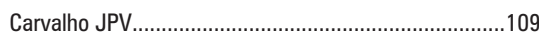

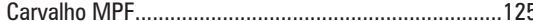

Carvalho WAP...........................................114, 116, 117

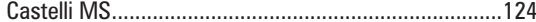

Castro ALS ............................................................ 72

Castro CC ..................................................................102

Catapani WR .......................................105, 106, 113, 114

Cavalheiro CM...................................106, 107, 108, 116

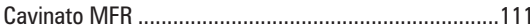

Chabaribery M ....................................................... 126

Chehter EZ ….......................................................... 114

Chicoli FA ...........................................................121, 122

Chien V.............................................................. 120

Chiota FL..........................................104, 115, 119, 122

Chiovatto RD .........................................................126

Christofolini D.....................................................123

Christofolini DM ...........106, 107, 108, 114, 116, 117, 122

Christofolini J..............................................................107

Ciancaglini JV ............................................................113

Cintra RMB …................................................113, 116

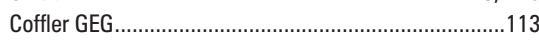

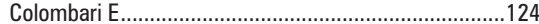

Conchão S.............................116, 117, 119, 124, 125, 126

Cordeiro RA.........................................105, 106, 113, 117

Cordts EB ..............................................................106

Correa JA................................102, 105, 111, 113, 120

Correa OMT.......................................................124, 125

Corsi CER …................................................................108

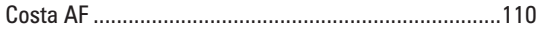

Costa AJV ................................................................. 113

Costa Junior RMM ...................................................121

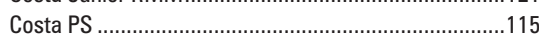

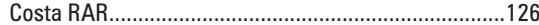

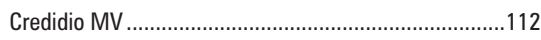

Cruz FM........................................................... 118

Cubero D.......................................................103, 117

Cudizio FFP ....................................................116, 123

Cunha LLG............................................................ 119

D

D'Elia G ........................................................123, 124

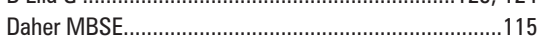

Daniel MB …............................................................104

Dantas JF......................................................... 124, 126

Delena PJ...................................................................121

Delgado PO .....................................................................126

Dias MCCPO …...................................................102, 120

E

Evo CPR ….....................................................106, 114

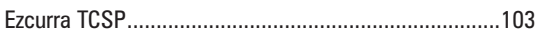

F

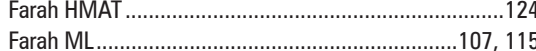

Faro Junior MP...................................................110, 111

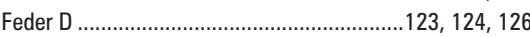

Feo LB...........................................104, 119, 125, 126

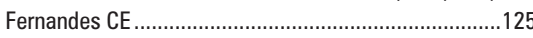

Fernandes HPA ................................................................ 117

Ferreira AACM ............................103, 104, 105, 119, 121

Ferreira FAY.................109, 110, 111, 112, 113, 120, 121

Ferreira GF ..............................................112, 115, 117

Fina R .

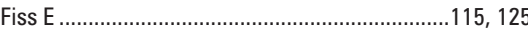

Fonseca ABF.............................................115, 119, 120

Fonseca FLA ...............................102, 106, 124, 125, 126

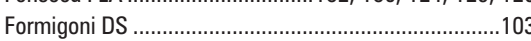

Freitas ACO

Freitas PHB ......................................................103, 105

Friaça AMV ................................................................. 111

Fugiki EN...................................................................... 111

Fuhro FE...................................................120, 121

Fujii EY ............................................102, 105, 111, 113

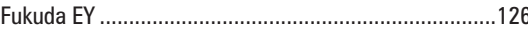

Fukushima WY ..........................................................111

Furquim ECG ........................................................... 108

(1)

Galego SJ...................................102, 105, 111, 113, 120

Garcia LF.......................................................107, 124

Garcia TJ....................................................114, 115

Gasparotti E ....................................................112, 119

Gava MM ...................................................107, 123

Genzini T .....................109, 110, 111, 112, 113, 120, 121

Giglio ABD......................................................107, 117

Giglio AD...........................................103, 107, 117, 118

Golfetti MG.................102, 105, 111, 113, 119, 120, 121

Gomes CO ................................................................. 122

Gomes Junior CAR …................................................114

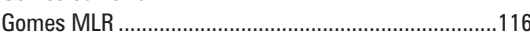

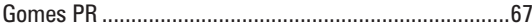

Gonçalves SR ............................................................67

Goulart LFVV ..............................................117, 126

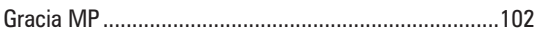

Guariento RT .................................................................117

H

Hamermesz B.....................................................115, 116

Henriques AC ........................................110, 120, 121

Herbst LG ..........................................................115, 125

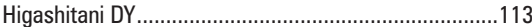

Higasiaraguti M.........................................102, 114, 115

Hirai CCG........................................103, 104, 105, 114

Hirata AM ............................................................... 118

Horiuti L ...................................................................120

I

J

Jeremias EG...............................................................119

Job ACG

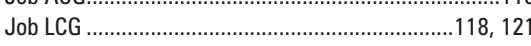

Julio $A D \ldots \ldots+119,121$

K

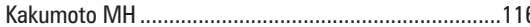

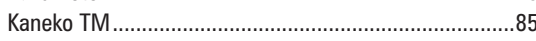

Kataguiri A ...................................................119, 121 
Kayaki EA...

Kharmandayan S

$106,107,114,123$ 119, 125, 126

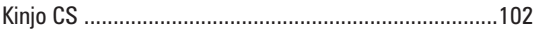
Kuster GW ……………………………………..... L

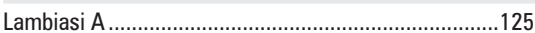
Lapa MS.................................................103, 104, 105 Lara PHS ...............................................114, 115, 119 Laranjeira M............................................................ 103

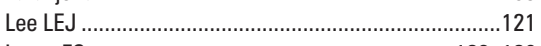
Leger FS.................................................123, 126 Lera AT .................................................103, 117, 118 Lerner TG ..............................103, 107, 108, 117, 118

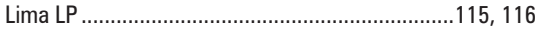
Longuino LFF...................................111, 112, 119, 121 Lucca NS .............................................................116 M

Machado Filho CDS....................................107, 115, 123

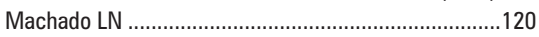

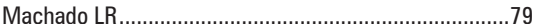

Machado MP .............................114, 116, 118, 123, 125 Machado MT...................................105, 119, 121, 122

Machado MT ..............................................................

Madeira MG .............................................................113

Mafra FA .......................................106, 107, 108, 122

Maia JMC ……………………………………125

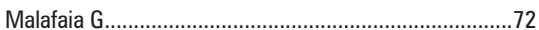

Manaia GF.............................................................113

Manchini CV........................................105, 115, 119

Marafanti I ...................................................123, 124

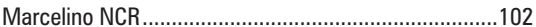

Marçon TA ...................................................................111

Margeotto FB...................................................104, 106

Marino MAZ …………………………………….....116

Martins NR ...........................................................124

Martins RF ……………………………………....102

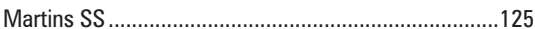

Maruyama MK ……………………………………….... 102

Massari LM .................................................................115

Matar MR …….............................................102, 114

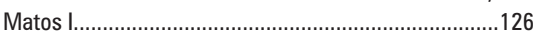

Matos LL _........................................107, 119

Matos P ……………………………………....126

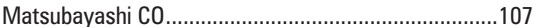

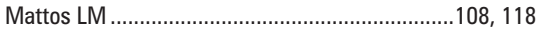

Matushita DKO …………………………………....115

Maximiano FL ..........................................................102

Melo LRC ……………………………………....113, 116

Melo PM ...........................................................116

Menezes SG.............................................114, 116, 117

Michaelis LF...............104, 112

Milazzotto PHM ........................................................111

Miranda MP _................109, 111, 112, 113, 120, 121

Miranda RR …………………………….....103, 105

Monteiro MIC …………………………………….....117

Moraes FA .................................................109, 120

Moraes GBB.......................103, 104, 105, 111, 112, 119

Moreira LA ......................................................104

Moreno R ....................104, 105, 106, 109, 113, 120, 126

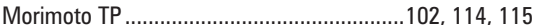
Mota RT ...........................103, 111, 112, 115, 116, 119

Moura F .............................................

Moya HD..................................................................122

Muller S ................................................................121

Munhoes DA ………………………………………....115

Nascimento VG ....................................................65

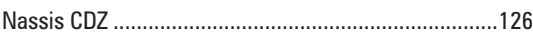

Navarro MS .............................................................115

Neto LCS..............................................................119
Neves Neto OC

Nicolau RN.

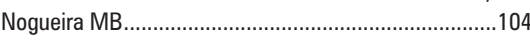

Nuñez GR ...................................................................

0

Okamoto ECG ...........................................103, 104, 12

Okawara M .............................................................. 118

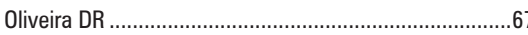

Oliveira E...............................................................125

Oliveira Filho MM........................................................125

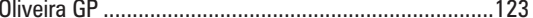

Oliveira LO..................109, 110, 111, 112, 113, 120, 121

Oliveira MM .................................................117, 125

Oliveira NM ................................................................. P

Pachon S.........................................103, 114, 115, 116 Paiva CP..........................................106, 107, 116, 122

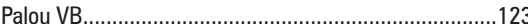

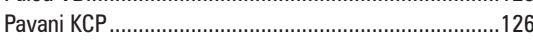

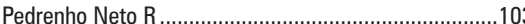

Pedroso C.............................................108, 113, 118

Peixoto GA ......................................105, 119, 12

Pelaggi ER ………………………………....108, 123

Perejão AM ………………………………….....114, 115

Person NC ……………………………………....105

Pessoa GB...........................................104, 106, 119

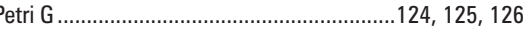

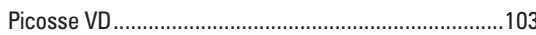

Pinhal MAS ....................................................107, 124

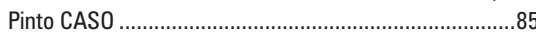

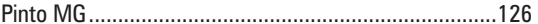

Pires AC ....................................................109, 120

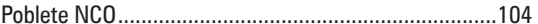

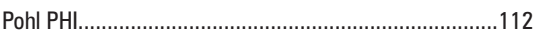

Pompeu ACL ……….....................................119, 121

Prescinotto R ………………………………….......103 R

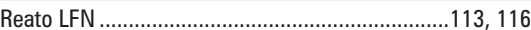

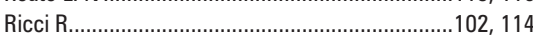

Rocha LFL .................................................102, 114

Rodrigues ASL ...........................................................

Rodrigues MCFS .............................................112, 125

Rodrigues NP .............................................................118

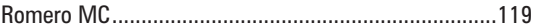

Ruis CF................................................................102

$S$

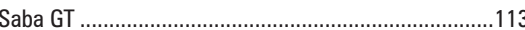

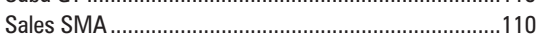

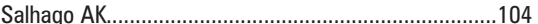

Salomão GHA..........................................103, 115, 116

Samos FM........................................................... 115

Santiago SN ..........................................................114

Santos AA...............................................106, 107, 114

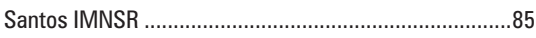

Santos JPM ..............................................102, 114

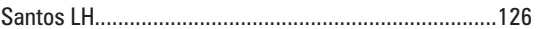

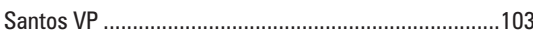

Sarni ROS...........................................................114, 126

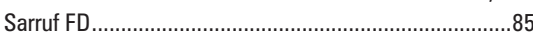

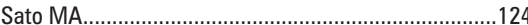

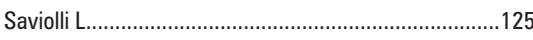

Scarpa MB ..........................................................

Schaffhausser HL.......................................................112

Schalch MS .......................................................103

Segre JM ........................................................110, 114

Serpa Neto A ………...................................104, 105

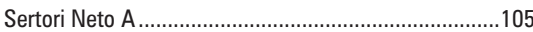

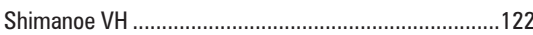

Shiroma ETM ..............109, 110, 111, 112, 113, 120, 121

Silva AMA ......................................109, 113, 120, 122
Silva BDKM.

.112

CDKM

Silva CMR ……......................102, 105, 111, 113, 120

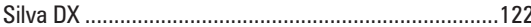

Silva EG ..............................................................119

Silva II JL ................................................................119

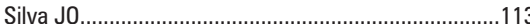

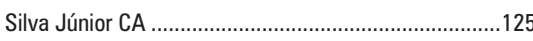

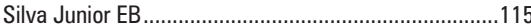

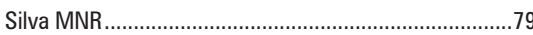

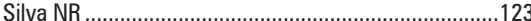

Silva PA...............................................110, 114, 126

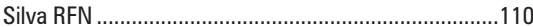

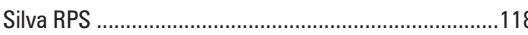

Silveira BS..................................................103, 111

Soares GA ..................................................105, 121

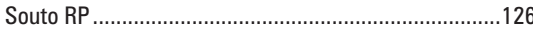

Souza AJF .............................................................110

Souza FIS …………………………………....114, 126

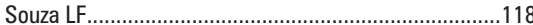

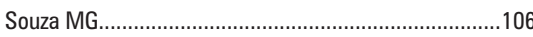

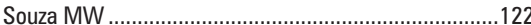

Spener RF ............................................................126

Sperling S............................................................ 125

Squarcino IM...................................................122, 123

Strufaldi VP ......................................................... 119

Tae B ………………………………………………...118

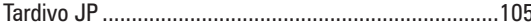

Tarragó MG ….......................................................110

Tateyama LTC...........................................................103

Teixeira BM ................................................................102

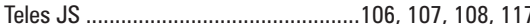

Toloi GC ...............................................103, 115, 116

Toneto BR...............................................105, 121

Towata F .............109, 110, 111, 112, 113, 115, 120, 121

Trevizan LLB ..........................................114, 115, 125

Trevizol AP …………………….......110, 111, 112, 113

Trigo LFB ..............................................................115

U

Ulrych BK ...............................................109, 111, 120

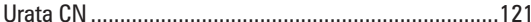

V

Vanzin AM.......................................111, 112, 119, 122

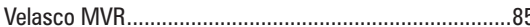

Veridiano JM...................................................124, 125

Victorino AA......................................................109, 111

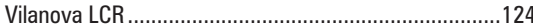

Vilarino $\mathrm{FL}$.....................................................................108

Vitoria W0 …...........117, 126

W

Waisberg J

Watanabe MS

109,122

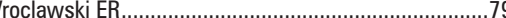

Y

Yamada FB .......................109, 110, 111, 112, 120, 121

Yamamoto AYP.........................................103, 112, 115

Yamashita ET...........................110, 111, 112, 113, 121

Yamauti LS ...............................................103, 115, 121

Yamazaki YR _..........................................111

Yonamine RY ..............................................................109

Yoshihara RN..................................................102

Yoshii HK ....................................................................104

Z

Zanellato RM..................................................103, 116

Zlochevsky AM .................................................115, 118 